
June 1940

\title{
INFLUENCE OF CYCLIC STRESS ON CORROSION PITTING OF STEELS IN FRESH WATER, AND INFLUENCE OF STRESS CORROSION ON FATIGUE LIMIT
}

\author{
By Dunlap J. McAdam, Jr. and Glenn W. Geil
}

\section{ABSTRACT}

By examination of surfaces and longitudinal sections of specimens of steel after stress corrosion, information has been obtained about the influence of cyclic stress (during corrosion) on the form and size of corrosion pits. A discussion is given of the theoretical stress concentration due to corrosion pits, and of the influence of size on the effective stress concentration.

By comparison of typical views of corrosion pits with curves representing the decrease of the fatigue limit with corrosion time, the forms and sizes of corrosion pits are correlated with the resultant lowering of the fatigue limit.

The stress corrosion process is discussed in terms of the general theory of corrosion of metals. With increase in cyclic stress and cycle frequency, the corrosion process is shifted from a cathodically controlled process toward an anodically controlled process.

\section{CONTENTS}

I. Introduction

II. Materials and method of investigation

1. Steels........

2. Specimens_... 687

3. Corrosion stage

4. Determination of the fatigue limit and evaluation of the damage caused by the corrosion

5. Method of investigation of forms and sizes of the corrosion pits_ 688

III. Influence of stress corrosion on the fatigue limit, and the stress-time-

cycle relationship for constant net damage . .

1. General description of diagrams representing the influence of both stressless corrosion and stress corrosion on the fatigue limit

2. Influence of stressless corrosion on the fatigue limit

3. Lowering of the fatigue limit by simultaneous corrosion and cyclic stress............. 689

4. Diagrams representing the stress-time-cycle relationship for constant net damage.

IV. Pits formed by stressless corrosion

1. Surface views of specimens after stressless corrosion

2. Longitudinal sections showing pits caused by stressless corrosion

V. Influence of form, size, and distribution of corrosion pits on effective stress concentration, and

1. Factors involved in effective stress concentration

2. Theoretical stress concentration due to corrosion pits ...... 695

3. Influence of size, and of the steepness of the stress gradient, on effective stress concentration

4. Effective stress-concentration factor for specimens previously corroded without stress _... 
VI. Pitting under simultaneous corrosion and cyclic stress, and its a-

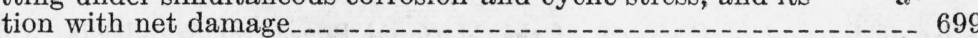

1. Pitting with frequency of 1,450 cycles per minute $\ldots \ldots \ldots 69$

2. Pitting with frequency of 500 cycles per minute............ 702

3. Pitting with frequency of 100 cycles per minute....... 703

4. Pitting with frequency of 50 cycles per minute

5. Pitting with frequency of 10 cycles per minute................ 706

6. Pitting with frequency of 1.5 cycles per minute..... 707

7. Pitting with frequencies of 0.5 cycle per minute and 5 cycles per hour

8. Summary of results of examination of specimens

VII. Stress-corrosion process.

VIII. References_.

\section{INTRODUCTION}

The influence of simultaneous cyclic stress and corrosion on the fatigue limit, and the influence of cyclic stress on corrosion, have been discussed by the senior author in previous papers [10 to 23]. ${ }^{1}$ In the first five of these papers, the cyclic stress conditions were such as to cause failure by fatigue (corrosion fatigue). In the later papers [15 to 23], each experiment involved two stages. In the first stage, the specimen (with or without cyclic stress) was corroded by water for a definite time, then removed from the water, dried, and oiled. In the second stage, the fatigue limit of the specimen was determined by subjecting it to cyclic stress in air. The decrease in the fatigue limit was used as a measure of the damage resulting from the prior corrosion.

The damage caused by simultaneous corrosion and cyclic stress (stress corrosion) tends to be greater than the damage caused in the same time by stressless corrosion. The greater the stress, cycle frequency, and time in the corrosion stage, the greater is the difference between the resultant damage and the corresponding damage caused by stressless corrosion. The difference in damage (net damage) thus is a measure of the influence of cyclic stress on corrosion.

Opportunity was not then available for study of the forms and sizes of the corrosion pits and their correlation with the cyclic stresses applied during corrosion. Later, however, through the courtesy of the Director of the United States Naval Engineering Experiment Station, Annapolis, Md., the specimens that had been used were made available for such investigation. The results of this examination are used in this paper to correlate the forms and sizes of the corrosion pits with the net damage.

The previous papers were devoted mainly to presentation of data obtained with a great variety of metals, corroded in several different kinds of water. They presented a gradually broadening view of the subject, with no adequate summarizing paper. This paper, therefore, includes a brief summary of the results previously obtained with steels in fresh water, so that these results may be correlated with the results of examination of the corroded specimens.

\section{MATERIALS AND METHOD OF INVESTIGATION}

\section{STEELS}

The steels used in the investigation of the influence of cyclic stress on corrosion include carbon steels, ordinary alloy steels, and stainless steels. Only five of the steels, however, were used in the investigation

1 Figures in brackets indicate the literature references at the end of this paper. 
of the influence of cyclic stress on the form and size of corrosion pits: carbon steel JR-W-10, nickel steels IW-W-10 and LQ-W-10, and chromium-nickel steels BC-W-10 and AX-W-10. The compositions of these steels are given in table 1, details of heat treatment are given in table 2 , and tensile properties are given in table 3.

\section{SPECIMENS}

The specimens used were fatigue-test specimens of the rotating cantilever type described in previous papers [9]. The specimens were conically tapered, and were so designed that the maximum stress was $3 / 4$ in. out from the inner fillet, and that the stress varied only about $1 \frac{1}{2}$ percent over a length of $1 \frac{1}{2}$ in. The diameter at the inner fillet was $1 / 2$ in. With this specimen, therefore, a comparatively large region could be subjected to simultaneous corrosion and cyclic stress.

Each specimen used in the two-stage experiments was machined to within about 0.01 in. of the final diameter. The finishing tool had a radius of $1 / 2$ in., the speed of the lathe was $90 \mathrm{rpm}$, and the feed was 130 threads per inch. The specimen, while rotating in the lathe, was then subjected to alternate circumferential and nearly longitudinal polishing. Circumferential polishing was done by the edge of a clothcovered, relatively thin, rapidly revolving disk, which was moved slowly along the specimen. Nearly longitudinal polishing was done by a rapidly revolving cloth-covered cylinder with the axis in a plane perpendicular to the specimen. Polishing was done by means of a series of powders of increasing fineness, as in ordinary metallographic polishing, the last powder being levigated alumina. By this method, the surface was made sufficiently smooth to permit examination of the microstructure at a magnification of $\times 100$.

\section{CORROSION STAGE}

In the corrosion stage, water was applied to each specimen in a small stream, which was directed diagonally to the revolving cantilever specimen, so that the entire tapered portion was covered by a thin moving layer of water. The size of the water stream, within wide limits, had no apparent effect on the damage, as measured by the lowering of the fatigue limit. Some specimens were corroded without stress; other specimens, during corrosion, were subjected to various cyclic stresses and cycle frequencies. After corrosion for the desired time, the specimen was removed from the machine, dried and oiled. It was then ready for insertion in another machine in order to determine its fatigue limit in air.

The water used in the experiments considered in this paper was a well water, whose composition is given in table 4. Like many well waters, this water consisted essentially of a solution of calcium and magnesium bicarbonates, calcium sulfate, and chlorides. The chloride content, however, is unusually high for a well water.

\section{DETERMINATION OF THE FATIGUE LIMIT AND EVALUATION OF THE DAMAGE CAUSED BY THE CORROSION}

In the second stage, the fatigue limit of each corroded specimen was determined by a rotating cantilever test. In the early experiments, it was necessary to use several similarly corroded specimens in order 
to determine the fatigue limit corresponding to a given time, stress, and cycle frequency in the corrosion stage. These specimens were tested at different cyclic stresses, and determination was made of the numbers of cycles necessary to cause fatigue failure. A stress-cycle curve could then be plotted, and an estimate could be made of the fatigue limit. Later, however, it was generally found possible to make a satisfactory estimate of the fatigue limit by use of only one specimen for a given corrosion condition. Such a result could be attained by selection of a stress that would cause failure at not much less than 1 million cycles. The fatigue limit was then estimated by extrapolation to 10 million cycles. Decrease in the accuracy owing to the use of only one specimen was slight, and was greatly outweighed by the increase in number of stress-corrosion experiments thus made possible.

The fatigue limits obtained with these specimens have been used in constructing diagrams of three types to represent the influence of cyclic stress, cycle frequency, and corrosion time on total and net damage. These diagrams are shown in figures 1 to 6 .

\section{METHOD OF INVESTIGATION OF FORMS AND SIZES OF THE CORROSION PITS}

The specimens were examined visually on the outer surfaces and photographed at low magnification, about $\times 4$. The pits were also viewed in longitudinal sections cut approximately through the axes of the specimens. Examination was made at magnifications of $\times 100$ and $\times 500$. Typical micrographs, originally at $\times 100$, have been reduced to $\times 50$; other micrographs, originally at $\times 500$, have been reduced to $\times 250$.

The photographs of the surfaces were made after removal of enough of the general rust layer to reveal the corrosion pits, without removal of the corrosion products from the pits. In some instances, photographs were made after each of several stages of removal of the rust layer.

To insure a correct sectional view of the pits, the polishing of the sections must be done in such a way as to avoid removal of corrosion products. (Removal of part of the corrosion products sometimes cannot be prevented.) The specimens, therefore, were prepared by dry polishing. At an early stage in the polishing, the specimen was mounted in Wood's metal. Each section was ground on a series of emery papers of increasing fineness, and finally with Aloxite 400 paper. It was then rubbed on 00 emery paper (previously somewhat worn) lubricated with graphite from a brush block. It was next polished by means of a revolving disk covered with a good grade of chamois skin, with smooth (hair) side outward. A small quantity of No. 600 emery powder was used on this wheel. The specimen was then transferred to an automatic polishing machine and polished on a disk covered with chamois skin. The polishing powder used in this final stage was magnesium oxide. Practice is necessary to determine the proper length of time in each polishing stage and the proper amount of polishing powder. 


\section{INFLUENCE OF STRESS CORROSION ON THE FATIGUE LIMIT, AND THE STRESS-TIME-CYCLE RELATIONSHIP FOR CONSTANT NET DAMAGE}

\section{GENERAL DESCRIPTION OF DIAGRAMS REPRESENTING THE INFLUENCE OF BOTH STRESSLESS CORROSION AND STRESS CORROSION ON THE FATIGUE LIMIT}

The influence of both stressless corrosion and stress corrosion on the fatigue limit may be represented by diagrams of the type shown in figures 1 to 4 . Abscissas in these diagrams represent durations of corrosion, and ordinates represent the resultant fatigue limits. Most of the experimental points on which the curves are based represent results obtained with the same specimens that have been used in the investigation of the forms and sizes of corrosion pits (sections IV and VI). The upper curve in each diagram represents the influence of stressless corrosion; the other curves represent the influence of simultaneous corrosion and cyclic stress. The numbers adjacent to each curve, and to some of the experimental points, represent the cyclic stress, in thousands of pounds per square inch.

\section{INFLUENCE OF STRESSLESS CORROSION ON THE FATIGUE LIMIT}

In figures 1 to 3 are curves representing the decrease of the fatigue limits of three steels with duration of stressless corrosion. The curve for each of these steels descends at a decreasing rate and eventually becomes nearly horizontal. Curves of this form, called "retarded damage" curves, have been obtained [10 to 23] with a great variety of carbon steels and ordinary alloy steels in well water, in salt water, and in distilled water. They have also been obtained with aluminum alloys.

Curves of very different form, however, were obtained by stressless corrosion of stainless steels. The curves for stainless steels in well water are horizontal at first, and remain horizontal throughout a long corrosion period (100 to 200 days). Eventually, however, the curves begin to descend, and the slope gradually increases. Curves of this form, called "accelerated damage" curves, were also obtained with monel metal and aluminum bronze. A number of curves of each form have been assembled in a previous paper by the senior author [22] and in a paper by McAdam and Clyne [24].

\section{LOWERING OF THE FATIGUE LIMIT BY SIMULTANEOUS COR- ROSION AND CYCLIC STRESS}

Under simultaneous corrosion and cyclic stress, as shown in figures 1 to 3 , the lowering of the fatigue limit is more rapid than under stressless corrosion. For a given cycle frequency, the rapidity of descent of a curve increases with the cyclic stress. At 1,450 c/min (fig. 1), stress of only $3,000 \mathrm{lb} /$ in. $^{2}$ causes the curve to descend considerably below the curve representing stressless corrosion; even lower stress $(2,000$ $\left.\mathrm{lb} / \mathrm{in}^{2}{ }^{2}\right)$, as shown in a previous paper [22], has appreciable effect. The effect of these small stresses becomes apparent only after a long corrosion time. The rapidity of the descent is much greater at a stress of 
$4,000 \mathrm{lb} / \mathrm{in}^{2}$, and increases greatly with further increase in the cyclic stress.

The influence of cycle frequency on the rate of decrease of the fatigue limit during corrosion may be observed by comparing curves (in figs. 1, 2,3) obtained with different cycle frequencies but with the same cyclic stress. An example of such comparison is given in figure 4 . The curves in this figure represent frequencies ranging from 1,450 to $10 \mathrm{c} / \mathrm{min}$ with cycle stress $13,000 \mathrm{lb} / \mathrm{in}^{2}$ Two experimental points, through which no curve is drawn, were obtained with frequency of 1.5 cycle per minute, but with cyclic stresses 20,000 and 25,000 $\mathrm{lb} /$ in. $^{2}$

Comparison of the curves shows that the rapidity of descent below the curve representing stressless corrosion increases greatly with the cycle frequency. A similar relationship may be observed by comparing the curve representing $10 \mathrm{c} / \mathrm{min}$ with the positions of the experimental points representing $1.5 \mathrm{c} / \mathrm{min}$. Although the stress was much greater at $1.5 \mathrm{c} / \mathrm{min}$, the decrease in the fatigue limit was more rapid at $10 \mathrm{c} / \mathrm{min}$.

The nearly horizontal portion of the curve representing $1,450 \mathrm{c} / \mathrm{min}$ must be attributed to a hardening influence of the cyclic stress on the metal around the growing corrosion pits. Because of increasing "effective stress concentration" (section V), the actual stress around the corrosion pits rises and approaches the fatigue limit from below. Such an approach tends to elevate the fatigue limit of the specimen, and thus opposes the tendency to lowering of the fatigue limit by the growing corrosion pits. At lower cycle frequencies (at this stress), the hardening effect is less rapid, and the removal of metal by growth of the pits tends to keep pace with the local hardening. The curve representing $500 \mathrm{c} / \mathrm{min}$, however, shows some evidence of delayed descent.

\section{DIAGRAMS REPRESENTING THE STRESS-TIME-CYCLE RELATIONSHIP FOR CONSTANT NET DAMAGE}

From diagrams of the type shown in figures 1,2 , and 3 may be derived diagrams to represent the interrelationship between cyclic stress, cycle frequency, corrosion time, and the resultant net damage. In previous papers by the senior author [16 to 23], numerous diagrams of two types are used to represent this interrelationship, for constant net damage. The constant value of net damage, on which these diagrams are based, is 15 percent. The method of deriving such diagrams is illustrated in figures 1,2 , and 3 . The broken line below each curve representing stressless corrosion is drawn so that its ordinates are 85 percent of the corresponding ordinates of the curve representing stressless corrosion. Each broken line, therefore, is the locus of all points representing 15-percent net damage. The coordinates of the intersections of this line with the lines representing stress corrosion consequently may be used in deriving diagrams to represent the relationship between cyclic stress, cycle frequency, and corrosion time, for constant net damage.

In representing this interrelationship in a two-dimensional diagram, one variable in addition to the net damage must be held constant. By this means, two types of two-dimensional diagrams have been derived and utilized in previous papers. In one of these types, cycle 
frequency is held constant (in each curve); in the other type, cyclic stress is held constant. Diagrams of these types were obtained with a variety of steels and nonferrous metals. It was found possible [18, $23]$ to combine all the diagrams of each type for carbon steels and ordinary alloy steels corroded in fresh water, and thus to form a composite diagram of each type. Such diagrams, based on data presented in previous papers, are shown in figures 5 and 6.

In figure 5, ordinates represent cyclic stresses; in figure 6 , ordinates represent numbers of cycles. In both figures, abscissas represent corrosion times. The abscissa scales in these figures, however, extend in opposite directions. This arrangement is used so that these diagrams may represent two views of a three-dimensional diagram, in which the vertical coordinates represent cyclic stresses and the horizontal coordinates represent corrosion times and numbers of cycles. Figure 6 thus represents the plan view of the three-dimensional diagram, and figure 5 represents a view in the direction indicated by the arrow in figure 6 . The curves in figure 6 , consequently, may be viewed as contour lines, and the graphs in figure 5 may be viewed as sloping lines, on the surface of a three-dimensional diagram.

Each of the experimental points in figure 5 represents a result obtained with one of the steels indicated in the legend. To avoid too much crowding, the graphs have been separated in figures $5(A)$ and $5(B)$ by shifting the abscissa scales as indicated. The graphs thus established have been assembled to form the diagram in figure $5(C)$.

In the absence of cyclic stress, corrosion pitting is known to be about the same for all steels of these types in fresh water [24]. The fact that a single diagram can be used to represent constant net damage for all these steels (fig. 5) suggests that the influence of cyclic stress on corrosion pitting in fresh water is practically unaffected by variations in composition, heat treatment, or mechanical properties. ${ }^{2}$

The relationship between cyclic stress and corrosion time for constant net damage, as illustrated by the graphs in figure 5 and in previous papers [18 to 23], is approximately a straight-line logarithmic relationship. The slope of a graph evidently decreases slightly with decrease in cycle frequency. The straight-line logarithmic relationship means that the corrosion time required for constant net damage varies inversely as a power of the cyclic stress. As the average rate of net damage varies inversely as the total corrosion time, the average rate evidently varies directly as a power of the stress. This relationship may be represented by the following equation, which has been discussed in previous papers [19 to 23]:

$$
R=C S^{n} \text {. }
$$

In this equation, $R$ represents the (average) rate of net damage, $S$ represents the cyclic stress, and $n$ represents the cotangent of the angle of slope of the graph (fig. 5). The coefficient $C$ represents the horizontal position of the graph in the diagram (the abscissa at a given ordinate); it depends on the intensity of the corrosion and on the cycle frequency.

2 Provided that alloying elements are not present in sufficient percentages to cause important increase in corrosion resistance. $229032-40-7$ 
For steels in well water with free access of air, as illustrated by the graphs in figure $5, n$ ranges from about 2.8 to 3.5. A different kind of water, such as distilled water [23], or a different kind of metal [21], may give a diagram very different from those in figures 5 and 6 .

\section{PITS FORMED BY STRESSLESS CORROSION}

\section{SURFACE VIEWS OF SPECIMENS AFTER STRESSLESS CORROSION}

Photographs of the surfaces of specimens were made at magnification of about $\times 4$. The size of the photographic prints, 8 by 10 in., was sufficient to include all of the tapered part of each specimen. Typical portions of many of these photographs have been included in this paper. Figures 7 and 8 show surfaces of specimens that have been corroded without stress. Each photograph includes practically the entire width of a specimen. The vertical direction in each photograph represents the longitudinal direction on the surface of a specimen. As the photograph shows a curved surface, the view is oblique except at the center, and the obliquity increases from the center toward the right and left edges. This should be kept in mind in studying the forms, sizes, and distribution of corrosion pits.

The views in figures 7 and 8 are arranged in the order of increasing corrosion time, and without regard for the composition of the steel. After 2 days' corrosion (fig. 7, $A$ ), the pits are just beginning to appear as small round spots. After 4.7 and 5.8 days (fig. $7, B$ and $C$ ), the pits have grown considerably and are still round. ${ }^{3}$ After 10 days (fig. $7, D$ ), the pits are much larger; some of the pits now are slightly elongated, and a few adjacent pits have grown together. After 50 and 59 days (fig. $7, E$ and $F^{\prime}$ ), the pits have increased greatly in size, and occupy a large proportion of the surface. The pitting now appears in two shades, depending on the depth of pitting. The darker shade is in round pits, either on the surface or within the boundaries of larger pits of lighter shade. Several of the dark round spots can be seen within many of the lighter areas; these spots are larger than those found after corrosion for only 10 days (fig. $7, D$ ). The pits evidently have grown by lateral extension, involving the merging of many of the originally round pits. The depth of the pits will be considered later.

With further increase in corrosion time, as shown in figure 8 (69 to 300 days), the pits continued to grow, but much less rapidly than during the first 50 days. Although the growth was largely by lateral extension, involving the merging of originally round pits, a few round pits are still visible both on the surface and within the larger, lighter pits. These relatively deep, round pits are conspicuous in figure 8 $(A, D$, and $F)$ They are generally larger than the round pits found after 50 and 59 days (fig. $7, E$ and $F^{\prime}$ ).

\section{LONGITUDINAL SECTIONS SHOWING PITS CAUSED BY STRESSLESS CORROSION}

In figures 9 and 10 at a magnification of $\times 50$, and in figure 33 at a magnification of $\times 250$, are micrographs of longitudinal sections showing pits caused by stressless corrosion. The Wood's metal in which the specimen is mounted appears at the left of each photograph.

\footnotetext{
3 The word "round" here refers to the surface view, not to the three-dimensional form.
} 
Corrosion products appear in all the pits. Although part of the corrosion products has been detached from some of the pits during examination of the outer surface, enough of these products are present to ensure that the photographs give the true forms of the pits. In each figure the photographs are arranged in order of increasing corrosion time and without regard to the composition of the steel.

It should be kept in mind that the sections shown in these micrographs do not pass through the centers of all the visible corrosion pits. An attempt has been made, however, to make each section pass approximately through the center of at least one pit. The micrographs shown have been selected from several micrographs (often five or more) of each section, and each section is represented (figs. 9 and 10) by either two separate micrographs or by a longer continuous micrograph. In studying the forms and sizes of the corrosion pits, frequent reference should be made to the surface views (figs. 7 and 8). Not all the specimens represented in figures 9 and 10 , however, are shown in figures 7 and 8 , and one specimen shown in a surface view (fig. $7, C$ ) is not shown in a sectional view. Nevertheless, comparison can be made between complementary views of specimens corroded for approximately equal times.

Sections through many of the pits that appear roughly circular in the surface views (figs. 7 and 8) appear roughly semicircular in figures 9 and 10 . Examples of this may be seen by comparing the micrographs listed below.

\begin{tabular}{|c|c|c|}
\hline \multicolumn{3}{|c|}{ Appearance } \\
\hline $\begin{array}{c}\text { Corrosion } \\
\text { time }\end{array}$ & Circular & Semicircular \\
& & \\
\hline & & \\
Days & & $9(A)$ \\
2 & $7(A)$ & $9(C)$ \\
4.7 & $7(B)$ & $9(E), 9(F)$ \\
47 to 50 & $7(E)$ & $10(B)$ \\
100 & $8(C)$ & \\
\hline
\end{tabular}

This evidence, supplemented by evidence found in other surface and sectional views still to be discussed, indicates that a large proportion of the pits are roughly hemispherical. Some roughly hemispherical pits are found even after other pits in the same specimen have extended laterally and merged. (Compare figs. 7, $E$, and 8, $C$, with figs. $9, E$ and $F$, and $10, B$.) Even in early stages of corrosion, however, some of the pits are saucerlike rather than hemispherical. This is illustrated in micrographs $B, C$, and $D$ of figure 9. In later stages, owing to the lateral extension of the pits, the saucerlike form predominates. Even after the merging of the pits, as illustrated in micrographs $G$ and $H$ of figure 9 and micrographs $A, E$, and $F$ of figure 10, the bottoms of the merged pits generally consist of numerous saucers. The shape of the saucers changes little with increase in corrosion time from about 50 to 300 days. 
After corrosion for 50 days or more, small salients are visible, projecting into the metal from many of the corrosion pits (figs. 9 and 10). Even after 10 days' corrosion, smaller projections are visible at a magnification of $\times 250$ (fig. $33, C$ ). These rootlike projections are due to the influence of oxygen concentration cells, which will be discussed later.

The size of the pits increases greatly during the first few days of corrosion. This is seen both in the surface views ( $A$ to $D$, inclusive, of fig. 7) and in the longitudinal sections (micrographs $A$ to $D$ of fig. 9). ${ }^{4}$ With increase in corrosion time beyond 10 days, the increase in (relative) size of the corrosion pits is slower; nevertheless, the growth is considerable between about 50 and 100 days. (Compare figs. $9, E$ and $F$, with fig. $10, B$ ). Beyond 100 days, the depth evidently increases little, but the breadth increases, largely by the merging of adjacent pits. Under stressless corrosion in well water, therefore, the increase in breadth eventually tends to be greater than the increase in depth.

No evidence is found that the differences in composition have had any important effect on the form or size of the corrosion pits. This relationship confirms the previously mentioned evidence (section III-4) that pitting under stressless corrosion is practically unaffected by variations in the composition or mechanical properties of the steels.

\section{INFLUENCE OF FORM, SIZE, AND DISTRIBUTION OF CORROSION PITS ON EFFECTIVE STRESS CONCENTRA- TION}

\section{FACTORS INVOLVED IN EFFECTIVE STRESS CONCENTRATION}

The lowering of the fatigue limit, represented by a curve in figures 1,2 , and 3 , must be attributed to stress concentration around corrosion pits. Because of stress concentration, the actual stress around a pit may be above the fatigue limit, when the nominal stress (estimated from the applied load and the dimensions of the specimen) is much less. Stress concentration, therefore, must be considered in any attempt to correlate the forms and sizes of corrosion pits with the lowering of the fatigue limit.

The effective stress-concentration factor due to a corrosion pit or other notch may be denoted by the ratio of the fatigue limit of an unnotched specimen to the fatigue limit of the notched specimen. The effective stress-concentration factor $\left(K_{F}\right)$ depends on the metal, on the theoretical stress-concentration factor $(K)$, and on the size of the notch. The theoretical stress-concentration factor, however, depends entirely on the form and relative size of the notch (size of the notch in relation to the size of the specimen). When the notch is small in relation to the size of the specimen, the theoretical stress concentration depends almost entirely on the form of the notch.

Theoretical stress-concentration factors are based on the mathematical theory of elasticity.

\footnotetext{
4 After 4 days' corrosion, the pits in figure 9 appear only slightly larger than in the section made after 2 days (fig. 9, A) and much smaller than in the section made after 4.7 days (fig. $9, C$ ). The section made after 4 days, however, probably either does not pass through the centers of the pits or does not show representative pits.
} 


\section{THEORETICAL STRESS CONCENTRATION DUE TO CORROSION PITS}

Although the theoretical stress-concentration factor $(K)$ due to corrosion pits cannot be estimated exactly, an approximate estimate can be made of the minimum value, and of the probable range of significant values. In such estimation, attention will be confined to values obtainable with pits caused by prior stressless corrosion. As the pits during the first few days of stressless corrosion are approximately hemispherical, the simplest approach to a study of the theoretical stress concentration is made by assuming that all the pits are modifications of smooth hemispherical cavities.

No investigation apparently has been made of the theoretical stressconcentration factor due to a hemispherical cavity. The stressconcentration factor for such a cavity, however, probably is about the same as the factor for a spherical cavity. This conclusion is based on analogous relationship for other forms of notch. The theoretical stress-concentration factor for a semicircular notch at the edge of a plate, or for a semicircular groove in a cylinder, has been found to be practically the same as the stress-concentration factor for a circular hole in a plate. Information as to the stress-concentration factor for a hemispherical cavity, therefore, can be derived from results of investigation of the theoretical stress concentration around a spherical cavity.

Leon [8] found that the maximum stress concentration around a spherical cavity, in a solid subjected to one principal stress, is at the equator. (The polar axis is assumed to be in the direction of the principal tensile or compressive stress.) The stress-concentration factor, for a range of Poisson's ratio $(\sigma)$ between $1 / 4$ and $1 / 3$, was found to range between 2.02 and 2.08. Southwell and Gough [26] obtained numerical values in good agreement with those of Leon [8], with whose work they evidently were unacquainted. Their formula for the stress-concentration factor is $(27-15 \sigma) /(14-10 \sigma)$. For values of $\sigma$ ranging between $1 / 4$ and $1 / 3$, this formula gives stress-concentration factors ranging between 2.02 and 2.06 .

Goodier [2] obtained the same formula that was obtained by Southwell and Gough. He also studied mathematically the general problem of the stress concentration due to spherical inclusions, as affected by variation of Poisson's ratio and the modulus of elasticity. When a spherical inclusion is less rigid than the surrounding metal, the stress distribution is qualitatively similar to that around a spherical cavity. Around a slag inclusion, the stress concentration was found to be only about 20 percent less than that around a spherical cavity. As the corrosion products in a pit are porous enough to permit diffusion of the aqueous solution during corrosion, the stress-concentration factor due to a hemispherical pit containing corrosion products probably is not appreciably less than that due to a hemispherical cavity. The theoretical stress-concentration factor for a hemispherical corrosion pit, therefore, probably is about 2 .

For a pitted specimen, however, the theoretical stress-concentration factor is not the mean of the stress-concentration factors for the individual pits, but is the factor for the pit whose size and form cause the highest effective stress concentration $\left(K_{F}\right)$. Although many of the pits are not far from hemispherical, the pit giving the highest 
theoretical stress-concentration factor probably has less resemblance to a hemisphere than to an oblate hemispheroid or to a hemiellipsoid of revolution, whose axis of revolution is the minor axis of an ellipse and is in the direction of the principal stress. Consideration, therefore, must be given to the theoretical-stress concentration around pits of this form.

The stress concentration due to ellipsoids of revolution has been investigated by Neuber [25]. His results may be represented by a curve, with abscissas denoting the eccentricity $(a / b)$ of the ellipsoid, and with ordinates denoting the corresponding values of $K$. In the ratio $a / b, a$ and $b$ represent the major and minor semiaxes, respectively, of the elemental ellipse. When $a / b$ is 1.0 , the cavity is spherical, and Neuber's value for $K$ is about the same as the value obtained by Leon [8], Southwell and Gough [26], and Goodier [2]. When the eccentricity ratio is 1.7 , which probably is about the maximum for pits formed during the first days of corrosion, $K$ is about 3. With further increase in the eccentricity, $K$ continues to increase rapidly; values of 3 and 5 for $a / b$ give values of about 5 and 7 , respectively, for $K$. Some of the pits formed under stress corrosion (section VI), have eccentricity ratios even higher than these.

Even in the early stages of stressless corrosion, however, the pits are not entirely smooth. With growth of the pits, projections appear on the boundaries. Some of these are blunt, others are root-like or roughly conical. Consideration, therefore, must be given to the influence of these projections on the theoretical stress concentration. Although no direct investigation has been made of the effect of such projections, an idea of the effect may be obtained from results of investigation of an analogous relationship for a hole in an infinite plate. Inglis [7] has shown that the theoretical stress-concentration factor for a circular hole with a semicircular notch at its edge is the product of the separate factors for the hole and notch. Although such a relationship may not apply quantitatively to the threedimensional stress concentration caused by a spherical or conical projection at the bottom of a hemispherical pit, it probably applies at least qualitatively. For a hemispherical pit with a much smaller hemispherical projection, consequently, the theoretical stress-concentration factor may be about 4. For a sharp conical projection, the theoretical stress-concentration factor may be somewhat higher.

Multiplication of the two separate factors to obtain the factor for the combination, as shown by Inglis [7], applies only when the projection is small enough to be contained within the very small region of high stress concentration around the larger notch or hole. With increase in the relative size of the projection, the theoretical stressconcentration factor for the combination falls rapidly.

With the first appearance of nearly hemispherical corrosion pits, therefore, the theoretical stress-concentration factor probably is not less than 2, and may become about 3 during the first few days of stressless corrosion. The factor tends to become still higher, with the appearance and growth of projections on the boundaries of the pits. This tendency, however, is opposed by the tendency of the stressconcentration factor to decrease with increase in the relative size of the projections. It is also opposed by the tendency of the pits to change from hemispherical to saucer-like form. 
The stress concentration around a pit may also be influenced by the nearness of another pit. If the line of centers of two pits (near together) is in the direction of the principal stress, each pit has a shielding effect on the other and the stress concentration is less than if the pits were far apart. If the line of centers is in the transverse direction, the stress concentration is greater than if the pits were far apart. Instances of this effect of distribution of pits will be mentioned in section VI.

\section{INFLUENCE OF SIZE, AND OF THE STEEPNESS OF THE STRESS GRADIENT, ON EFFECTIVE STRESS CONCENTRATION}

That the size of a notch has great influence on the effective stressconcentration factor $\left(K_{F}\right)$ has been established by a number of investigations. It is possible to mention only one of these. The influence of small, relatively deep scratches and other small grooves has been investigated by Thomas [28]. The grooves were classified in two series, differing in size and in the method of formation. The smaller grooves ranged in depth from 0.00058 to 0.00244 in.; the larger grooves ranged from 0.0050 to 0.0448 in. The depth of each groove and the root radius were determined by microscopical examination of sections of gelatin casts. For each groove, therefore, an estimate could be made of the value of $K$.

The values of $K$, with allowance for the influence of the relative depth, ranged from 3.2 to 6.3 for the smaller grooves, and from 3.2 to 4.05 for the larger grooves. The corresponding values for the effective stress-concentration factor $\left(K_{F}\right)$ ranged from 1.16 to 1.41 for the smaller grooves, and from 1.37 to 2.07 for the larger grooves. The discrepancy between corresponding values of $K$ and $K_{F}$ evidently increased with the decrease in the size of the groove. This discrepancy, therefore, must be attributed mainly to the influence of absolute size. The lowest value (1.16) of $K_{F}$ differs little from the value (1.0) for an unnotched specimen. Results obtained by Thomas [28] with scratches caused by emery led him to the conclusion that the effect of even a sharp groove is negligible, if the depth is no more than about 0.0001 in.

In previous discussion, the influence of the theoretical stress concentration and of the size of the notch on the fatigue limit have been treated (in the conventional way) as if they were independent. Evidence obtained by a number of investigators, however, indicates that the effect of size on the fatigue limit increases with the theoretical stress-concentration factor. It has already been shown, moreover, that the effect of the theoretical stress-concentration factor decreases with the size of the notch. This interrelationship is due to the combined influence of the theoretical stress-concentration factor and absolute size on the steepness of the stress gradient.

The theoretical stress gradient around a circular hole is invariant with size, if distances from the hole are expressed in terms of the radius. If distances are expressed in absolute units, however, the steepness of the gradient evidently increases with decrease in the absolute size of the hole. The steepness of the stress gradient, therefore, varies directly with $K$ and inversely with the size of the notch. A suitable index of steepness of the gradient, consequently, would have as numerator an index of the range of stress in the gradient, 
and as denominator an index of notch size. An index proposed by the authors is derived by representing the approximate stress range of the gradient by $K-1$, and the size of the notch by the root radius $(r)$. This index, therefore, is $(K-1) / r$.

The available evidence indicates that the discrepancy between $K$ and $K_{F}$ tends to increase with the steepness of the stress gradient. The fracture of a metal, either by single or repeated loading, apparently is not determined by the highest stress in the theoretical gradient (at a geometrical line), but by the mean stress over an appreciable width of the gradient. The steeper the gradient, therefore, the greater is the difference between this mean stress and the highest stress of the theoretical gradient, and the greater is the difference between $K$ and $K_{F}$. The gradient may even be so steep and narrow that the stress peak has practically no effect on the fatigue limit. (Space is not available for discussing the reasons for this behavior of metals.)

Although a sharp projection on a corrosion pit may cause a very high value of $K$, this value is associated with a very low value of $r$. Such a projection, therefore, gives a very high value of $(K-1) / r$, the index of steepness of the stress gradient. The sharp projection evidently superposes a very steep, narrow gradient on the broader, less steep gradient induced by the general form of the pit. The stress peaks at such projections may be so sharp that they have no important effect on the fatigue limit. Consequently, when a projection is very small in relation to the size of a corrosion pit, the only significant value of the theoretical stress-concentration factor is that based on the general form of the pit.

\section{EFFECTIVE STRESS-CONCENTRATION FACTOR FOR SPECIMENS PREVIOUSLY CORRODED WITHOUT STRESS}

The influence of prior corrosion time on the effective stress-concentration factor may be studied by means of the values of $K_{F}$ obtained from the stressless corrosion curves in figures 1,2 , and 3 . With increase in prior corrosion time, $\mathrm{K}_{F}$ evidently increases rapidly during the first few days of corrosion. The rate of increase of $K_{F}$, however, decreases with time, and eventually becomes small. The course of each curve appears to indicate that $K_{F}$ approaches an asymptotic value of about 2. As shown in a paper by McAdam and Clyne [24], however, $K_{F}$ tends to increase with the hardness of the steel. The curves presented in that paper suggest that, with increase in the hardness of the steel and with increase in corrosion time, $K_{F}$ approaches an asymptotic value of 3 or 4 .

As the theoretical stress-concentration factor for the pits formed during the first few days of corrosion may be as high as 3 , and as the asymptotic value of $K_{F}$ apparently is not much higher, the evidence indicates that the course of the stressless corrosion curves in figures 1,2 , and 3 is due chiefly to increase in the size of the corrosion pits. The tendency toward increase of $K$ due to the formation of projections on corrosion pits probably is nearly counterbalanced by the tendency toward decrease of $K$ with change of pits from roughly hemispherical to saucer-like form. 


\section{PITTING UNDER SIMULTANEOUS CORROSION AND CYCLIC STRESS, AND ITS CORRELATION WITH NET DAMAGE}

\section{PITTING WITH FREQUENCY OF 1,450 CYCLES PER MINUTE}

In studying the influence of cyclic stress (during corrosion) on the forms and sizes of corrosion pits, comparison will be made between surface views and longitudinal sections of corroded specimens, and between specimens corroded with and without cyclic stress. Attention will be given first to specimens that have been subjected to stress corrosion with frequency of 1,450 cycles per minute. Typical portions of the surfaces of these specimens, at a magnification of $\times 4$, are shown in figures 11 and 12 ; typical sectional views are shown in figures 13 and 14. In each of these figures are views of specimens that have been corroded at $1,450 \mathrm{c} / \mathrm{min}$ but under different cyclic stresses and for different times. Comparison of the views in each figure, therefore, reveals the influence of both cyclic stress and corrosion time, with constant cycle frequency. The views in each figure are arranged primarily in the order of decreasing cyclic stress, secondarily in the order of increasing corrosion time, and without regard to the composition of the steel. The vertical direction in each view represents the longitudinal direction of the specimen. Below each figure are listed, for each view, the cyclic stress, the corrosion time, and the symbol for the steel.

In the surface views (figs. 11 and 12), some pits appear round, like the pits caused by stressless corrosion. Other pits consist of round or broad irregular cavities apparently crossed by transverse cracks. ${ }^{5}$ The corresponding sectional views at higher magnification (figs. 13 and 14), however, show that these are not cracks but are sharp, deep corrosion pits; they are filled with corrosion products similar to those found in round pits. The sharp, deep pits are found at the highstress end of the series of views (figs. 11, 12, 13, and 14); at the lowstress end of the series, the pits are entirely of the rounded form. The magnitude of the stress, therefore, is one of the factors determining whether or not the sharp projections shall be formed. Another factor, as will be shown, is the corrosion time.

The first stages of development of projections of this form, however, cannot be determined by examination of surface views, especially at low magnification. Even when such projections do not appear on the surface, an examination of a longitudinal section may reveal sharp, wedge-shaped projections extending inward from rounded pits. Instances of this kind will be mentioned in detailed discussion of the photographs. In future discussion, the sharp, transversely extended pits visible in surface views will be called fissures. The less advanced, wedge-shaped pits not visible on the surface will be called crevices. A crevice and a fissure thus differ only in degree.

To show clearly the influence of stress on the development of fissures, the effect of varying stress should be studied with constant corrosion time. Such a study may be made by comparing the six surface views (figs. 11 and 12) representing the effects of different cyclic stresses acting during the same corrosion time, 10 days. These

5 Transverse to the direction of principal tensile stress in the specimen. 
six views ( $A, C, E$, and $F$ of fig. 11 and $A$ and $B$ of fig. 12) represent the effects of cyclic stresses ranging from 15,000 to $8,000 \mathrm{lb} / \mathrm{in}^{2}$ In the view representing stress of $8,000 \mathrm{lb} / \mathrm{in}^{2}{ }^{2}$ (fig. $12, B$ ), the corrosion pits appear round, like pits caused by stressless corrosion. In the other five views, representing stresses ranging from 15,000 to 9,000 $\mathrm{lb} /$ in. $^{2}$, round or irregularly extended pits are traversed by fissures. Fissures evidently do not appear during 10 days' corrosion at 1,450 c/min, when the cyclic stress is less than about $9,000 \mathrm{lb} / \mathrm{in}^{2}$

The influence of cyclic stress on the development of fissures and crevices is similarly revealed by comparison of nine sectional views (figs. 13 and 14), most of which correspond to surface views in figures 11 and 12 . These sectional views $(A, D, F, G$, and $I$ of fig. 13 and $C, E, G$, and $I$ of fig. 14) represent specimens that have been corroded under stresses ranging from 15,000 to $5,000 \mathrm{lb} / \mathrm{in}^{2}$, with constant corrosion time, 10 days. ${ }^{6}$ The sectional views of specimens corroded under cyclic stresses of $9,000 \mathrm{lb} /$ in. $^{2}$ or more show sharp, wedgeshaped pits, which evidently are sections of fissures such as those seen in surface views (figs. 11 and 12). The sectional views of specimens corroded at $8,000 \mathrm{lb} / \mathrm{in}^{2}$ or less show only rounded pits, like those caused by stressless corrosion. Comparison of both surface views and sectional views, therefore, leads to the conclusion that the limiting stress above which fissures develop (during 10 days' corrosion at $1,450 \mathrm{c} / \mathrm{min}$ ) is $8,000 \mathrm{lb} / \mathrm{in}^{2}$

There is evidence, however, that some crevices may have appeared during 10 days' corrosion at $8,000 \mathrm{lb} / \mathrm{in}^{2}$ Although the specimen corroded for 10 days at this stress shows no crevices (fig. 14, $C$ ), another specimen corroded at the same stress for only 4 days (fig. $14, B)$ shows sharp inward projections from rounded corrosion pits. As these projections are filled with adherent corrosion products, they evidently are sections of crevices. Similar crevices, therefore, may have formed beneath some of the rounded pits in the specimen that was corroded at the same stress for 10 days. Another specimen corroded at the same stress for 24 days (fig. $14, D$ ) shows typical sections of transverse fissures. In specimens corroded at stresses less than $8,000 \mathrm{lb} /$ in. $^{2}$, no fissures or crevices are visible in either surface views or longitudinal sections, even after corrosion for much longer than 10 days (views $C$ to $F$, inclusive, of fig. 12 and views $E$ to $K$, inclusive, of fig. 14).

At sufficiently high stress, tranverses fissures appear after corrosion for much less than 10 days. This is illustrated by surface views $B$ and $D$ of figure 11 and by sectional views $B$ and $C$ of figure 13 . After corrosion at $11,000 \mathrm{lb} /$ in $^{2}$ for 3 days, the surface view (fig. $11, D$ ) shows short transverse fissures extending from a few of the rounded pits. The longitudinal section (fig. 13, E), however, does not cut any of these fissures but shows only rounded pits.

Although some of the sectional views of fissures (figs. 13 and 14) show the rounded pits from which the fissures started, a few sections of fissures do not show rounded origins. Absence of rounded pits in sections of fissures, however, does not mean that the fissures started inward directly from the surface. All the fissures, as shown in the surface views, have started at rounded corrosion pits and have

\footnotetext{
- In specimens that had been subjected to fatigue test after the corrosion stage, the pits did not differ in appearance from those in specimens that had not been subjected to fatigue test.
} 
extended both transversely and inward. Some of the sections in figures 13 and 14 are nearly at the centers, and some are at the edges of the rounded origins of fissures. Others are at a distance from these origins.

The influence of corrosion time on the forms of corrosion pits is revealed also by comparison of views obtained after corrosion at $9,000 \mathrm{lb} /$ in. $^{2}$ for 4,10 , and 50 days. After corrosion for 4 days, only round pits are visible on the surface (not shown) and no fissures or crevices are found in a sectional view (view $H$ of fig. 13). Corrosion for 10 days, as already shown (view $A$ of fig. 12 and view $I$ of fig. 13), has caused long, deep fissures. After 50 days at the same stress (view $A$ of fig. 14), the fissures are deeper and have broadened greatly at the surface.

The evidence in figures $11,12,13$, and 14 , therefore, indicates that stress-corrosion pits in steel corroded in fresh water are merely modifications of pits formed by stressless corrosion. The number of pits per unit area and their distribution, consequently, are determined by the same uncontrollable variables that determine the number and distribution of pits formed by stressless corrosion. Great differences may be found in the number and distribution of these anodic regions after apparently identical corrosion conditions. The size of the pits, moreover, generally varies inversely with the number. Occasional mention will be made of typical instances of such variation in number, size, and distribution of pits.

The fissured pits (figs. 11, 12, 13, and 14) generally are much larger than pits formed in corresponding times by stressless corrosion (figs. $7,8,9$, and 10). Cyclic stress evidently tends to increase the size of corrosion pits. This effect of cyclic stress on the rate of corrosion, moreover, evidently tends to be greatest at the equator of a roughly hemispherical corrosion pit. The tendency to form sharp equatorial fissures may be attributed to the fact, mentioned by Southwell and Gough [26], that nearly all the concentration of stress is in a narrow equatorial ring. With development of a fissure, this stress concentration is intensified. The influence of stress concentration on the rate of corrosion is discussed further in section VII.

To facilitate comparison between the corrosion pits (shown in figs. 11, 12, and following figures) and the corresponding net damage, the forms of the corrosion pits are classified by means of the symbols used to designate the experimental points in figures 1 to 4 . Different symbols are used to designate fissures, crevices, and rounded pits. The fissures caused by corrosion for 10 days at stresses ranging from 13,000 to $9,000 \mathrm{lb} /$ in $^{2}$ (views $C, E$, and $F$ of fig. 11, and $A$ of fig. 12) have lowered the fatigue limit from $64,000 \mathrm{lb} / \mathrm{in}^{2}{ }^{2}$ to values ranging between 24,000 and 26,000 lb/in. ${ }^{2}$ These values are far below the fatigue limit $\left(44,000 \mathrm{lb} / \mathrm{in}^{2}\right)$ that would be found after 10 days' corrosion without stress. The net damage caused by crevices tends to be intermediate between the damage caused by fissures and that caused by rounded pits. Considerable net damage may be caused by stress corrosion even in the absence of fissures or crevices. This is illustrated by the positions of the points representing effects of corrosion for 10 days at stresses less than $8,000 \mathrm{lb} / \mathrm{in}^{2}$ 


\section{PITTING WITH FREQUENCY OF 500 CYCLES PER MINUTE}

Surface views of specimens corroded with frequency of 500 cycles per minute are shown in figure 15 , and sectional views are shown in figures 16 and 33 .

This series, unlike the series obtained at $1,450 \mathrm{c} / \mathrm{min}$, is not well adapted to reveal the effect of varying the cyclic stress with constant corrosion time. The limiting stress above which fissures appear within a given corrosion time, however, evidently is higher at 500 than at $1,450 \mathrm{c} / \mathrm{min}$. Whereas corrosion at $1,450 \mathrm{c} / \mathrm{min}$ at 9,000 $\mathrm{lb} / \mathrm{in}^{2}{ }^{2}$ for 10 days (fig. 12, $A$ ) has caused long transverse fissures, corrosion at $500 \mathrm{c} / \mathrm{min}$ at $9,000 \mathrm{lb} / \mathrm{in} .{ }^{2}$ for 9 days has caused rounded pits with no evidence of fissures or crevices (figs. 15, $E$, and 16, $E$ ). Corrosion at $13,000 \mathrm{lb} /$ in. $^{2}$ for 15 days at $500 \mathrm{c} / \mathrm{min}$, moreover, has caused only a few short fissures (fig. 15, B).

After corrosion at $14,000 \mathrm{lb} / \mathrm{in} .{ }^{2}$ for 4 days (fig. $15, A$ ), nearly all the pits appear round. Some of the pits, however, have merged so as to form rounded transversely elongated pits. Short transverse fissures, moreover, have started at a few of the rounded pits. A sectional view of typical fissured pits is shown in figure $16(A)$. The theoretical stress-concentration factor for these sharp fissures is very high. Because of their small size, however, the effective stress-concentration factor (obtained from fig. 3 ) is only about 2 .

The influence of corrosion time on the development of transverse fissures is revealed by a comparison of the surface views of specimens corroded at $13,000 \mathrm{lb} / \mathrm{in} .{ }^{2}$ for 15 days and 45 days, respectively (views $B$ and $C$ of fig. 15). With increase in the corrosion time from 15 to 45 days, the fissures have increased greatly in number and length and have broadened at the surface. The increase of net damage with the development of these fissures is represented by the corresponding curve in figure 1.

Corrosion at $12,000 \mathrm{lb} / \mathrm{in} .^{2}$ for 4 days, at $10,000 \mathrm{lb} / \mathrm{in} .{ }^{2}$ for 6 days, at $9,000 \mathrm{lb} /$ in. $^{2}$ for 9 days, and at $8,000 \mathrm{lb} /$ in. $^{2}$ for 10 days, as shown in figures 15, 16, and 33, has caused neither fissures nor crevices. (Some of these specimens are not shown in both surface and sectional views.) After corrosion at $8,000 \mathrm{lb} / \mathrm{in}^{2}{ }^{2}$ for 25 days, the surface view (not shown) reveals only rounded pits, some of them surrounded by shallower, broad corroded areas. The sectional view (fig 16, $G$ ), however, shows sharp crevices extending inward from some of the rounded pits. After corrosion at the same stress for 33 days, the surface view (fig. $15, F^{\prime}$ ) shows no evidence of transverse fissures, and a longitudinal section (fig. $33, E$ ) shows no crevices. The sectional view shows a tendency of corrosion pits to extend by burrowing along the surface. Such salients may appear whether or not the specimen is under cyclic stress. The considerable net damage caused by the pitting of this specimen probably is due to one or more large pits, such as those shown in figure $15(F)$.

After corrosion at $7,000 \mathrm{lb} / \mathrm{in}^{2}$ for 19 days, no fissures are visible in the surface view (not shown) but a sectional view (fig. 16, $H$ ) reveals a crevice extending inward from a rounded pit. Crevices such as this may account for the net damage shown in figure 1.

Considerable net damage, as shown in figures 1 and 3 , is caused by the rounded stress-corrosion pits. Reasons for this may be found by comparing surface views in figure 15 with surface views of speci- 
mens corroded for corresponding times without stress (figs. 7, and 8). Cyclic stress (during corrosion) evidently tends to increase the size of the rounded pits, especially of a few of the pits in each specimen. This is illustrated by views $B$ and $F$ of figure 15 . Cyclic stress thus tends to increase not only the mean size but also the range of size of corrosion pits.

\section{PITTING WITH FREQUENCY OF 100 CYCLES PER MINUTE}

Surface views of specimens corroded with frequency of 100 cycles per minute are shown in figure 17, and longitudinal sections are shown in figures 18 and 33. Photographs of surface views corresponding to sectional views $H$ to $K$, inclusive, of figure 18 are not included in this paper.

At the high-stress end of the series of views, fissures have started from some of the rounded pits. These fissures are shown in views $A, B, D$, and $E$ of figure 17 and in views $A, B, C$, and $F$ of figure 18 . The limiting stress below which fissures or crevices do not appear during a given corrosion time is much higher at $100 \mathrm{c} / \mathrm{min}$ than at 500 or $1,450 \mathrm{c} / \mathrm{min}$. The limiting stress for about 10 days' corrosion time may be found by comparing view $F$ of figure 17 with views $G$ and $H$ of figure 18 . After corrosion at $13,000 \mathrm{lb} / \mathrm{in} .^{2}$ for 9 days, the surface view (fig. 17, F) shows no clear evidence of fissures, although the contour of a few of the pits (as seen with a lens) suggests that fissures may be starting. The sectional view (fig. 18, $G$ ), however, shows deep crevices. After corrosion at $12,000 \mathrm{lb} /$ in. $^{2}$ for 11 days, no fissures appear in the surface view (not shown) and no crevices appear in the sectional view (fig. 18, H). During about 10 days' corrosion at $100 \mathrm{c} / \mathrm{min}$, therefore, transverse fissures or crevices evidently do not appear unless the stress is more than about $12,000 \mathrm{lb} /$ in. $^{2}$ This limiting stress is about 50 percent greater than the corresponding stress for 10 days' corrosion at $1,450 \mathrm{c} / \mathrm{min}$ (sec. VI-1).

The influence of corrosion time on the development of fissures is illustrated by views $C$ and $D$ of figure 17 , view $D$ of figure 18 , and view $F$ of figure 33 . After corrosion for 3.5 days at $20,000 \mathrm{lb} / \mathrm{in}^{2}{ }^{2}$ (figs. 17, $C$ and $18, D$ ), no fissures or crevices are visible. After 4.5 days at the same stress, the surface view (fig. 17, D) shows short transverse fissures traversing a few of the rounded pits and a longitudinal section (fig. 33, $F$ ) shows a crevice. The corresponding curve in figure 1 shows a rapid increase of net damage with corrosion at this stress.

As no crevices were found after corrosion at $12,000 \mathrm{lb} / \mathrm{in}^{2}{ }^{2}$ for 11 days (fig. 18, $H$ ), no crevices would be expected after corrosion at 11,000 lb./in. ${ }^{2}$ for only 3 days longer. Although the surface view of the specimen corroded at $11,000 \mathrm{lb} /$ in. $^{2}$ for 14 days shows only rounded pits, however, a sectional view (fig. $18, I$ ) shows a thin crevice. The early development of crevices in this specimen, and the resultant disproportionally rapid net damage represented by the corresponding curve in figure 1 , probably are due to the previously mentioned uncontrollable variables affecting the number and distribution of corrosion pits. Another instance of the influence of these variables may be found by comparing the number of corrosion pits in view $E$ of figure 17 with the numbers in the other views of this figure. Because of the relatively small number and consequent relatively large size 
of the pits shown in view $E$, the net damage (fig. 1) is disproportionally large.

The influence of crevices on net damage, as shown in figure 1, tends to be intermediate between the influences of fissures and rounded stress-corrosion pits. This fact indicates that thin inward projections from pits in figure 18 are sections of crevices and not of root-like projections, which sometimes are formed under the influence of oxygen concentration cells. Sharp root-like projections cause much less net damage than thin transverse crevices.

Considerable net damage, as shown in figures 1 and 3, may be caused by rounded stress-corrosion pits. Probable reasons for this may be found in figures 17 and 18 . In views $A, B, C$, and $D$, which show results of corrosion at high stresses for a few days, the size of at least a few of the rounded pits is much greater than that of pits caused by corrosion for corresponding times without stress. The evidence indicates that cyclic stress tends to increase the size of both fissured and rounded pits. This influence of cyclic stress on the size of pits probably accounts for the net damage caused by the rounded stress-corrosion pits. This effect, however, may be accentuated by the transverse merging of rounded pits.

\section{PITTING WITH FREQUENCY OF 50 CYCLES PER MINUTE}

Surface views of specimens corroded with frequency of 50 cycles per minute are shown in figures 19,20 , and 21 ; sectional views are shown in figures 22,23 , and 34 .

Transverse fissures, some just starting and others far advanced, are visible in the surface views of specimens corroded under cyclic stresses of $15,000 \mathrm{lb} / \mathrm{in}^{2}{ }^{2}$ or higher. They are visible in all the views of figure 19 and in all the views of figure 20 except view $E$, which represents results of corrosion at $15,000 \mathrm{lb} / \mathrm{in}^{2}$ for 17 days. Although view $E$ shows no clear evidence of fissures, some pits have merged transversely and a few show indications of incipient fissures. After corrosion at the same stress for 24.5 days (fig. $20, F$ ), transverse merging has proceeded further than in view $E$ and transverse fissures are clearly visible.

In the series of sectional views (figs. 22 and 23 ), some sections are shown for which no corresponding surface views are shown in figures 19,20 , or 21 . Comparison of the series of sectional views with the series of surface views leads to the conclusion that the limiting stress below which no fissures or crevices appear during 10 days' corrosion is about $15,000 \mathrm{lb} / \mathrm{in}^{2}$. After corrosion at $16,000 \mathrm{lb} / \mathrm{in} .{ }^{2}$ for 4 days, no fissures are found in the surface view (not shown) and no crevices are found in a sectional view (fig. $23, D$ ). After corrosion at the same stress for 9 days, no fissures are found in the surface view (not shown) but a crevice is found in a longitudinal section (fig. 23, $E$ ). As fissures have just started after corrosion at $15,000 \mathrm{lb} / \mathrm{in}^{2}{ }^{2}$ for 17 days (fig. $20, E$ ), and as no crevices are found in the sectional view (fig. $23, F$ ), no fissures or crevices probably would appear during 10 days at this stress. No fissures are found in the specimens corroded at stresses less than $15,000 \mathrm{lb} / \mathrm{in}^{2}$, although the corrosion times were much longer than 10 days. Crevices, however, are found in the specimens corroded at $13,000 \mathrm{lb} /$ in. $^{2}$ for 20 days (fig. $23, H$ ) and 34 days (not shown). 
The limiting stress $\left(15,000 \mathrm{lb} / \mathrm{in}^{2}{ }^{2}\right)$, therefore, is about 25 percent higher at this frequency than at $100 \mathrm{c} / \mathrm{min}\left(12,000 \mathrm{lb} / \mathrm{in} .^{2}\right)$ and is nearly twice as high as at $1,450 \mathrm{c} / \mathrm{min}\left(8,000 \mathrm{lb} / \mathrm{in} .{ }^{2}\right)$.

The influence of corrosion time on the development of fissures is illustrated by the surface views of specimens after corrosion at 30,000 $\mathrm{lb} / \mathrm{in}^{2}$ for 5,6 , and 8 days (views $C, D$, and $E$ of fig. 19) and after corrosion at $25,000 \mathrm{lb} / \mathrm{in}^{2}$ for $4,6,7$, and 9 days (view $F$ of fig. 19 and views $A, B$, and $C$ of fig. 20). In the first view of each of these series, short fissures traverse a few of the rounded pits. With increase in corrosion time, the number of rounded pits so traversed increases, and the fissures increase in length and in breadth at the surface. Within these broadened fissures may be seen the outlines of deeper rounded pits. The corresponding curves of decrease of the fatigue limit with corrosion time are shown in figures 2 and 3.

The net damage caused by specimens that show crevices in sectional views (views $B, E$, and $H$ of fig. 23) but no fissures in surface views, as shown in the corresponding diagram of figure 2, is intermediate between the net damage caused by fissures and that caused by rounded stress-corrosion pits. The net damage due to the rounded stresscorrosion pits must be attributed to the influence of cyclic stress on the size of these pits, and probably on the form of a few of the larger pits. The influence of cyclic stress on the size of rounded pits is illustrated by a number of views in figures 19,20, and 21 .

The rounded pits caused by corrosion at $35,000 \mathrm{lb} / \mathrm{in}^{2}$ for 3 days (fig. $19, B$ ) are about as large as pits caused by stressless corrosion for 10 days (fig. $7, D$ ). After corrosion at $25,000 \mathrm{lb} / \mathrm{in}^{2}$ for 4 days (fig. $19, F^{\prime}$ ), parts of the surface are occupied by groups of very small pits. Some of the pits, however, have grown as large as those caused by stressless corrosion for 10 days. After corrosion for 6 days at the same stress (fig. 20, A), the groups of smaller pits have increased in number without much increase in size. Some of the larger pits, however, have increased greatly in size, and some round pits of intermediate size have merged to form transversely extended pits. After 9 days' corrosion of another specimen of the same steel at the same stress (fig. 20,C), very few of the small pits are visible but the larger pits have increased considerably in size.

After corrosion of a specimen of another steel at $20,000 \mathrm{lb} / \mathrm{in} .{ }^{2}$ for 10 days (fig. $20, D$ ), pits are more numerous, and consequently are smaller, than those caused by stressless corrosion for 10 days (fig. $7, D)$. Some of the pits in figure $20(D)$ however, have merged to form transversely extended pits, and some of these are traversed by short fissures. The net damage shown by this specimen may be attributed mainly to the influence of cyclic stress on the form of corrosion pits.

$C$ and $D$ of figure 21 are views of two specimens of the same steel after corrosion at $10,000 \mathrm{lb} /$ in. $^{2}$ for 27 and 28 days, respectively. These views illustrate the great differences that may be found in the distribution of anodic and cathodic areas after exposure to apparently identical corrosion conditions. In view $C$, the round pits are about as numerous and as large as those in view $B$. In view $D$ are a few very large pits, evidently caused by the merging of pits of medium size. Around these large pits are nearly circular areas containing numerous very small pits, and around these areas are nearly uncor- 
roded cathodic areas. Early in the process, the anodic areas probably were confined to the large pits. With accumulation of corrosion products around these anodes, new oxygen concentration cells (section VII) evidently were formed, and thus caused the new small anodic areas which now appear as minute corrosion pits.

After corrosion at $8,000 \mathrm{lb} / \mathrm{in}^{2}$ for 95 days (fig. $21, E$ ), a large proportion of the surface is covered with broad irregular pits containing some small, relatively deep, round pits. This view should be compared with views $B$ and $C$ of figure 8 , which show specimens that have been corroded for 93 and 100 days, respectively, without stress. Such comparison suggests that the pits caused by corrosion under cyclic stress tend to spread less along the surface and thus tend to be deeper than the pits caused in the same time by stressless corrosion. This may account for the net damage (fig. 2) caused by the pits shown in figure $21(E)$. Reasons for this effect of cyclic stress are given in section VII.

\section{PITTING WITH FREQUENCY OF 10 CYCLES PER MINUTE}

Surface views of specimens corroded with frequency of 10 cycles per minute are shown in figures 24 and 25 , and sectional views are shown in figure 26.

After corrosion at $45,000 \mathrm{lb} /$ in. $^{2}$ for 2.8 days, no fissures are visible in the surface view (fig. $24, A$ ) and no crevices are visible in a sectional view (not shown). After corrosion at $40,000 \mathrm{lb} /$ in $^{2}$ for 5 days, no fissures are visible in the surface view (fig. 24, $B$ ). Many of the pits, by growth and merging, have formed transversely extended pits with sharp ends. A sectional view through such pits (not examined) probably would show crevices. After corrosion for 6.5 days at the same stress, a sectional view (fig. $26, B$ ) shows sharp inward projections from rounded pits. No surface view was examined.

Effects of corrosion at $35,000 \mathrm{lb} / \mathrm{in}^{2}$ for times ranging from 6.5 to 9 days are shown in surface views $C$ and $D$ of figure 24 and in sectional views $C$ and $D$ of figure 26. After corrosion for 6.5 days, a few incipient fissures are visible in the surface view (fig. $24, C$ ). No fissures or crevices, however, are found in the sectional view obtained after corrosion for 7 days (fig. 26, C). After corrosion for 9 days, fissures have made considerable progress.

After corrosion at $30,000 \mathrm{lb} / \mathrm{in}^{2}{ }^{2}$ for 9 and 12 days, no fissures are visible in the surface views (views $E$ and $F$ of fig. 24 ). Sharp crevices, however, are revealed by the corresponding sectional views (fig. $26, E$, and another sectional view, not shown). After corrosion at 25,000 $\mathrm{lb} /$ in. $^{2}$ for 11 days, no fissures are visible in the surface view (fig. $25, A$ ) and no crevices are found in the sectional view (fig. $26, F^{\prime}$ ). The results obtained at 30,000 and $25,000 \mathrm{lb} / \mathrm{in}^{2}$, therefore, indicate that the limiting stress below which fissures or crevices do not appear during 10 days' corrosion at $10 \mathrm{c} / \mathrm{min}$ evidently is between 25,000 and 30,000 $\mathrm{lb} / \mathrm{in}^{2}$ The limiting stress is more than 50 percent higher at this cycle frequency than at $50 \mathrm{c} / \mathrm{min}$, and more than three times the corresponding stress at $1,450 \mathrm{c} / \mathrm{min}$.

After corrosion at $22,000 \mathrm{lb} / \mathrm{in} .{ }^{2}$ for 15 days, only large rounded pits are visible in the surface view (not shown). The sectional view shows thin curved projections extending inward from rounded pits. The 
small size and irregular course of these projections suggest that they probably are rootlike projections rather than transverse crevices.

$B$ to $E$, inclusive, of figure 25 are views of specimens that have been corroded at stresses ranging from 18,000 to $13,000 \mathrm{lb} / \mathrm{in}^{2}{ }^{2}$ and for times ranging from 20 to 36 days. Each of these views shows a few large pits, some of them formed by the merging of smaller pits. No fissures are visible in these surface views. Two of the sectional views ( $H$ and $L$ of fig. 26), however, reveal small crevices.

Evidence that cyclic stress (during corrosion) tends to increase the size of rounded pits may be found by comparing the sizes of pits shown in figures 24 and 25 with the sizes of pits caused by stressless corrosion for corresponding times (figs. 7 and 8). In each view of figure 24 and in several views of figure 25, some of the pits are much larger than those caused in corresponding times by stressless corrosion.

After corrosion at $12,000 \mathrm{lb} / \mathrm{in}^{2}$ for 70 days (view $F$ of fig. 25), many groups of round pits have merged to form large broad pits, within which relatively deep round pits are still visible. This view should be compared with view $A$ of figure 8 representing results of stressless corrosion for 69 days. After the stressless corrosion, the round pits within the broad areas caused by the merging are less distinct than after corrosion for the same time at $12,000 \mathrm{lb} / \mathrm{in} .^{2} \mathrm{Al}-$ though this difference may be due largely to difference in the composition of the two steels, it may be due in part to the previously mentioned influence of cyclic stress. Cumulative evidence appears to indicate that the tendency to deepening of pits is greater for stress corrosion than for stressless corrosion. To such a tendency may be attributed the numerous examples, already mentioned, of net damage caused by rounded pits.

\section{PITTING WITH FREQUENCY OF 1.5 CYCLES PER MINUTE}

Surface views after corrosion at $1.5 \mathrm{c} / \mathrm{min}$ are shown in figure 27 , and sectional views are shown in figures 28,29 , and 35 .

No fissures are visible in the surface views (fig. 27). Sharp inward projections from rounded pits, however, are visible in some of the sectional views (figs. 28 and 29). As the net damage caused by these pits is rather small (fig. 2), it appears possible that these projections are not crevices but are rootlike projections caused by oxygen concentration cells. Such projections may be formed even in the absence of cyclic stress. It is important, therefore, to know the approximate width of the inward projections shown in figures 28 and 29.

To obtain this information, successive layers, each 0.001 in. thick, were removed from some of the sections shown in figures 28 and 29 . After removal of each layer, the section was again polished, examined, and photographed. Views $D$ to $G$, inclusive, of figure 28 and view $A$ of figure 29 show five successive sectional views thus obtained with a specimen corroded at $25,000 \mathrm{lb} / \mathrm{in}^{2}{ }^{2}$ for 42 days. The subdivisions of these five views are correspondingly numbered; it is thus possible to follow the changes in each subdivision. Only the smaller of the two pits in view $D-3$, however, is shown in the four subsequent sections.

The pit in subdivision 1 decreases gradually in width from section $D-1$ of figure 28 to section $A-1$ of figure 29 . This change occurred with removal of a total of 0.004 in. from section $D-1$, in which the 229032-40-8 
maximum width of the rounded pit is about 0.025 in. Section $D-1$, therefore, probably is nearly at the center of the rounded pit. With removal of about 0.008 in. more from section $A-1$ of figure 29 , the pit probably would disappear. (The repeated grinding and repolishing necessary to obtain these five sections caused gradual removal of corrosion products, so that none remain in section $A-1$.) The pit in subdivision 2 also decreases greatly in size from section $D-2$ of figure 28 to section $A-2$ of figure 29. (The section of the pit may have been enlarged slightly in polishing after removal of the corrosion products.) The apparently smaller pit in subdivision 3 decreases slightly from section $D-3$ to section $E-3$, and then increases greatly from section $E-3$ of figure 28 to section $A-3$ of figure 29 , which probably is nearly at the center. This pit evidently is nearly as large as the pit shown in $D-1$. The pit in subdivision 4 increases slightly from section $D-4$ to section $E-4$ of figure 28 , then increases greatly to section $F-4$ and decreases slightly to section $G-4$. With removal of an additional 0.001 in., the pit has disappeared; it is not found, therefore, in view $A$ of figure 29. The maximum section of this pit evidently is section F-4.

The sharp projection shown in section $D-2$ is much smaller in section $E-2$, is still smaller in section $F-2$, and is not found in section $G$-2. Removal of less than 0.003 in. from section $D-2$, therefore, has caused the projection to disappear. As section $D-2$ probably is nearly at the center of the round pit and of its projection, the projection probably is not more than 0.005 in. wide (in direction perpendicular to section $D-2)$. As the maximum thickness of the projection (section $D-2$ ) is about 0.0015 in., the width probably is three or four times the maximum thickness. The projection, consequently, is not root-shaped. Cyclic stress evidently has caused the projection to extend transversely as well as inward, and thus has formed a narrow wedge-shaped crevice. The width of the crevice, however, is only about one-fourth the diameter of the rounded pit from which the crevice started.

Corrosion at $20,000 \mathrm{lb} / \mathrm{in}^{2}{ }^{2}$ for 96 days has caused the rounded pits seen in the surface view (fig. $27, F^{\prime}$ ). Sections through three of the pits are shown in figure $29(B)$. In section $B-1$, the pit has several small inward projections. After removal of 0.001 in. $(C-1)$, one of these projections has become deeper and much thicker. After removal of 0.002 in., the projection has become thinner $(D-1)$. With removal of 0.003 and 0.004 in., the projection has decreased in depth and become much blunter. As the width of this projection evidently is not more than about 0.005 in., the maximum thickness is only about one-third the width. This projection, therefore, is a very narrow transverse crevice, only about one-fourth the diameter of the rounded pit from which it started.

In section $B-2$ (fig. 29), the pit has a shallow, blunt projection. After removal of 0.001 in. $(C-2)$, this projection has been replaced by three smaller projections. After removal of 0.002 in. (D-2), a larger, blunt projection has appeared. After removal of another 0.001 in. $(E-2)$, this projection has almost disappeared. It therefore was only about 0.002 in. wide and evidently was root-shaped rather than wedge-shaped. The theoretical stress concentration due to this projection, therefore, is much less than that due to the projection seen in subdivision 1 . 
Although section $B-3$ is not at the center of the rounded pit, it probably is not far from the center of the sharp inward projection. After removal of 0.001 in. $(C-3)$, the projection has become somewhat larger. After removal of another 0.001 in. $(D-3)$, the projection has become very small. Nevertheless, traces of the projection are visible after removal of additional layers $(E-3$ and $F-3)$. This projection evidently is a narrow transverse crevice, less than one-fourth the breadth of the rounded pit.

The cyclic stress during the 96 days' corrosion, therefore, evidently has caused the sharp inward projections from corrosion pits to be wider (and probably deeper) than they would have been after corrosion for the same time without stress. The increased stress concentration due to these crevices probably accounts for part of the slight net damage shown in figure 2 .

The pits seen in surface views $A, D$, and $E$ of figure 27 are larger than pits caused by stressless corrosion for corresponding times (figs. 7 and 8). Transversely merged pits are seen in views $B$ and $D$. After corrosion at $20,000 \mathrm{lb} / \mathrm{in}^{2}{ }^{2}$ for 96 days (view $F$ of fig. 27 ), many groups of the round pits have merged to form large broad pits. This view should be compared with views $B$ and $C$ of figure 8, which show effects of corrosion for about the same time without stress. The round, relatively deep pits within the larger areas are more distinct after corrosion at $20,000 \mathrm{lb} / \mathrm{in}^{2}$ than after corrosion for the same time without stress. This relationship supports previously mentioned evidence that pits tend to spread less and deepen more under stress corrosion than under stressless corrosion.

\section{PITTING WITH FREQUENCIES OF 0.5 CYCLE PER MINUTE AND 5 CYCLES PER HOUR}

Surface views after corrosion at $0.5 \mathrm{c} / \mathrm{min}$ and at $5 \mathrm{c} / \mathrm{hr}$ are shown in figure 30 ; sectional views are shown in figures 31,32 , and 35 .

No fissures are visible in the surface views (fig. 30). Sharp inward projections from rounded pits, however, are visible in some of the sectional views (figs. 31, 32, and 35). As the net damage caused by these pits was rather small (figs. 2 and 3 ), successive layers 0.001 in. thick were removed from one of these specimens in order to determine whether or not the projections are transverse crevices.

The successive sections after removal of these layers are shown in views $B$ to $F$, inclusive, of figure 31 . The four pits shown in view $B$ are shown in views $C, D$, and $E$; only two of these pits remain in view $F$. The inward projection from the rounded pit is less deep in view $C-4$ than in view $B-4$. After removal of an additional $0.001 \mathrm{in.}(D-4)$, this projection has disappeared. No sharp projection appears in views $E-4$ and $F-4$. The width of the projection (within the 0.004-in. layer examined), therefore, is less than 0.002 in. and more than 0.001 in. The thickness, as shown in $B-4$, is only about 0.0003 in. The projection, therefore, is a thin narrow crevice; its width is much less than the diameter of the rounded pit from which it projects. This projection probably was due chiefly to an oxygen concentration gradient. The cyclic stress changed it from a rootlike projection to a thin crevice. Because of the small size of such crevices, the resultant net damage generally is small. 
The influence of corrosion time is illustrated by views $C$ and $D$ of figure 30 . After corrosion at $35,000 \mathrm{lb} / \mathrm{in} .{ }^{2}$ for 19 days (view $C$ ), many of the pits are large and a few have begun to extend transversely. After corrosion (of another steel) at the same stress for 40 days (view $D$ ), the pits are much larger and many have merged transversely. To these effects of the cyclic stress, rather than to the small sharp inward projections from rounded pits (fig. $35 E$ ), may be attributed the resultant net damage (fig. 2). Corrosion at $5 \mathrm{c} / \mathrm{hr}$. at $40,000 \mathrm{lb} / \mathrm{in}^{2}{ }^{2}$ for 146 days (fig. $30 \mathrm{~F}$ ), has caused broad rounded pits, many of which have merged and are surrounded by broad, shallower areas. A sectional view (fig. $32 E$ ) reveals no transverse crevices. The appreciable net damage (not shown in a diagram) probably was due chiefly to the influence of cyclic stress on the relative depth of the corrosion pits (compare fig. $30 F$ with view $D$ of fig. 8 , which shows a specimen corroded for about the same time without stress).

\section{SUMMARY OF RESULTS OF EXAMINATION OF SPECIMENS}

The results of examination of specimens corroded with and without cyclic stress indicate that cyclic stress tends to increase the size of corrosion pits, to cause transverse extension and merging, and to cause increase in relative depth. When the combined influence of stress, cycle frequency, and corrosion time is sufficiently great, transverse fissures appear at the equators of the rounded corrosion pits. When the combined influence of these three variables is somewhat less, transverse crevices are formed. When the combined influence is still less, the rounded pits may merely extend laterally and deepen, without loss of rounded contour. When the combined influence is small, the chief effect may be an increase in the size and relative depth of the rounded pits.

Cyclic stress, while increasing the size of the pits, apparently decreases the tendency of pits to spread and form shallow saucers. Cyclic stress may have great effect on the size of a few pits, while having little apparent effect on the size of most of the pits. The range of both form and size of the corrosion pits on any one specimen may thus be greatly increased.

\section{STRESS-CORROSION PROCESS}

The evidence presented in figures 7 to 35 , inclusive, confirms the conclusions expressed in previous papers [14, 15] that pitting under stress corrosion differs only in degree and form from pitting under stressless corrosion. The process of stress corrosion, therefore, must be interpreted in terms of the general theory of corrosion of metals.

When a metal is submerged in a corrosive aqueous solution, metal ions tend to go into solution in some regions (anodic areas), and a corresponding number of hydrogen ions tend to give up their electric charge and leave the solution at other regions (cathodic areas). The cathodic areas thus tend to become covered with hydrogen. Under ordinary corrosion conditions in neutral or alkaline waters, however, very little hydrogen is evolved from the cathodic areas. Removal of hydrogen as gas is so slow that the corrosive action practically ceases because of polarization, unless the hydrogen is continuously removed by chemical action. It can be so removed by combination with 
oxygen dissolved in the aqueous solution. Continuous progress of ordinary corrosion thus depends on a continuous supply of dissolved oxygen to the cathodic areas.

Continuous corrosion, however, requires also a continuous removal of metal ions from the anodic areas and a continuous supply of negative ions (such as hydroxyl or chloride ions) to the anodic areas. Obstruction to continuous inward and outward flow of these ions by accumulation of corrosion products causes anodic polarization, just as obstruction to continuous flow of dissolved oxygen to cathodic areas causes cathodic polarization. With some metals in some corrosion conditions, polarization tends to be greater at the anode than at the cathode. At the cathode, under these conditions, the concentration of dissolved oxygen is greater than the concentration of hydrogen. The rate of corrosion, then, is controlled by the rate of reaction at the anode, and depends very little on the rate of supply of oxygen to the cathode. With other metals, or even with the same metal under different corrosion conditions, polarization tends to be much greater at the cathode than at the anode. The concentration of dissolved oxygen at the cathode, then, is much less than the concentration of deposited hydrogen, and the rate of corrosion depends chiefly on the rate of supply of dissolved oxygen. The rate of corrosion, therefore, sometimes is controlled by the rate of depolarization of the anodes, and sometimes by the rate of depolarization of the cathodes. Under other conditions, the concentrations of hydrogen and dissolved oxygen at the cathode do not differ greatly. The rate of corrosion, then, is neither anodically nor cathodically controlled.

The rate of corrosion of carbon steels and ordinary alloy steels in natural waters generally depends chiefly on the rate of arrival of dissolved oxygen at the cathodic areas. To reach these areas, oxygen of the air must dissolve at the surface of the water and be transferred (by diffusion or convection) to the coating on the metal. This coating consists of a layer of primary and secondary corrosion products permeated by water solution. When the steel is some distance below the surface of the water, the rate of arrival of oxygen at the cathodic areas, and hence the rate of corrosion, may depend chiefly on the rate of transfer of dissolved oxygen downward through the water. When the surace of water in contact with air is small in relation to the volume of water, the rate of supply of oxygen to the cathode may depend chiefly on the rate of solution of oxygen in the water. The effects shown in figures 1 to 35 , however, were obtained by rotating each specimen in a small stream of water, so that the specimen was surrounded by a thin layer of water previously almost saturated with dissolved oxygen. The initial rate of corrosion under these conditions would depend primarily on the rate of anodic reaction. With accumulation of corrosion products, however, the rate of reaction would depend more and more on the rate of diffusion of oxygen through the cathodic coating.

The previous brief outline of the corrosion process applies primarily to the process of stressless corrosion. The accelerating influence of cyclic stress on corrosion was discussed in previous papers $[13,17]$ briefly as follows: Cyclic stress may accelerate corrosion, not only by increasing the permeability of the film and layer of corrosion products, 
but also by increasing the solution pressure of the metal. ${ }^{7}$ The relative importance of these two factors probably varies with the kind of metal, the intensity of the general corrosion, the properties of the corrosion products, the cycle frequency, and the stress. Under moderate or severe general corrosion, the important factor is the influence of cyclic stress (in the metal) on the permeability of the coating. Under slight general corrosion, and especially under relatively high stress, an important factor may be the influence of stress on the solution pressure of the metal. These views are practically unaltered by the evidence presented in figures 1 to 35 .

The observed effects of cyclic stress on the corrosion pitting of steel in fresh water (figs. 7 to 35 ) are explainable on the assumption that cyclic stress increases the permeability of the film and the layer of corrosion products. When the combined influence of stress and cycle frequency is so small that it manifests itself only after a long corrosion time, the acceleration of corrosion pitting probably is due chiefly to the increase in the permeability of the cathodic coating. Stress concentration at the anodes (corrosion pits), under such conditions, would have little influence on the rate of corrosion pitting. Cyclic stress, therefore, would be expected to increase the size of corrosion pits, but to have little effect on their form. Numerous examples have been given of such an effect of cyclic stress when either stress or frequency is sufficiently low.

With increase of the stress or the cycle frequency above certain values (depending on the corrosion time), however, evidence appears that the rate of corrosion has been influenced by the stress concentration at the corrosion pits. The equatorial enlargement of the pits is evidence that corrosion has been most rapid in regions of highest local stress. The acceleration of corrosion, therefore, has been caused by increase in the permeability of both the cathodic and anodic coatings. The higher the stress and cycle frequency, the more is the rate of corrosion influenced by the resultant increase in the permeability of the anodic coating.

This tendency toward an anodically controlled process, due to cyclic stress, manifests itself not only in the equatorial enlargement of the corrosion pits, but also in a decreased tendency of the pits to spread along the metal surface (with increase in the corrosion time beyond about 10 days). The tendency of pits to spread along the surface is due chiefly to the effect of accumulation of secondary corrosion products on the cathodic area around each corrosion pit. The resultant obstruction to the flow of oxygen to these cathodic areas tends to cause new oxygen-concentration cells, and thus tends to cause new anodic areas in what were originally cathodic areas. Cyclic stress, by increasing the permeability of the cathodic coating, tends to prevent the formation of anodes within originally cathodic areas, and thus decreases or delays the spreading of the corrosion pits. Cyclic stress, consequently, opposes the tendency to a decrease in the ratio of cathodic to anodic areas, and thus opposes the approach to a cathodically controlled process.

For the same reason, decrease in the number of anodes per unit area tends to shift the corrosion process toward an anodically con-

7 This does not necessarily imply that the acceleration is due to the stress itself. The acceleration may be due directly to the plastic strain caused by the stress. 
trolled process. Under cyclic stress, as shown in section VI, a few pits often grow much more rapidly than the surrounding pits. The surrounding small pits may even appear no larger than if cyclic stress had been absent. The increased corrosion at a few large pits tends to increase the surrounding cathodic areas, and may thus bring into these areas some of the smaller pits. This tendency of cyclic stress to decrease the number of active anodes is a manifestation of the tendency to shift the corrosion process toward an anodically controlled process. ${ }^{8}$

The rate of the anodic reaction is a function of both the solution pressure of the metal and the permeability of the anodic coating. When the rate of corrosion is controlled by the anodic reaction, cyclic stress may accelerate corrosion not only by increasing the permeability of the anodic coating, but also by increasing the solution pressure of the metal. Such increase of the solution pressure probably is not due directly to the stress or to the elastic strain, but is due to plastic deformation. In regions of plastic deformation, especially at slip planes, the solution pressure probably is higher than in regions free from plastic deformation. $^{9}$ Evidence tending to substantiate this view has been given by Gough and coworkers [3 to 6] as a result of their investigation of corrosion fatigue of crystals of aluminum. They report that corrosion-fatigue cracks started at slip planes caused by the cyclic stress.

The equatorial enlargement of corrosion pits, due to the influence of cyclic stress on corrosion, has been mentioned as evidence that the corrosion process has been shifted toward an anodically controlled process. As the rate of anodic reaction is a function of both the solution pressure of the metal and the permeability of the anodic coating, consideration must now be given to the relative importance of these two factors in causing the observed equatorial enlargement of corrosion pits. The solution pressure probably is increased only when the stress is high enough to cause plastic deformation, at least locally. The possibility that corrosion will be accelerated because of enhanced solution pressure, therefore, probably is small when the cyclic stress is small, but increases with the stress, and becomes large when the stress (at least in regions of high stress concentration) exceeds the fatigue limit.

The possibility that corrosion will be accelerated because of enhanced solution pressure also increases as the corrosion process is shifted from a cathodically controlled toward an anodically controlled process. The possibility would thus be expected to increase not only with the stress but also with the cycle frequency. The possibility would be greatest for metals and corrosion conditions such that the corrosion process would be anodically controlled even in the absence of cyclic stress. Other factors being equal, therefore, the possibility would be greater for such metals as aluminum and stainless steel than for carbon steels or ordinary alloy steels in natural waters. ${ }^{10}$

The possibility that increased solution pressure plays an important part in stress corrosion of the steels represented in figures 1 to 35 , therefore, need be considered only when the stress is initially high or

\footnotetext{
${ }^{8}$ The shift of the process with corrosion time is not necessarily in the same direction as the shift with increase in stress or cycle frequency.

- Much of the evidence generally given in support of this view, however, is inconclusive. Evans [1] has shown that some of the examples of increased corrosion at plastically deformed regions are due chiefly to breaking of the film during the plastic deformation.

10 Under some corrosion conditions, enhanced solution pressure possibly affects the rate of corrosion of ordinary steels.
} 
has become locally high because of stress concentration. The influence of increase in solution pressure probably is small in comparison with the influence of increased permeability of the coating, unless the stress (at least locally) is not far below the ordinary fatigue limit. Even if the initial stress is far below the fatigue limit, however, the actual local stress (because of increasing stress concentration) may eventually reach or even exceed the fatigue limit. By reference to curves such as those in figures 1 to 4 , it is possible to determine approximately when the stress concentration at corrosion pits has raised the actual stress to the fatigue limit. If the actual fatigue limit of the metal has not been altered even locally by the cyclic stress, the actual stress would reach the fatigue limit when the nominal fatigue limit (represented by ordinates in figs. 1 to 4 ) has fallen to equality with the nominal cyclic stress (in the corrosion stage).

As shown in figures 1 to 4 , the actual stress in some of the experiments eventually exceeded the fatigue limit. The fatigue limit, however, usually was reached long after the appearance of crevices or fissures. Crevices or fissures, therefore, are not evidence of actual fatigue, or that the process has been influenced appreciably by enhancement of solution pressure. Appearance of crevices at actual stresses so far below the fatigue limit suggests that the influence of cyclic stress on the forms of these pits consisted chiefly in increase of the permeability of the anodic coating. Even when the actual stress has risen almost to the fatigue limit, the rate of corrosion (of ordinary steels in fresh water) probably depends much more on the permeability of the cathodic and anodic coatings than on any enhancement of solution pressure.

The evidence presented by Gough and coworkers [3 to 6] that corrosion-fatigue cracks in aluminum crystals started at slip planes is not in conflict with the evidence in figures 1 to 35 . Although the cyclic stress used in their experiments was low, it was high enough to cause numerous slip planes in a metal that corrodes with anodic control even in the absence of cyclic stress. Conclusions drawn from those experiments, therefore, cannot be applied without modification to ordinary steels corroded at stresses so far below the fatigue limit that slip planes must have been few. Even in the results of the experiments with aluminum, moreover, evidence may be found that rounded corrosion pits have been increased in size and altered in form by cyclic stress. Mention is made of "local attack" consisting of several large corrosion pits, for which no cause was assigned. A crack had started at one of the larger round pits. Mention is also made of a tendency to merging of small pits. If fatigue failure had not occurred at cracks starting from slip lines, therefore, it probably would have occurred eventually at cracks starting from rounded pits.

The evidence presented in figures 1 to 35 indicates that the accelerating influence of cyclic stress on corrosion, for steels in aerated natural waters, is due to increase in the permeability of the coating. The effect is primarily on the cathodic coating. The influence of permeability of the anodic coating, however, increases with the stress and cycle frequency.

Acknowledgment is made to H. O. Willier for the careful preparation and photographing of the metal specimens. 


\section{REFERENCES}

[1] U. R. Evans, Metallic Corrosion, Passivity, and Protection (Edward Arnold \& Co., London, 1937).

[2] J. N. Goodier, Concentration of stress around spherical and cylindrical inclusions and flaws, Trans. Am. Soc. Mech. Engrs., APM 55, 7 (1933).

[3] H. J. Gough and D. G. Sopwith, The behavior of a single crystal of alumınum under alternating torsional stresses while immersed in a slow stream of tap water, Proc. Roy. Soc. (London) [A] 135, 392-411 (1932).

[4] H. J. Gough and G. Forrest, The Behavior of a Single Crystal of Aluminum Subjected to Stressless Corrosion in Tap Water, Followed by Test to Destruction in Air Under Alternating Torsional Stresses, Aeron. Research Comm. Reports and Memoirs No. 1476 (1932).

[5] H. J. Gough, Corrosion-fatigue of metals, Eleventh Autumn Lecture, J. Inst. Metals 49, 17-92 (1932).

[6] H. J. Gough and D. G. Sopwith, Corrosion-fatigue characteristics of an aluminum specimen consisting of two crystals, J. Inst. Metals 52, 57-72 (1933).

[7] C. E. Inglis, Stresses in a plate due to the presence of cracks and sharp corners, Trans. Inst. Naval Arch., pt. 1, 55, 219 (1913).

[8] A. Leon, Über die Störungen der Spannungsverteilung die in elastischen Körpern. und Bläsen entstehen, Österr. Wochschr. öffent. Baudienst 14, 163 (1908)'

[9] D. J. McAdam, Jr., Endurance properties of steel: Their relation to othe physical properties and to chemical composition, Proc. Am. Soc. Testing Materials 23, pt. 2, 56 (1923).

[10] D. J. McAdam, Jr., Stress-strain-cycle relationship and corrosion fatigue of metals, Proc. Am. Soc. Testing Materials 26, pt. 2, 224 (1926).

[11] D. J. McAdam, Jr., Corrosion-fatigue of metals as affected by chemical composition, heat treatment and cold worlking, Trans. Am. Soc. Steel Treating 11, 355 (1927).

[12] D. J. McAdam, Jr., Corrosion-fatigue of nonferrous metals, Proc. Am. Soc. Testing Materials $2 \%$, pt. 2, 102 (1927).

[13] D. J. McAdam, Jr., Fatigue and corrosion fatigue of metals, Proc. Int. Cong. Testing Materials 1, 305 (1927).

[14] D. J. McAdam, Jr., Fatigue and corrosion fatigue of spring materials, Trans. Am. Soc. Mech. Engrs., APM 45, 511 (1929).

[15] D. J. McAdam, Jr., Corrosion of metals as affected by time and by cyclic stress, Trans. Am. Inst. Mining Met. Engrs., Inst. Metals Div. 571 (1928).

[16] D. J. McAdam, Jr., Some factors involved in corrosion and corrosion fatigue of metals, Proc. Am. Soc. Testing Materials 28, pt. 2, 117 (1928).

[17] D. J. McAdam, Jr., Corrosion of metals as affected by stress, time, and number of cycles, Trans. Am. Inst. Mining Met. Engrs., Inst. Metals Div. 56 (1929).

[18] D. J. McAdam, Jr., Corrosion of metals under cyclic stress, Proc. Am. Soc. Testing Materials 29, pt. 2, 250 (1929).

[19] D. J. McAdam, Jr., The influence of stress range and cycle frequency on corrosion, Proc. Am. Soc. Testing Materials 30, pt. 2, 411-447 (1930).

[20] D. J. McAdam, Jr., Stress and corrosion, Third International Congress of Applied Mechanics, Stockholm, 2, 269-293 (1930).

[21] D. J. McAdam, Jr., Influence of stress on corrosion, Trans. Am. Inst. Mining Met. Engrs., Inst. Metals Div. 99, 282-318 (1932).

[22] D. J. McAdam, Jr., Stress corrosion of metals, Proc. Zurich Cong., Int. Assn. Testing Materials, 1, 228-246 (1931).

[23] D. J. McAdam, Jr., Influence of water composition on stress corrosion, Proc. Am. Soc. Testing Materials, 31, pt. 2, 259-278 (1931).

[24] D. J. McAdam, Jr., and R. W. Clyne, Influence of chemically and mechanically formed notches on fatigue of metals, J. Research NBS 13, 527-572 (1934).

[25] H. Neuber, Elastischstrenge Lösungen zur Kerbwirkung bei Schreiben-und Umdrehungs Körpern, Z. Math. Mech. 13, 13 (1933).

[26] R. V. Southwell and H. J. Gough, On the Concentration of Stress in the Neighborhood of a Small Spherical Flaw, and on the Propagation of Fatigue Fractures in a Statistically Isotropic Material, Brit. Aeron. Research Comm. Reports and Memoirs, No. 1003 (Jan. 1926).

[27] F. N. Speller, Corrosion: Causes and Prevention (McGraw-Hill Book Co., Inc., New York, N. Y., 1926).

[28] W. N. Thomas, The Effect of Scratches and of Various Workshop Finishes Upon the Fatigue Strength of Steel, Brit. Aeron. Research Comm. Reports and Memoirs, No. 860 (March 1923). 
TABLE 1.-Chemical composition

\begin{tabular}{|c|c|c|c|c|c|c|}
\hline Material & $\begin{array}{c}\text { Designa- } \\
\text { tion }\end{array}$ & C & Mn & $\mathrm{Si}$ & $\mathrm{Cr}$ & $\mathrm{Ni}$ \\
\hline Carbc & \multirow{3}{*}{$\begin{array}{c}\text { JR } \\
\text { a LQ } \\
\text { IW } \\
\text { BC } \\
\text { AX }\end{array}$} & $\begin{array}{l}\% \\
0.46\end{array}$ & $\begin{array}{l}\% \\
0.65\end{array}$ & $\begin{array}{l}\% \\
0.016\end{array}$ & $\%$ & $\%$ \\
\hline $\begin{array}{l}\text { Nickel steel.... } \\
\text { Do }\end{array}$ & & .28 & .5 & .19 & 0.26 & \\
\hline $\begin{array}{l}\text { Chromium-nickel steel } \\
\text { Do }\end{array}$ & & $\begin{array}{l}.28 \\
.36\end{array}$ & $\begin{array}{l}.69 \\
.48\end{array}$ & .21 & $\begin{array}{r}.73 \\
1.55\end{array}$ & $\begin{array}{l}\text { 1. } 51 \\
\text { 3. } 26\end{array}$ \\
\hline
\end{tabular}

a About the same in composition as IW.

TABLE 2.-Thermal treatment

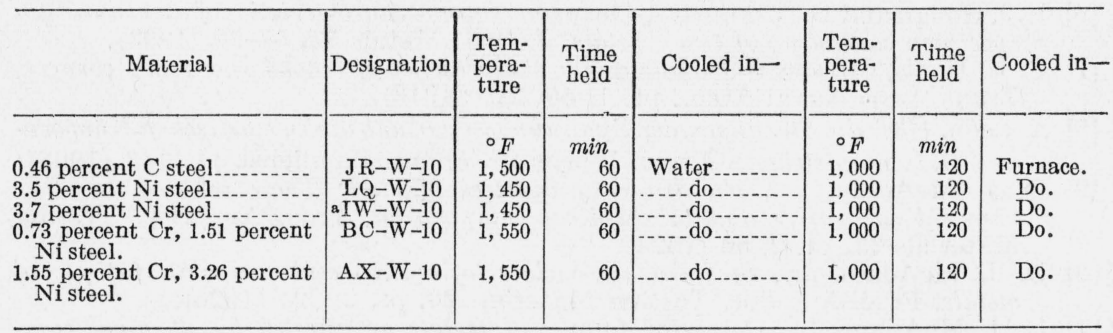

a Previously heated to $1,675^{\circ} \mathrm{F}$ for $60 \mathrm{~min}$, cooled in air.

\section{TABLE 3.-Tensile properties}

[Usually these values are the average for at least 4 determinations.

"Johnson's limit" is the stress at that point on the stress-strain diagram at which the tangent is $3 / 3$ that at the origin. "Proof stress" is the stress that, after release of load, will cause permanent extension of 0.01 percent. "Elastic limit" is the highest stress that, after release of load, will cause no appreciable permanent extension. "Proportional limit" is the highest stress that will not cause appreciable departure from a linear stress-strain relationship. (The smallest divisions of the extensometer scale were 0.0001 in. but estimate could be made to 0.00002 in. The extensometer was of a type that permitted accurate determination of permanent extension).]

\begin{tabular}{|c|c|c|c|c|c|c|c|c|}
\hline Material & Designation & $\begin{array}{l}\text { Tensile } \\
\text { strength }\end{array}$ & $\begin{array}{l}\text { John- } \\
\text { son's } \\
\text { limit }\end{array}$ & $\begin{array}{l}\text { Proof } \\
\text { stress }\end{array}$ & $\begin{array}{c}\text { Elastic } \\
\text { limit }\end{array}$ & $\begin{array}{c}\text { Propor- } \\
\text { tional } \\
\text { limit }\end{array}$ & $\begin{array}{l}\text { Elon- } \\
\text { gation }\end{array}$ & $\begin{array}{l}\text { Reduc- } \\
\text { tion of } \\
\text { area }\end{array}$ \\
\hline $\begin{array}{l}0.46 \% \mathrm{C} \text { steel } \\
3.5 \% \mathrm{Ni} \text { steel } \\
3.7 \% \mathrm{Ni} \text { steel } \\
0.73 \% \mathrm{Cr}, 1.51 \% \mathrm{Ni} \text { steel } \\
1.55 \% \mathrm{Cr}, 3.26 \% \mathrm{Ni} \text { steel }\end{array}$ & $\begin{array}{l}\text { JR-W-10 } \\
\text { LQ-W-10 } \\
\text { IW-W-10 } \\
\text { BC-W-10 } \\
\text { AX-W-10 }\end{array}$ & $\begin{array}{l}\text { Lb. } \text { in. }^{2} \\
129,800 \\
133,700 \\
128,100 \\
135,900 \\
157,700\end{array}$ & $\begin{array}{l}\text { Lb./in.2 } \\
100,000 \\
121,300 \\
114,000 \\
119,100 \\
141,000\end{array}$ & $\begin{array}{l}\text { Lb./in.2 } \\
101,400 \\
123,300 \\
114,600 \\
121,700 \\
142,000\end{array}$ & $\begin{array}{r}\text { Lb./in.2 } \\
99,500 \\
121,300 \\
110,000 \\
119,100 \\
139,000\end{array}$ & $\begin{array}{r}\text { Lb./in.2 } \\
92,300 \\
106,400 \\
94,300 \\
111,500 \\
115,000\end{array}$ & $\begin{array}{l}\% \\
\text { in } 2 \text { in. } \\
17.5 \\
21.0 \\
20.6 \\
20.0 \\
17.5\end{array}$ & $\begin{array}{l}\% \\
51.9 \\
63.8 \\
61.8 \\
62.2 \\
50.7\end{array}$ \\
\hline
\end{tabular}

TABLE 4.-Composition of well water, parts per million

[pH values ranged from 7.0 to 7.2 ]

\begin{tabular}{|c|c|c|c|c|c|c|c|c|c|}
\hline Date & Solids & $\begin{array}{l}\text { Organic } \\
\text { and } \\
\text { volatile } \\
\text { matter } \\
(\mathrm{O}+\mathrm{V})\end{array}$ & Alka- & $\mathrm{Cl}$ & $\mathrm{SO}_{3}$ & $\mathrm{CaO}$ & $\mathrm{MgO}$ & $\begin{array}{c}\mathrm{Al}_{2} \mathrm{O}_{3} \text { and } \\
\mathrm{Fe}_{2} \mathrm{O}_{3}\end{array}$ & $\mathrm{SiO}_{2}$ \\
\hline $\begin{array}{l}\text { April 12, 1928 } \\
\text { April 20, 1928 } \\
\text { May 22, 1928 } \\
\text { September 5, 1929 }\end{array}$ & $\begin{array}{l}579.4 \\
614.0 \\
556.2 \\
410.5\end{array}$ & $\begin{array}{r}158.4 \\
108.3 \\
98.4 \\
142.7\end{array}$ & $\begin{array}{r}111.6 \\
97.4 \\
104.9 \\
98.0\end{array}$ & $\begin{array}{l}244.5 \\
240.8 \\
209.0 \\
117.0\end{array}$ & $\begin{array}{c}9.14 \\
10.7 \\
48.1 \\
4.3\end{array}$ & $\begin{array}{r}151.1 \\
70.3 \\
148.3 \\
51.8\end{array}$ & $\begin{array}{l}25.5 \\
67.8 \\
18.6 \\
19.3\end{array}$ & 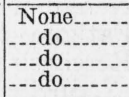 & $\begin{array}{r}15.4 \\
9.8 \\
9.6 \\
3.9\end{array}$ \\
\hline
\end{tabular}

Alkalinity is expressed in terms of $\mathrm{CaCO}_{2}$. 

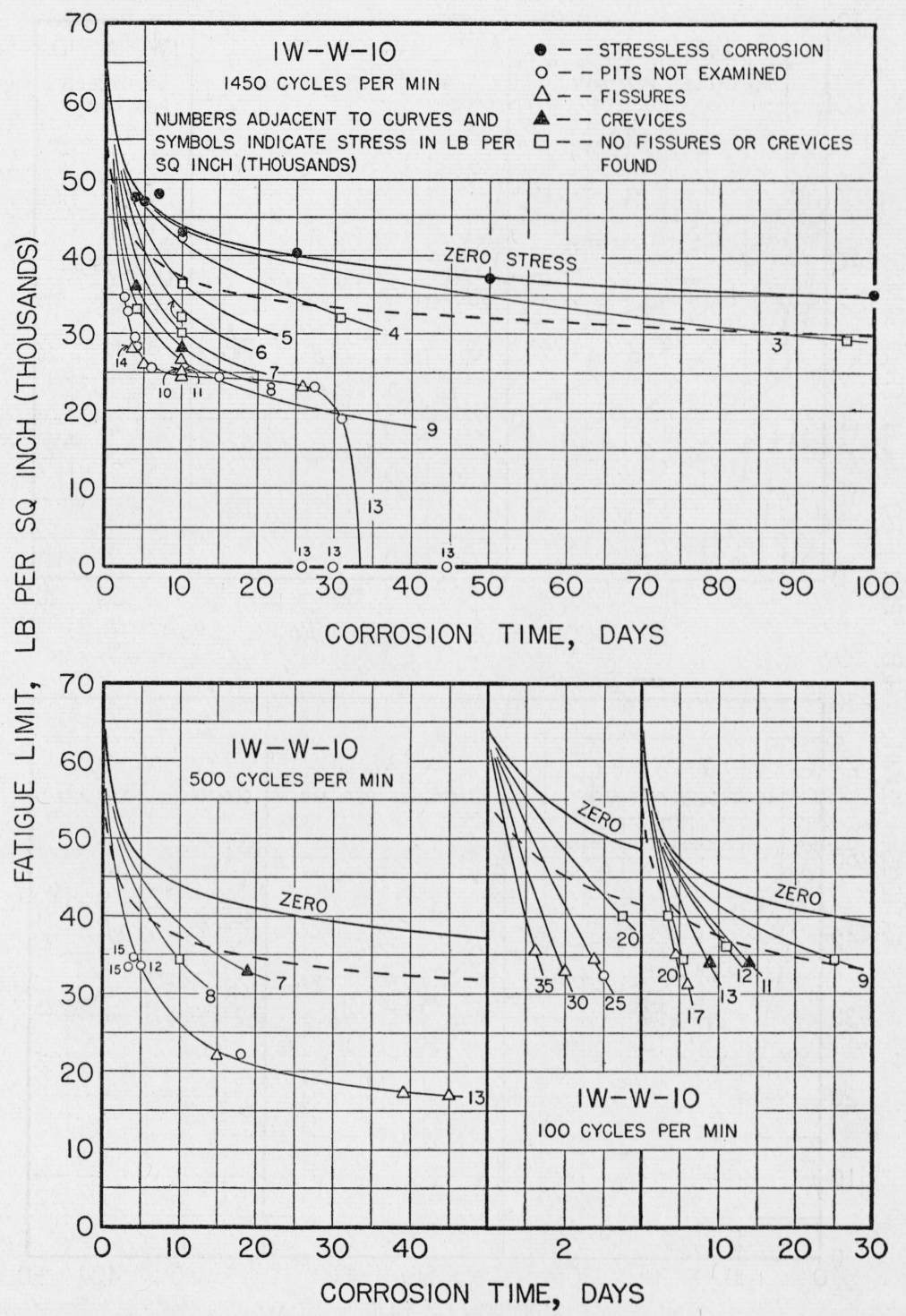

FIGURE 1.-Influence of corrosion time, at various stresses and cycle frequencies, on the fatigue limit of a nickel steel. 


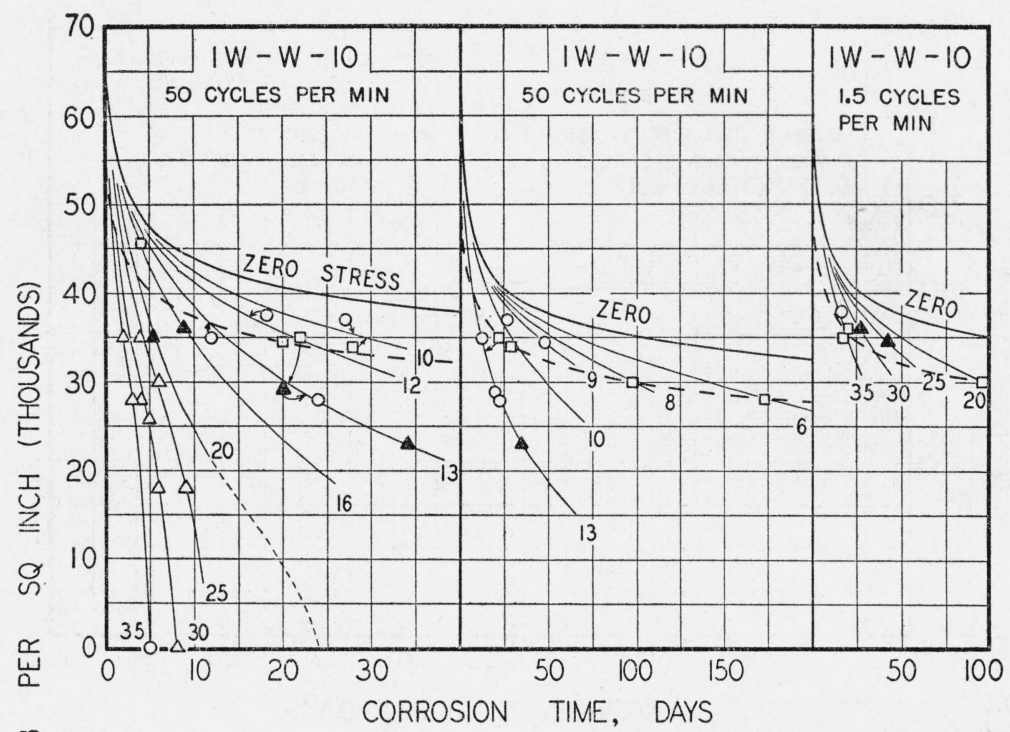

$m$

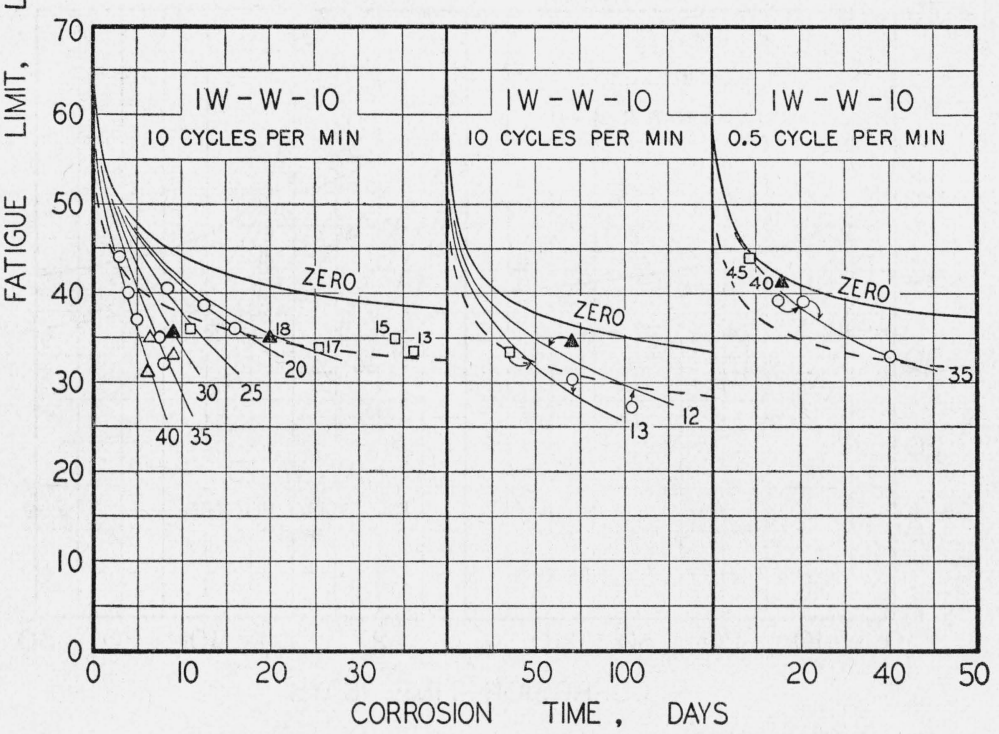

FIGURe 2.-Influence of corrosion time, at various stresses and cycle frequencies, on the fatigue limit of a nickel steel. 

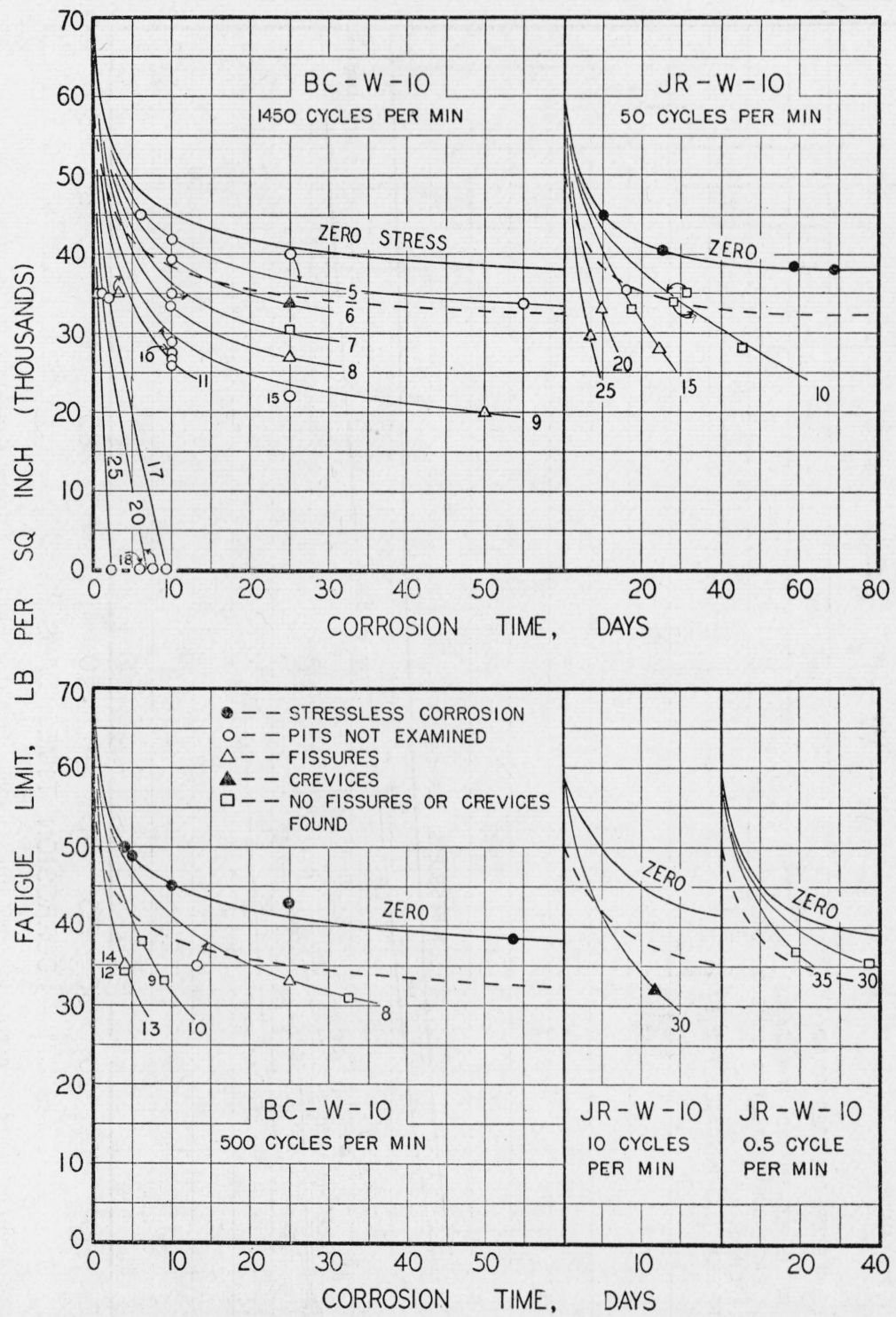

FIGURE 3.-Influence of corrosion time, at various stresses and cycle frequencies, on the fatigue limit of a carbon steel and a chromium-nickel steel. 


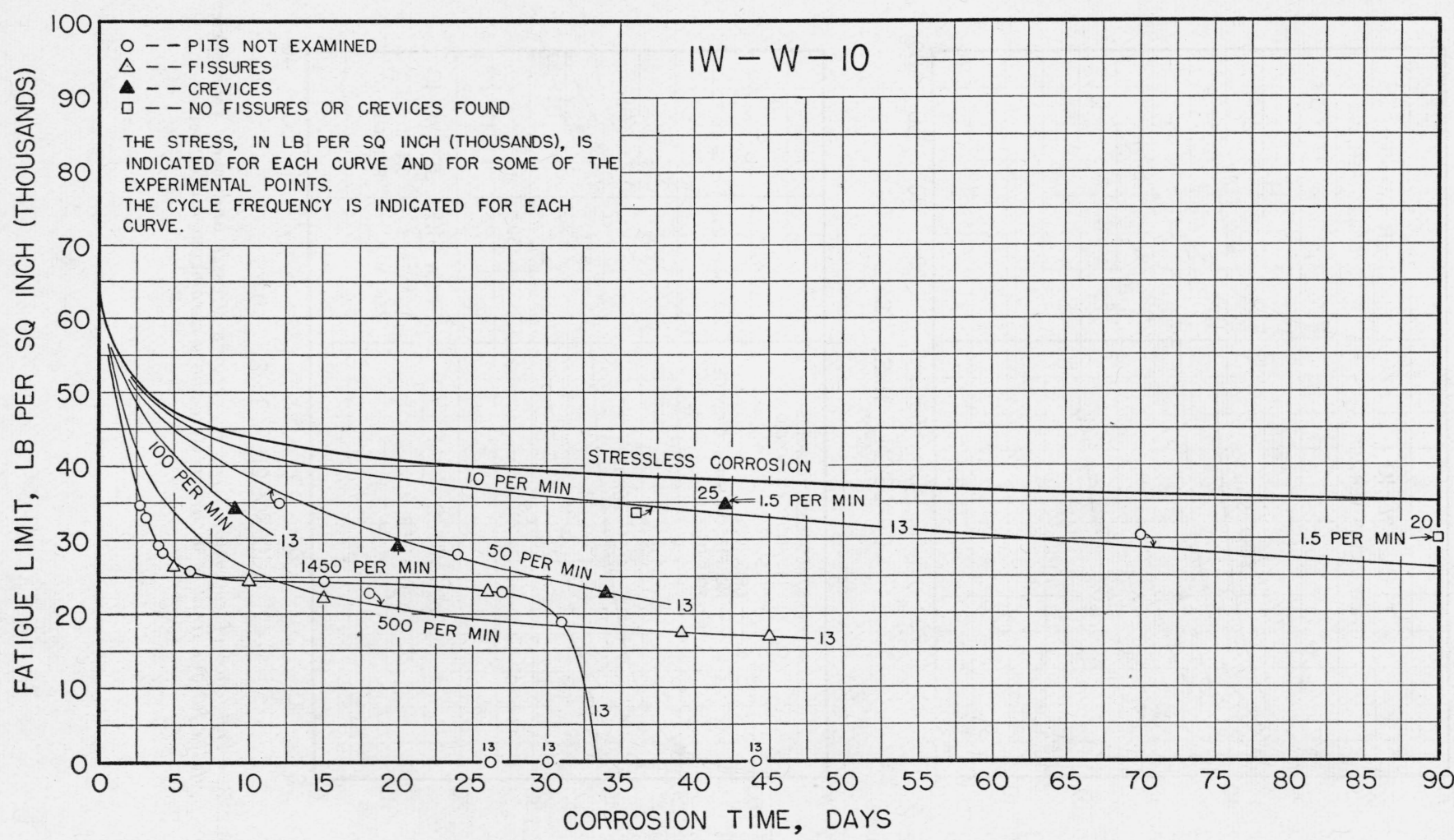

FIGURE 4.-Influence of corrosion time and of cycle frequency on the fatigue limit of a nickel steel. 


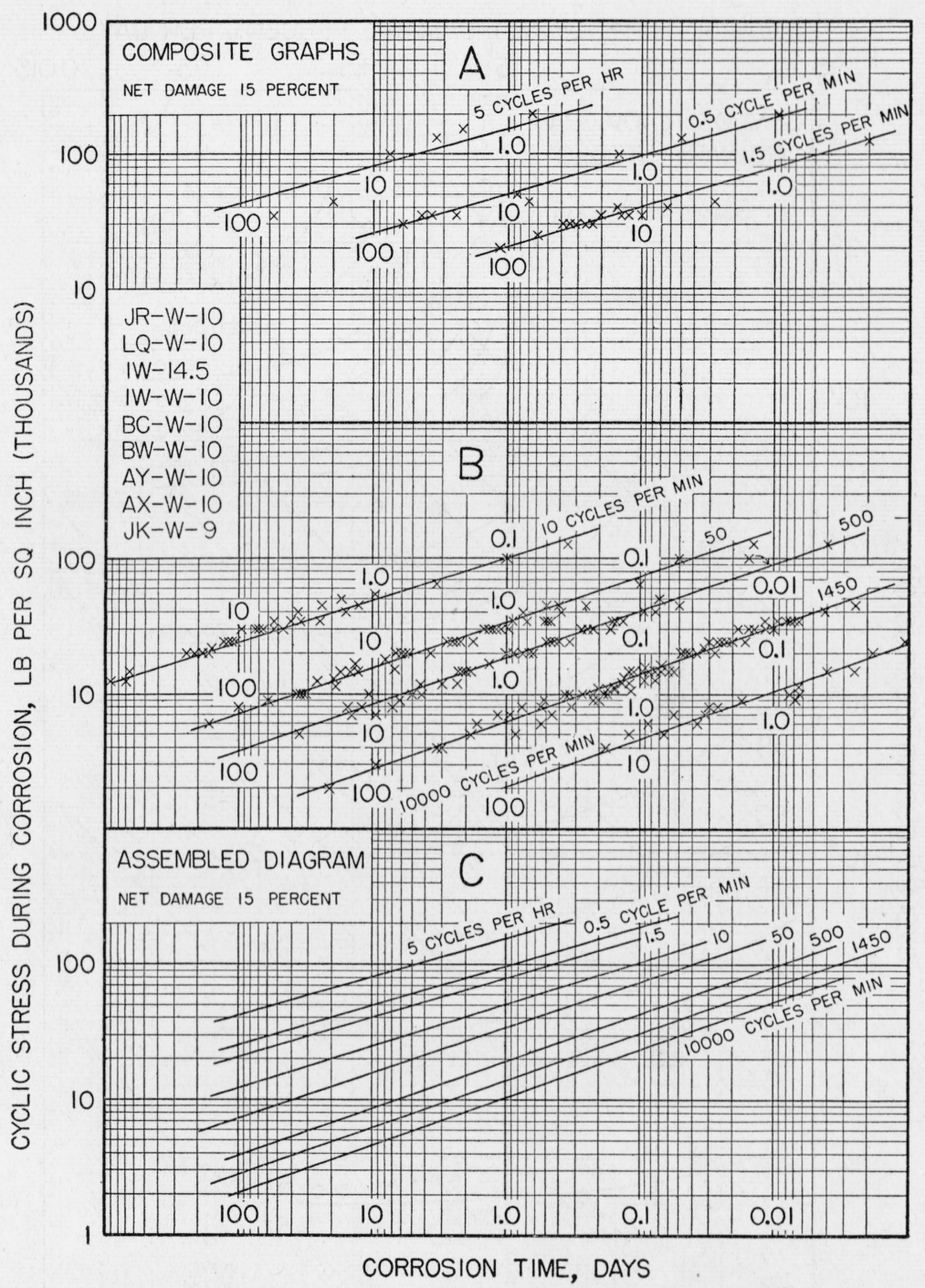

FIGURE 5.-Composite diagram representing the influence of cyclic stress and cycle frequency on corrosion time, for constant net damage.

JR-W-10 $0.46 \% \mathrm{C}$.

LQ-W-10 $3.5 \% \mathrm{Ni}$

IW-14.5 $3.7 \%$ N

IW-W-10 $3.7 \% \mathrm{Ni}$

BC-W-10 $0.73 \%$ Cr., $1.5 \%$ Ni.
BW-W-10 $0.92 \% \quad \mathrm{Cr}, 1.83 \% \mathrm{Ni}$.

AY-W-10 $\quad 0.95 \% \quad$ Cr, $2.16 \%$ Ni.

AX-W-10 $1.55 \% \quad \mathrm{Cr}, 3.26 \% \mathrm{Ni}$

JK-W-10 $0.82 \%$ Cu. 
AVERAGE RATE OF NET DAMAGE, PERCENT PER DAY

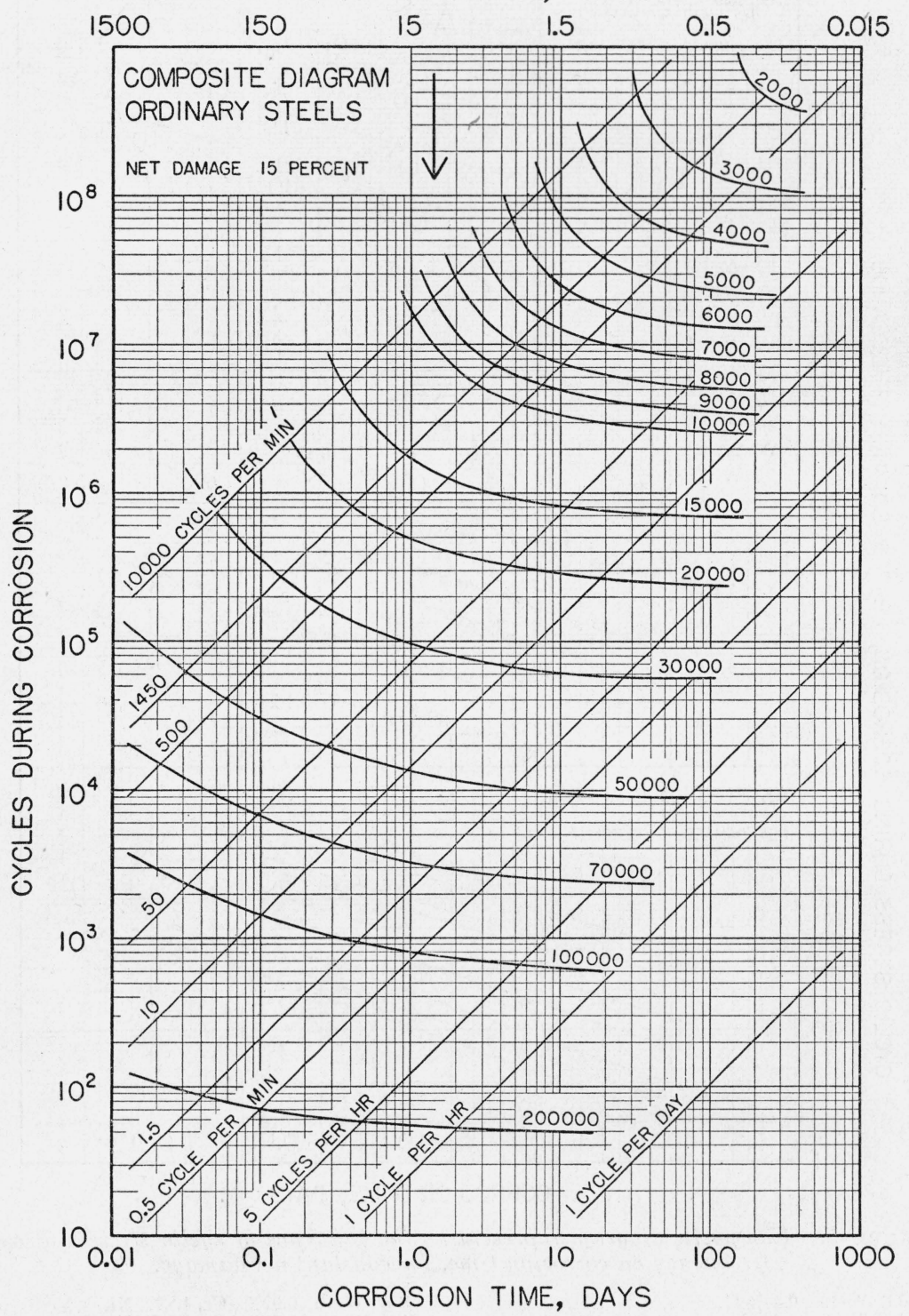

FIGURE 6.-Composite diagram representing the influence of number of cycles and of cycle frequency on corrosion time, for constant net damage.

Washington, March 1, 1940. 


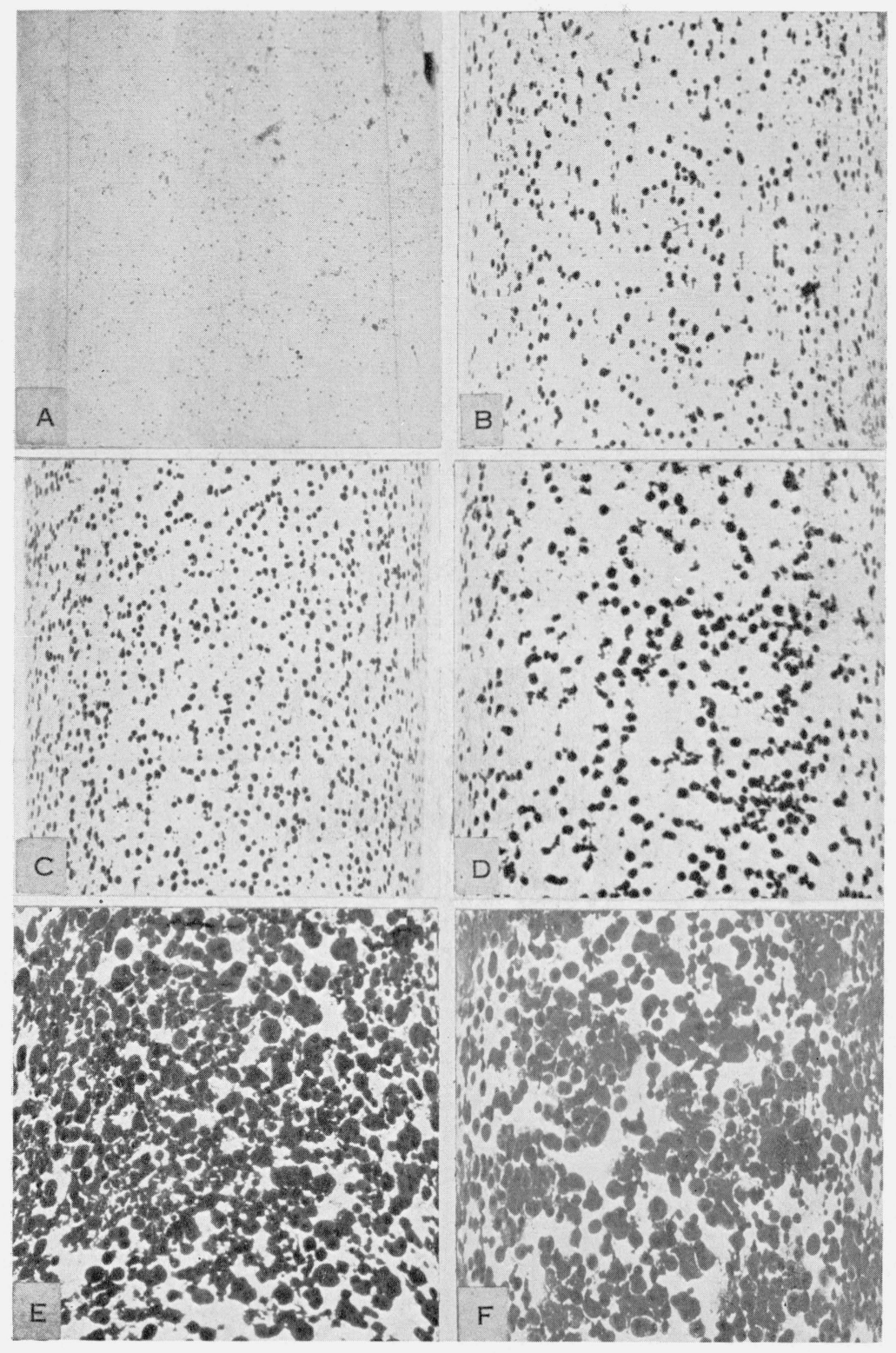

FIGURE 7.-Stressless corrosion; outer surfaces; $\times 4$.

A, 2 days, $\mathrm{AX}-\mathrm{W}-10$.

$B, 4.7$ days, IW-W-10.

$C, 5.8$ days, $\mathrm{IW}-\mathrm{W}-10$

$D, 10$ days, JR-W-10.

$E$, 50 days, $\mathrm{IW}-\mathrm{W}-10$.

$F$, 59 days, JR-W-10. 

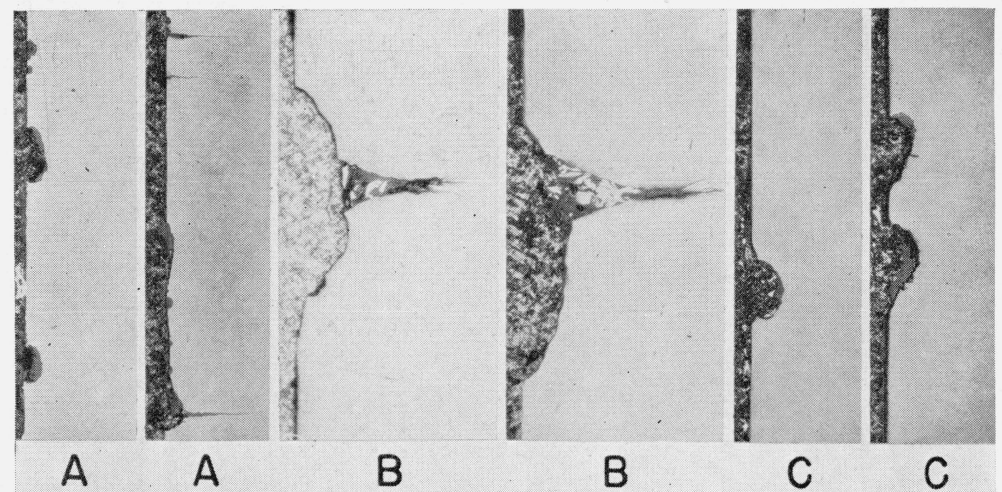

A
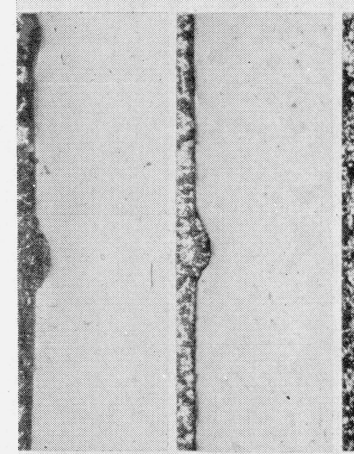

B

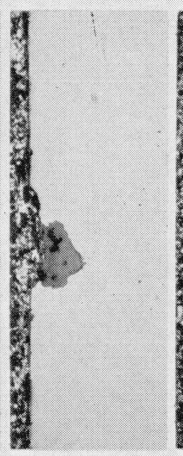

B

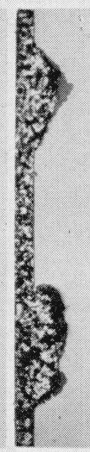

C

C

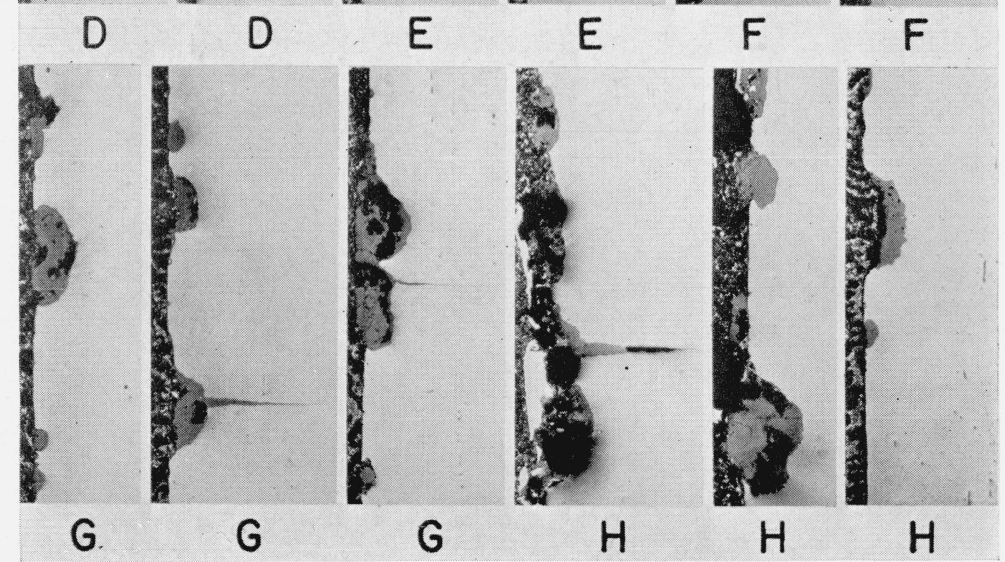

Figure 16. - 500 c/min; longitudinal sections; $\times 50$.

A, 14,000 lb/in. ${ }^{2}, 4$ days, BC-W-10.

$B, 13,000 \mathrm{lb} / \mathrm{in} .^{2} 15$ days, $\mathrm{IW}-\mathrm{W}-10$.

$C, 12,000 \mathrm{lb} / \mathrm{in}^{2}, 4$ days, $\mathrm{BC}-\mathrm{W}-10$

$D, 10,000 \mathrm{lb} / \mathrm{in}^{2}, 6$ days, $\mathrm{BC}-\mathrm{W}-10$.

E, $9,000 \mathrm{lb} /$ in. $^{2}, 9$ days, $\mathrm{BC}-\mathrm{W}-10$.

$F, 8,000 \mathrm{lb} /$ in $^{2}, 10$ days, $\mathrm{IW}-\mathrm{W}-10$.

$G, 8,000 \mathrm{lb} / \mathrm{in}^{2}, 25$ days, $\mathrm{BC}-\mathrm{W}-10$.

$H, 7,000 \mathrm{lb} /$ in $^{2}$, 19 days, IW-W-10. 


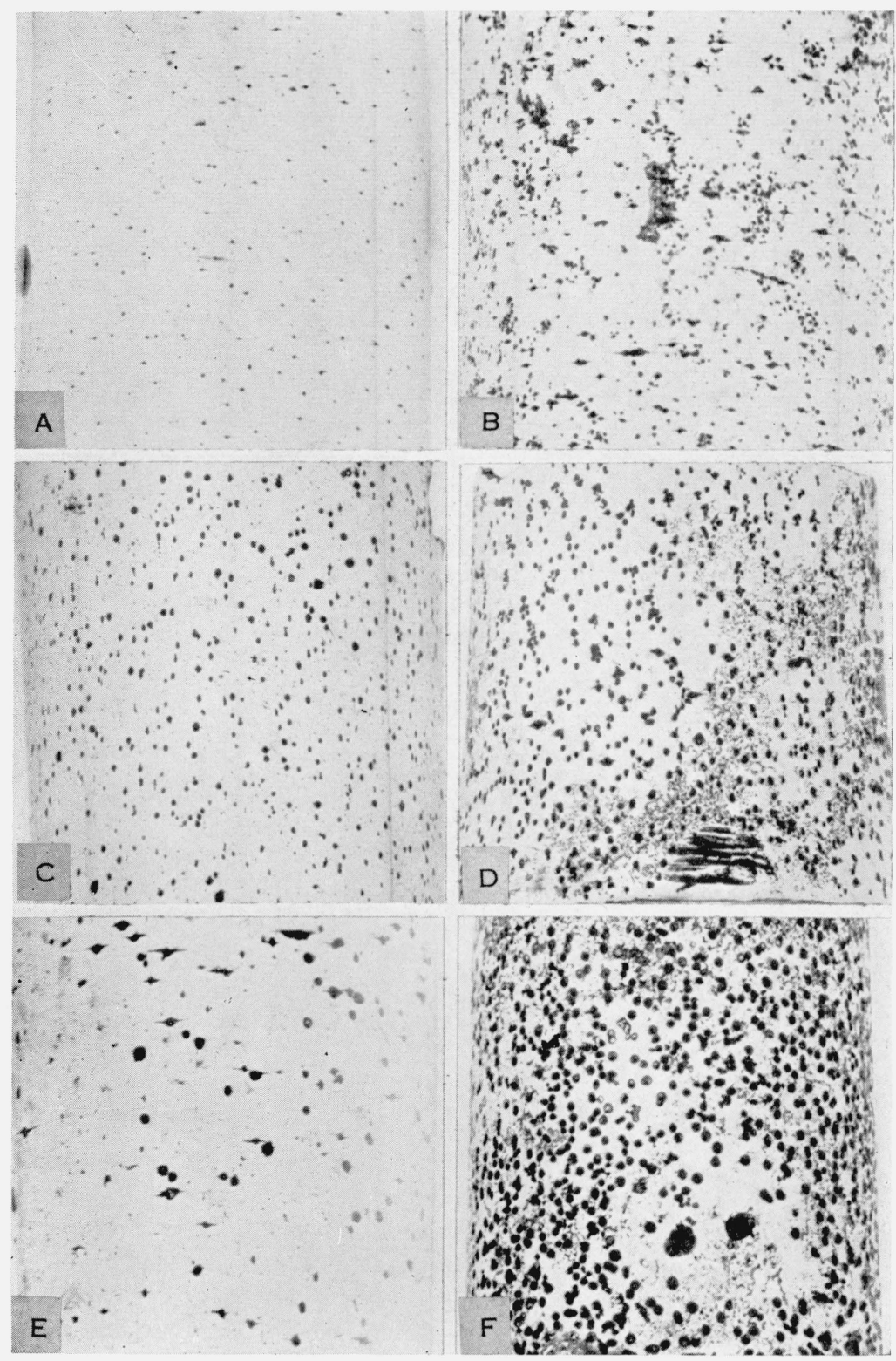

FiguRe 17.-100 c/min; outer surfaces; $\times 4$.

$A, 35,000 \mathrm{lb} / \mathrm{in}^{2}, 1.2$ days, $\mathrm{IW}-\mathrm{W}-10$

$B, 30,000 \mathrm{lb} /$ in $^{2}, 2$ days, IW-W-10.

C, $20,000 \mathrm{lb} / \mathrm{in} .{ }^{2}, 3.5$ days, IW-W-10

$D, 20,000 \mathrm{lb} / \mathrm{in}^{2}, 4.5$ days, IW-W-10.

$E, 17,000 \mathrm{lb} / \mathrm{in}^{2}, 6$ days, $\mathrm{IW}-\mathrm{W}-10$.

$F, 13,000 \mathrm{lb} /$ in. $^{2}, 9$ days, IW-W-10. 


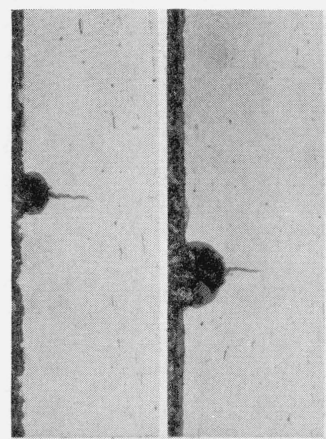

A

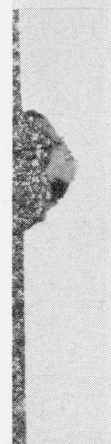

D

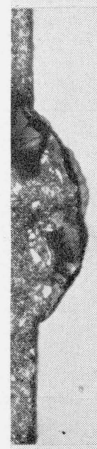

H
A

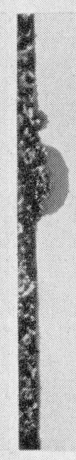

E

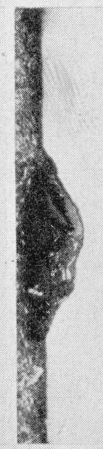

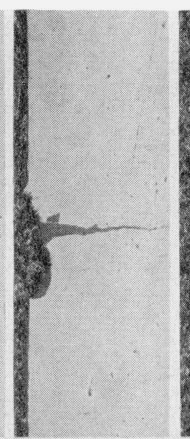

B
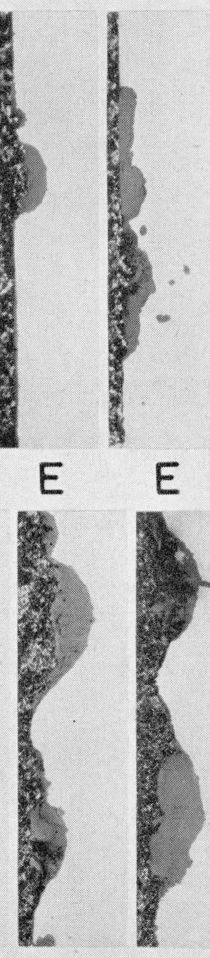

E

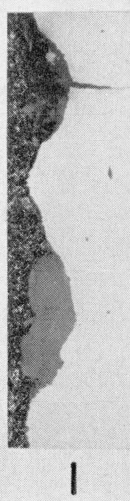

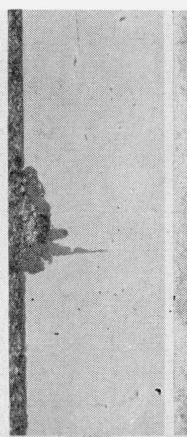

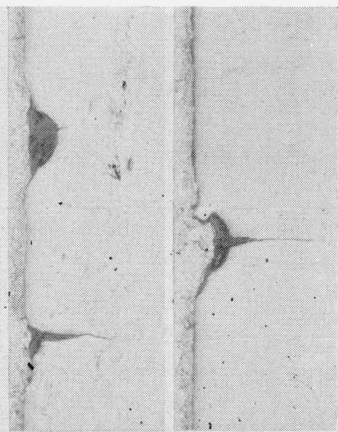

B
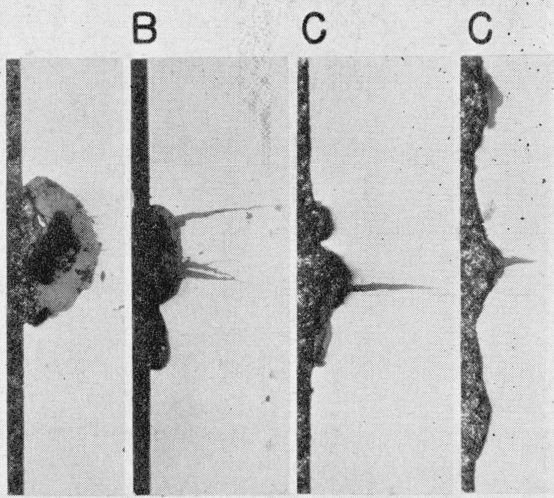

F

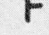

F

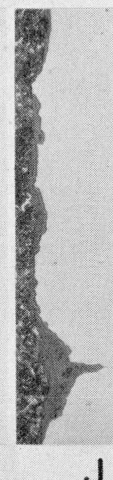

G

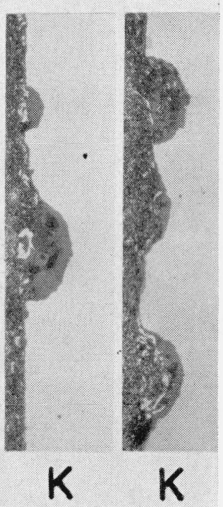

Figure 18. - $100 \mathrm{c} / \mathrm{min}$; longitudinal sections; $\times 50$.

$A, 35,000 \mathrm{lb} /$ in. ${ }^{2}, 1.2$ days, IW-W-10. $B, 30,000 \mathrm{lb} /$ in. $^{2}, 2$ days, $\mathrm{IW}-\mathrm{W}-10$.

$C, 25,000 \mathrm{lb} /$ in. $^{2}, 2.8$ days, $\mathrm{IW}-\mathrm{W}-10$. $D, 20,000 \mathrm{lb} / \mathrm{in}^{2}, 3.5$ days, $\mathrm{IW}-\mathrm{W}-10$. $E, 17,000 \mathrm{lb} / \mathrm{in}^{2}, 5.5$ days, IW-W-10. $F, 17,000 \mathrm{lb} /$ in. $^{2}, 6$ days, IW-W-10.

$G, 13,000 \mathrm{lb} / \mathrm{in.}^{2}, 9$ days, IW-W-10. $H, 12,000 \mathrm{lb} / \mathrm{in}^{2}{ }^{2}, 11$ days, IW $-\mathrm{W}-10$. $I$, $11,000 \mathrm{lb} / \mathrm{in}^{2}, 14$ days, $\mathrm{IW}-\mathrm{W}-10$. $J, 10,000 \mathrm{lb} / \mathrm{in}^{2}{ }^{2}, 29$ days, JR-W -10. $K, 9,000 \mathrm{lb} / \mathrm{in}^{2}, 25$ days, IW-W-10. 


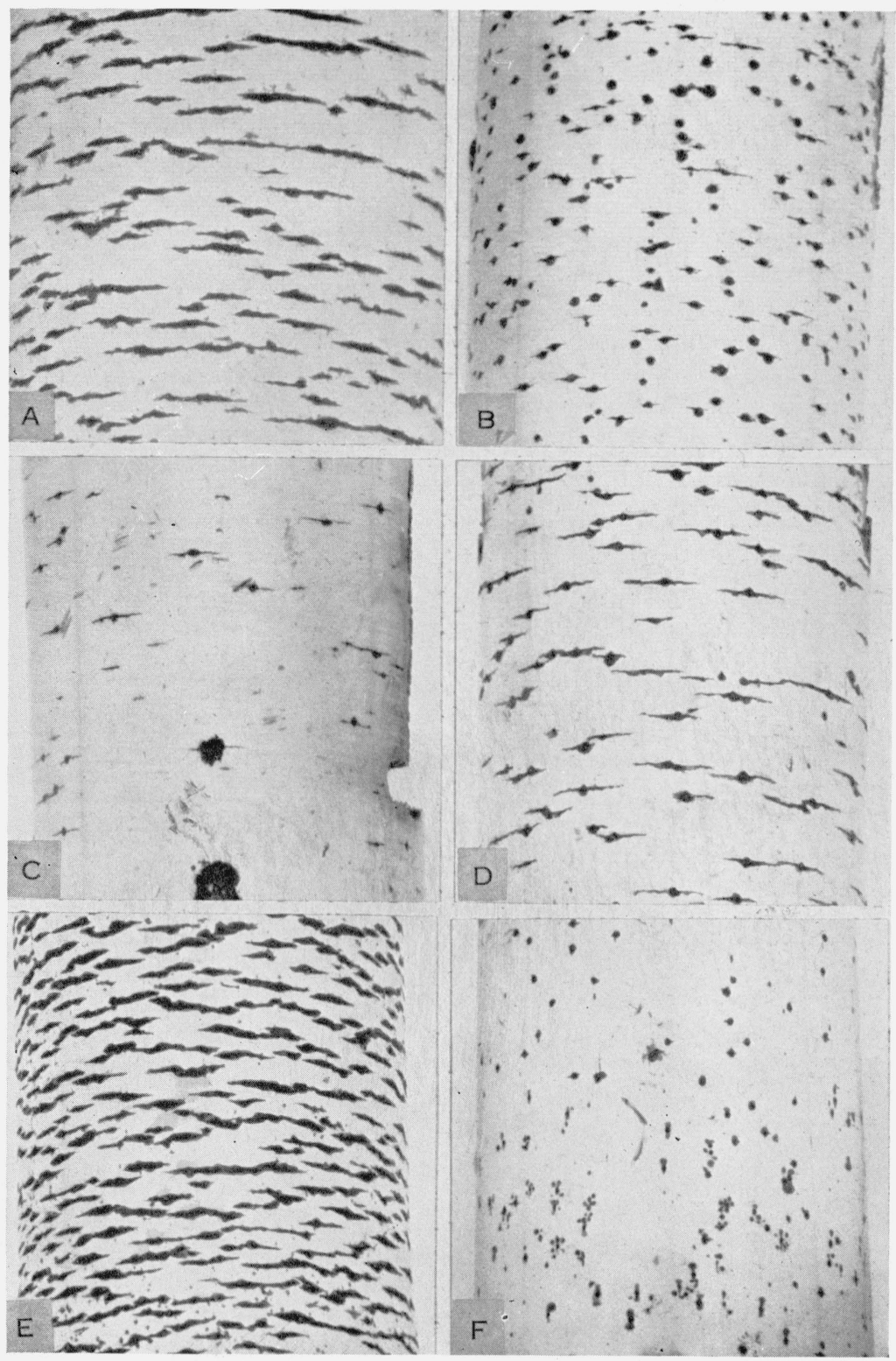

Figure 19. -50 c/min; outer surfaces; $\times 4$.

$A, 68,000 \mathrm{lb} / \mathrm{in}^{2}, 1.1$ days, IW-W-10.

$B, 35,000 \mathrm{lb} / \mathrm{in} .^{2}, 3$ days, $1 \mathrm{~W}-\mathrm{W}-10$.

C, 30,000 lb/in. 2,5 days, I W-W-10

D, $30,000 \mathrm{lb} / \mathrm{in}^{2}, 6$ days, IW-W-10.

$E, 30,000 \mathrm{lb} / \mathrm{in}^{2}, 8$ days, $\mathrm{IW}-\mathrm{W}-10$

$F, 25,000 \mathrm{lb} /$ in. $^{2}, 4$ days, IW-W-10 


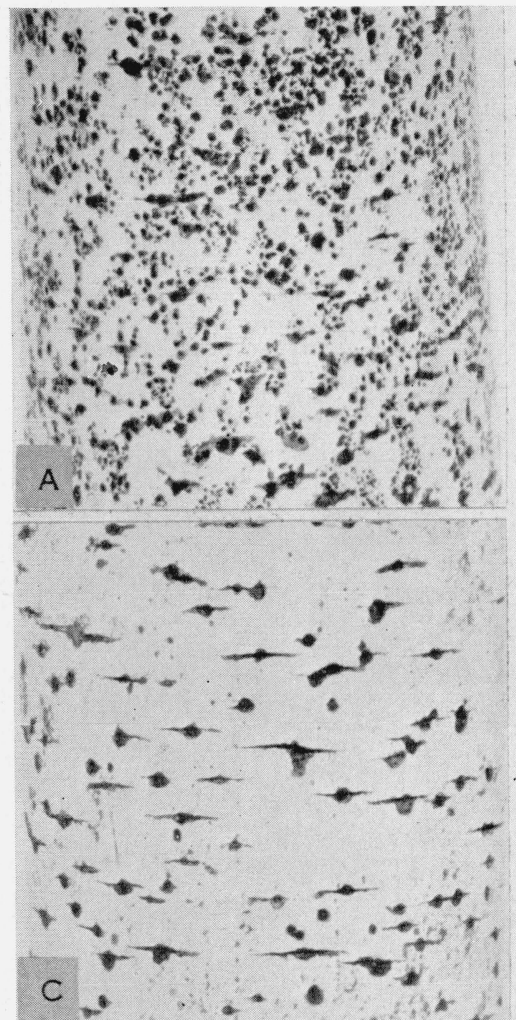

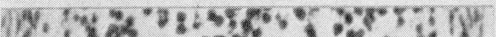

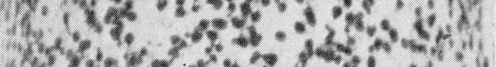

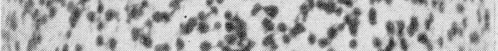

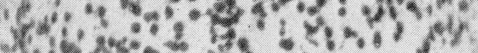
\{.

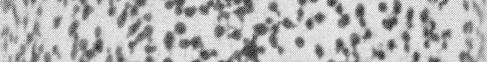

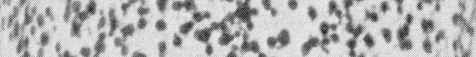

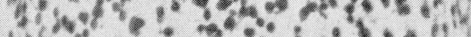

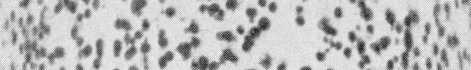

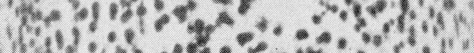

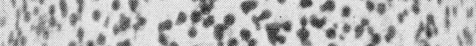

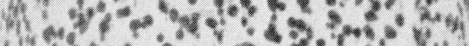
ly

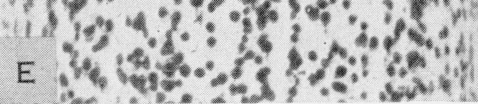

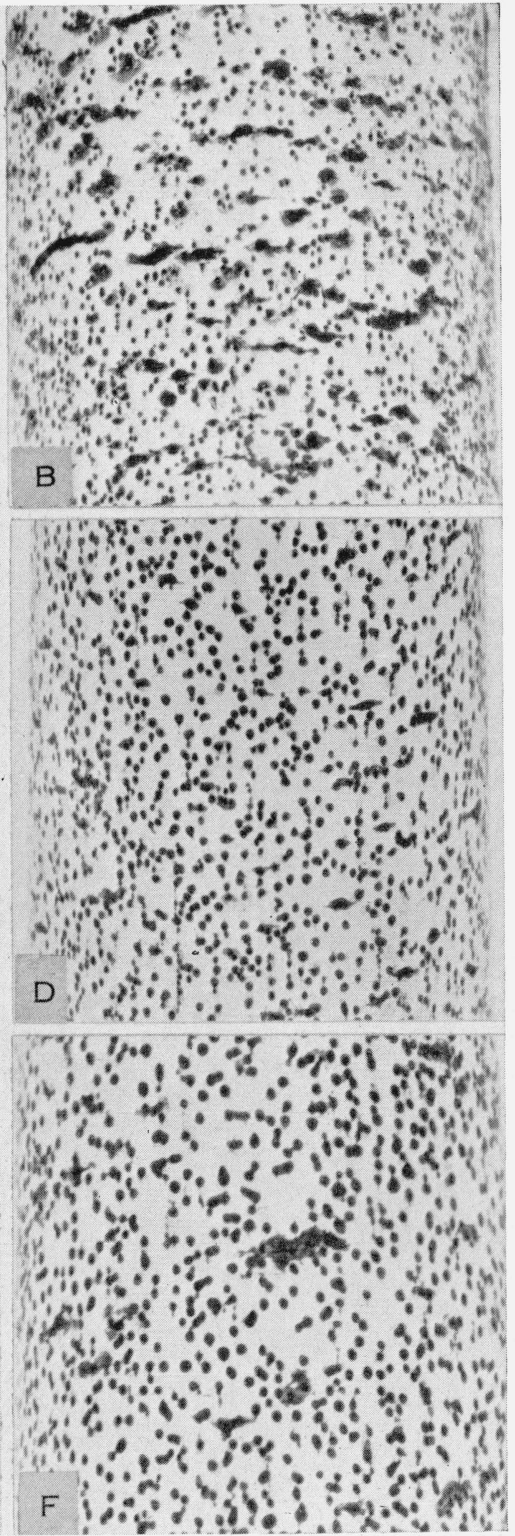

Figure 20. $-50 \mathrm{c} / \mathrm{min} ;$ outer surfaces; $\times 4$.

$A, 25,000 \mathrm{lb} / \mathrm{in}^{2}{ }^{2}, 6$ days, $\mathrm{IW}-\mathrm{W}-10$.

$B, 25,000 \mathrm{lb} / \mathrm{in}^{2}, 7$ days, $\mathrm{JR}-\mathrm{W}-10$.

$C, 25,000 \mathrm{lb} / \mathrm{in} .^{2}, 9$ days, IW-W-10

$D, 20,000 \mathrm{lb} / \mathrm{in}^{2}, 10$ days, J R-W -10 .

$E, 15,000 \mathrm{lb} / \mathrm{in}^{2}, 17$ days, J R-W-10.

$F, 15,000$ lb/in.2, 24.5 days, J R-W-10. 


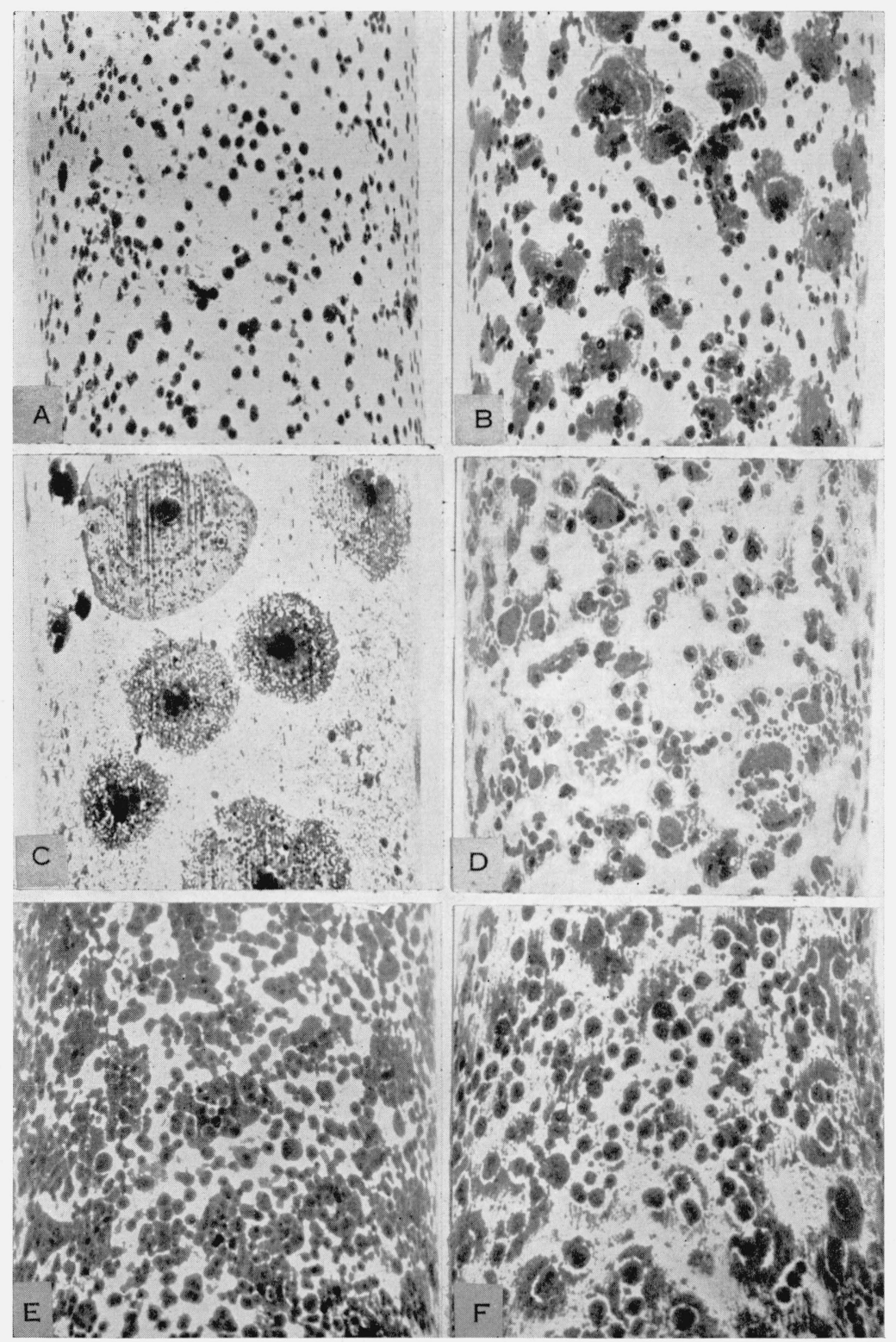

Figure 21.-50 c/min; outer surfaces; $\times 4$.

$A, 13,000 \mathrm{lb} / \mathrm{in} .^{2}, 20$ days, IW-W-10.
$B, 13,000 \mathrm{lb} / \mathrm{in} .^{2}, 34$ days, IW-W-10.
$C, 10,000 \mathrm{lb} / \mathrm{in} .^{2}, 27$ days, IW-W-10.
$D, 10,000 \mathrm{lb} / \mathrm{in} .^{2}, 28$ days, IW-W-10.
$E, 8,000 \mathrm{lb} / \mathrm{in} .^{2}, 95$ days, IW-W-10.
$F, 6,000 \mathrm{lb} / \mathrm{in}^{2}, 173$ days, IW-W-10.



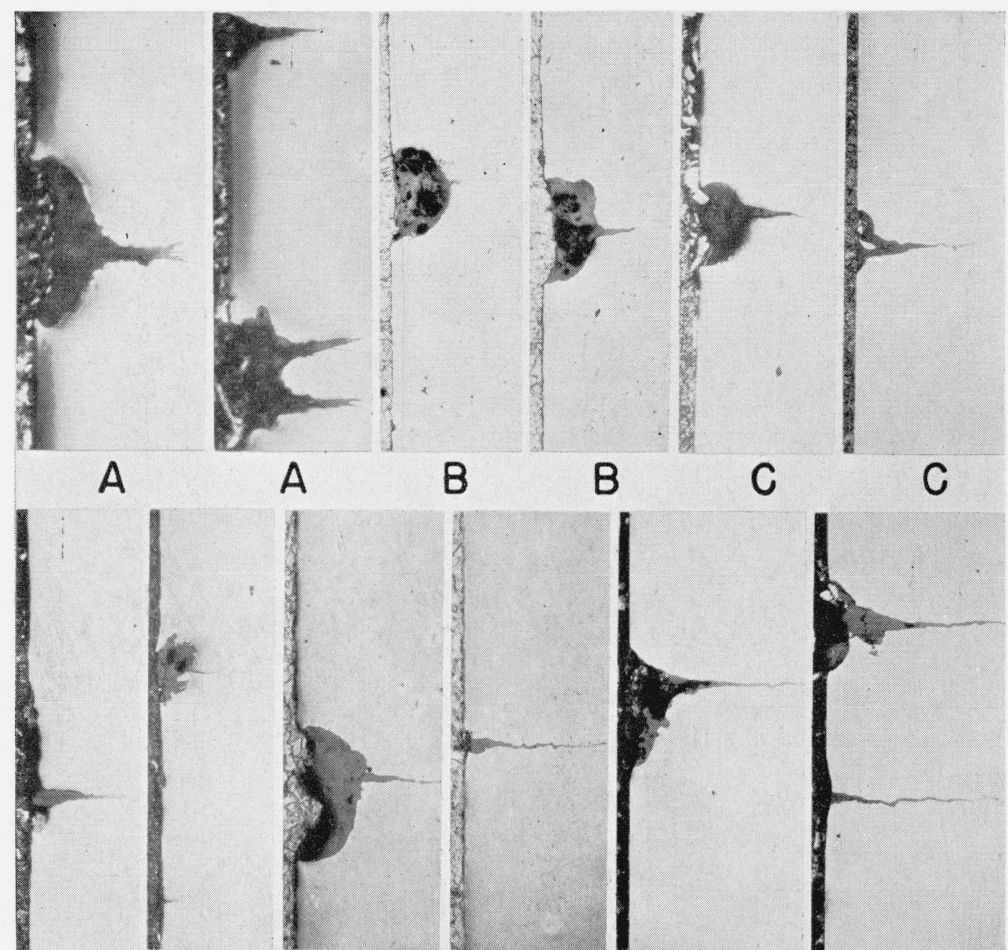

A

B

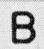

C

C

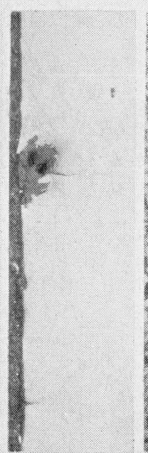

D

D
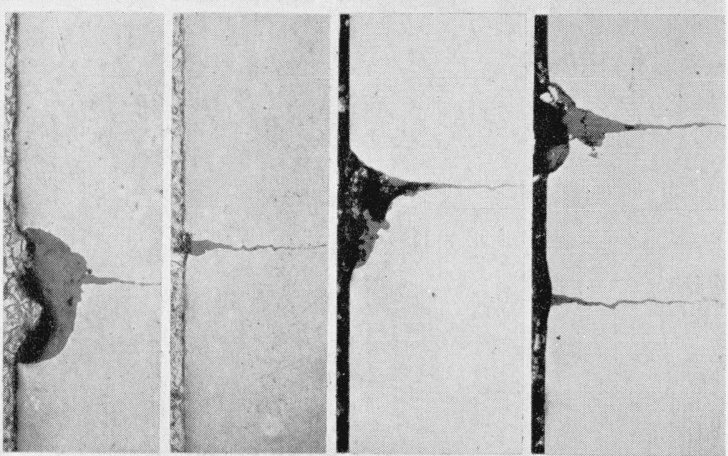

E

E

$\mathbf{F}$

$\mathbf{F}$

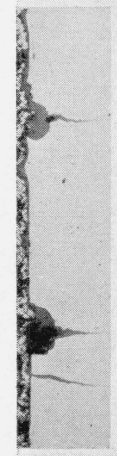

G G
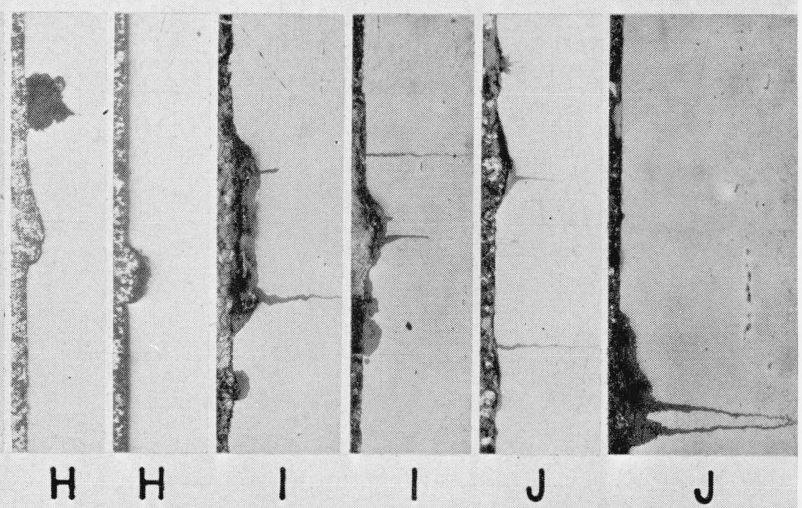

FIGURE 22.-50 c/min; longitudinal sections; $\times 50$.

$A, 68,000 \mathrm{lb} / \mathrm{in}^{2}, 1.1$ days, IW-W-10. $B, 35,000 \mathrm{lb} /$ in. $^{2}, 2$ days, IW-W-10.

$C, 35,000 \mathrm{lb} / \mathrm{in}^{2}, 3$ days, IW-W-10.

$D, 30,000 \mathrm{lb} / \mathrm{in.}^{2}, 4$ days, IW-W-10.

E, 30,000 lb/in. ${ }^{2}, 5$ days, IW-W-10.
F, 30,000 lb/in. ${ }^{2}, 6$ days, IW-W-10.

$G, 30,000 \mathrm{lb} / \mathrm{in}^{2}, 8$ days, I W-W -10 .

$H, 25,000 \mathrm{lb} / \mathrm{in}^{2}, 4$ days, I W-W-10.

$H, 25,000 \mathrm{lb} / \mathrm{in}^{2}, 4$ days, $\mathrm{W}-\mathrm{W}-10$.

J, 25,000 lb/in. ${ }^{2}, 7$ days, J R-W-10. 

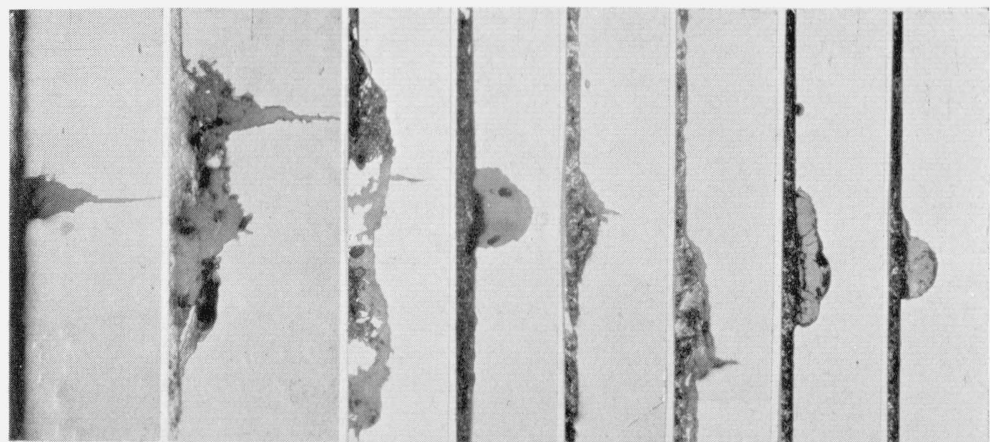

A
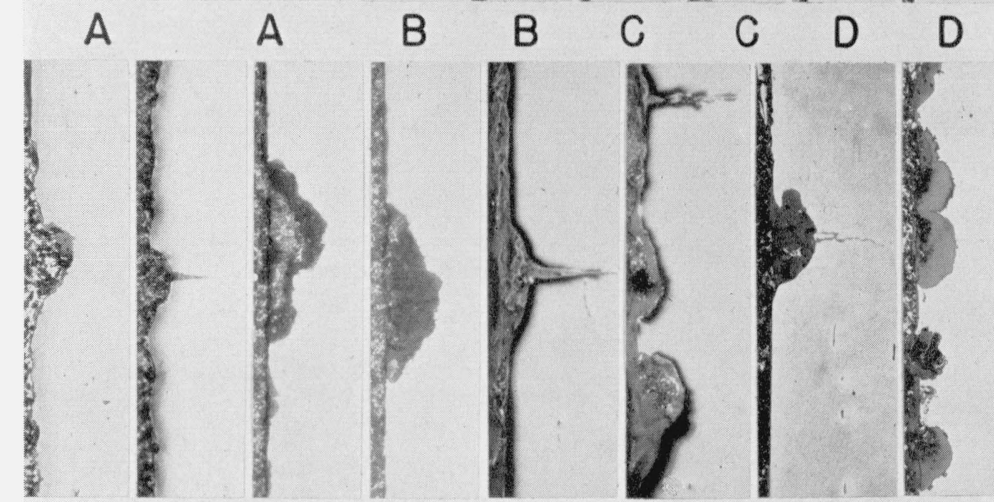

E
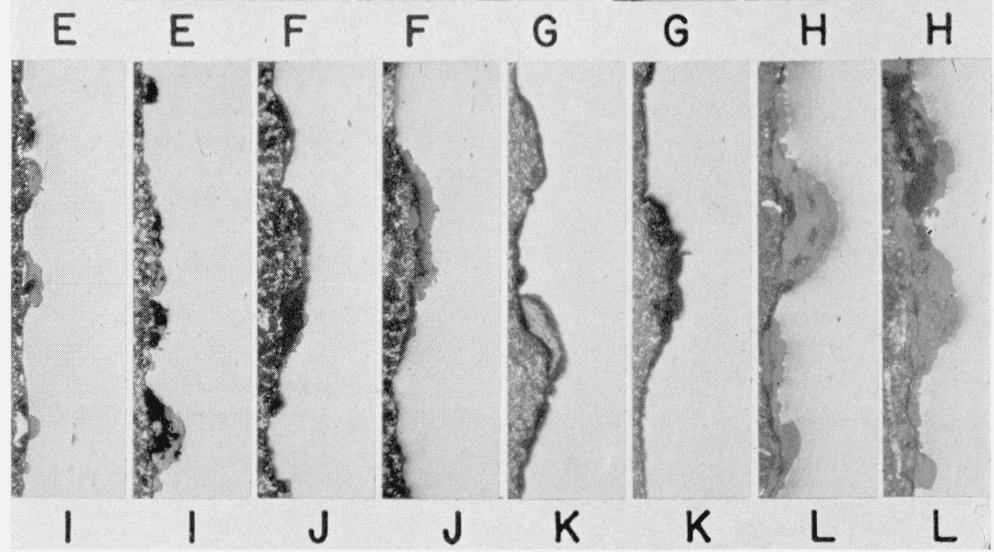

Figure 23. $-50 \mathrm{c} / \mathrm{min}$; longitudinal sections; $\times 50$.

$A, 25,000 \mathrm{lb} / \mathrm{in}^{2}, 9$ days, $\mathrm{IW}-\mathrm{W}-10$. $B, 20,000 \mathrm{lb} / \mathrm{in}^{2}, 5.5$ days, $\mathrm{I} \mathrm{W}-\mathrm{W}-10$. $C, 20,000 \mathrm{lb} / \mathrm{in} .^{2}, 10$ days, J R-W-10. $D, 16,000 \mathrm{lb} / \mathrm{in} .^{2}, 4$ days, $\mathrm{I} \mathrm{W}-\mathrm{W}-10$. E, $16,000 \mathrm{lb} /$ in $^{2}, 9$ days, I W-W -10 . $F, 15,000 \mathrm{lb} / \mathrm{in}^{2}, 17$ days, JR-W-10.
$G, 15,000 \mathrm{lb} /$ in. $^{2}, 24.5$ days, J R-W-10 $H, 13,000 \mathrm{lb} / \mathrm{in}^{2}{ }^{2}, 20$ days, IW-W-10. $I, \quad 12,000 \mathrm{lb} / \mathrm{in}^{2}, 20$ days, I W $-\mathrm{W}-10$. $J, 10,000 \mathrm{lb} /$ in $^{2}, 28$ days, $\mathrm{IW}-\mathrm{W}-10$. $K, 10,000 \mathrm{lb} / \mathrm{in}^{2}, 45$ day s, JR-W-10. $L, 6,000$ lb/in. ${ }^{2}, 173$ days, $I W-W-10$. 

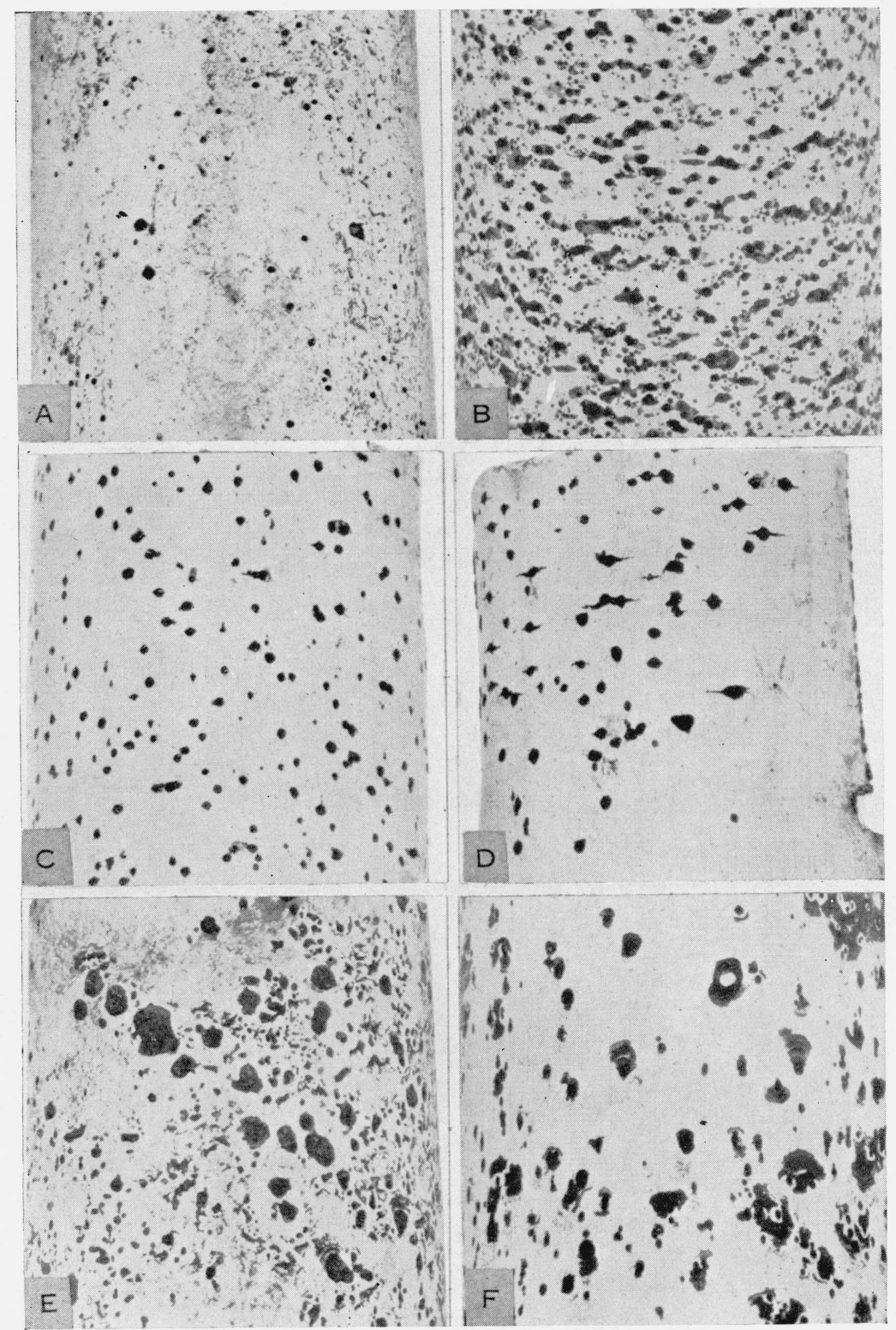

Figure 24. $-10 \mathrm{c} / \mathrm{min}$; outer surfaces; $\times 4$.

$A, 45,000 \mathrm{lb} / \mathrm{in.}^{2}, 2.8$ days, IW-W-10.

$B, 40,000 \mathrm{lb} / \mathrm{in}^{2}, 5$ days, IW-W-10.

$C, 35,000 \mathrm{lb} / \mathrm{in}^{2}, 6.5$ days, $\mathrm{I} \mathrm{W}-\mathrm{W}-10$

$D, 35,000 \mathrm{lb} / \mathrm{in} .^{2}, 9$ days, IW-W-10.

$E, 30,000 \mathrm{lb} / \mathrm{in}^{2}, 9$ days, IW-W-10.

$F$, 30,000 lb/in.2, 12 days, J R-W-10. 


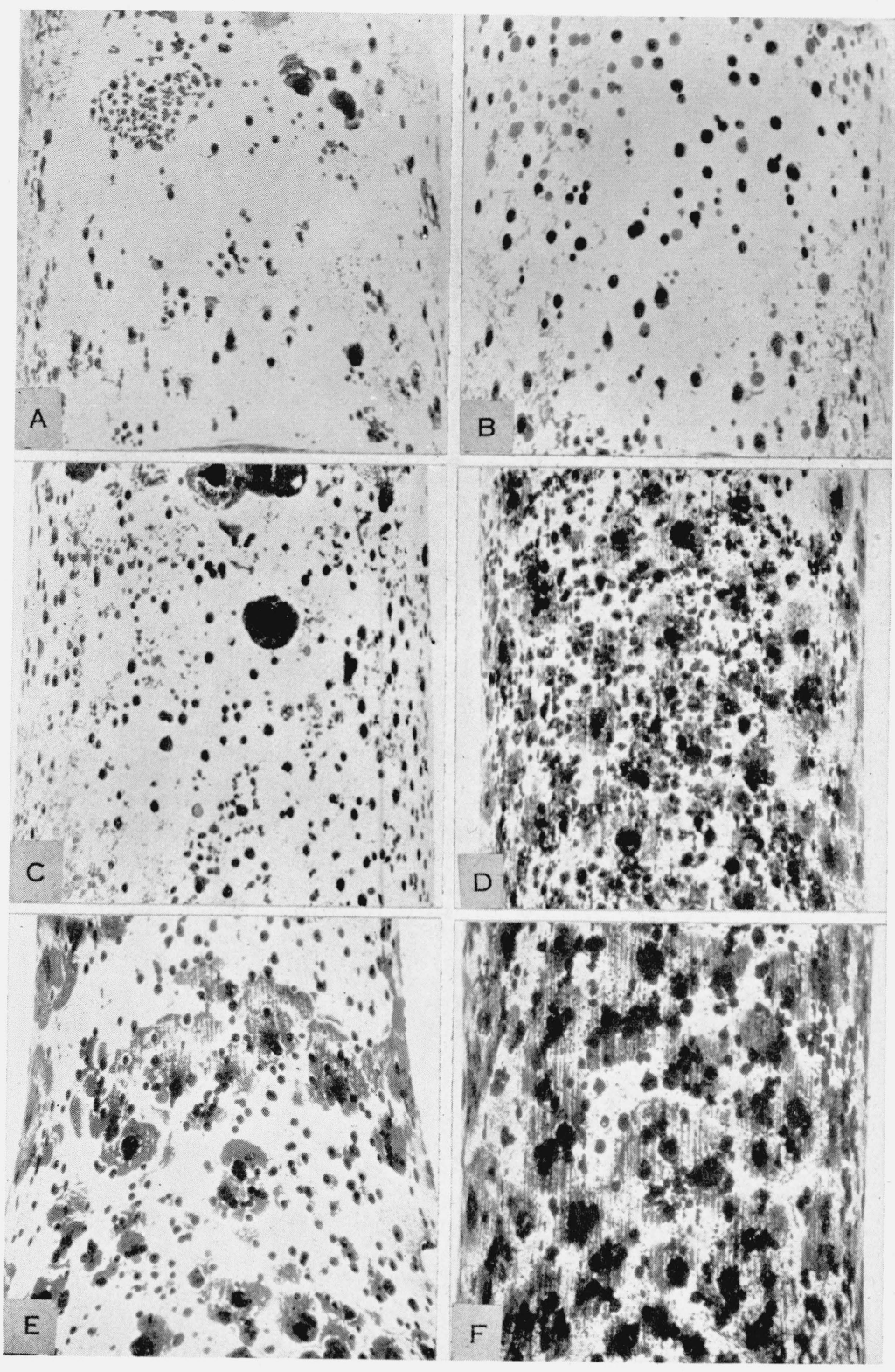

Figure 25.-10 c/min; outer surfaces; $\times 4$.

A, 25,000 lb/in. ${ }^{2}, 11$ days, IW-W-10.

$B, 18,000 \mathrm{lb} / \mathrm{in}^{2}{ }^{2}, 20$ days, $\mathrm{IW}-\mathrm{W}-10$. $C, 17,000 \mathrm{lb} / \mathrm{in} .{ }^{2}, 25$ days, $\mathrm{IW}-\mathrm{W}-10$ $D, 15,000 \mathrm{lb} / \mathrm{in}^{2}{ }^{2}, 34$ days, I W-W-10. $E, 13,000 \mathrm{lb} / \mathrm{in}^{2}{ }^{2}, 36$ days, $\mathrm{IW}-\mathrm{W}-10$ $F, 12,000 \mathrm{lb} / \mathrm{in} .^{2}, 70$ days, IW-W-10. 

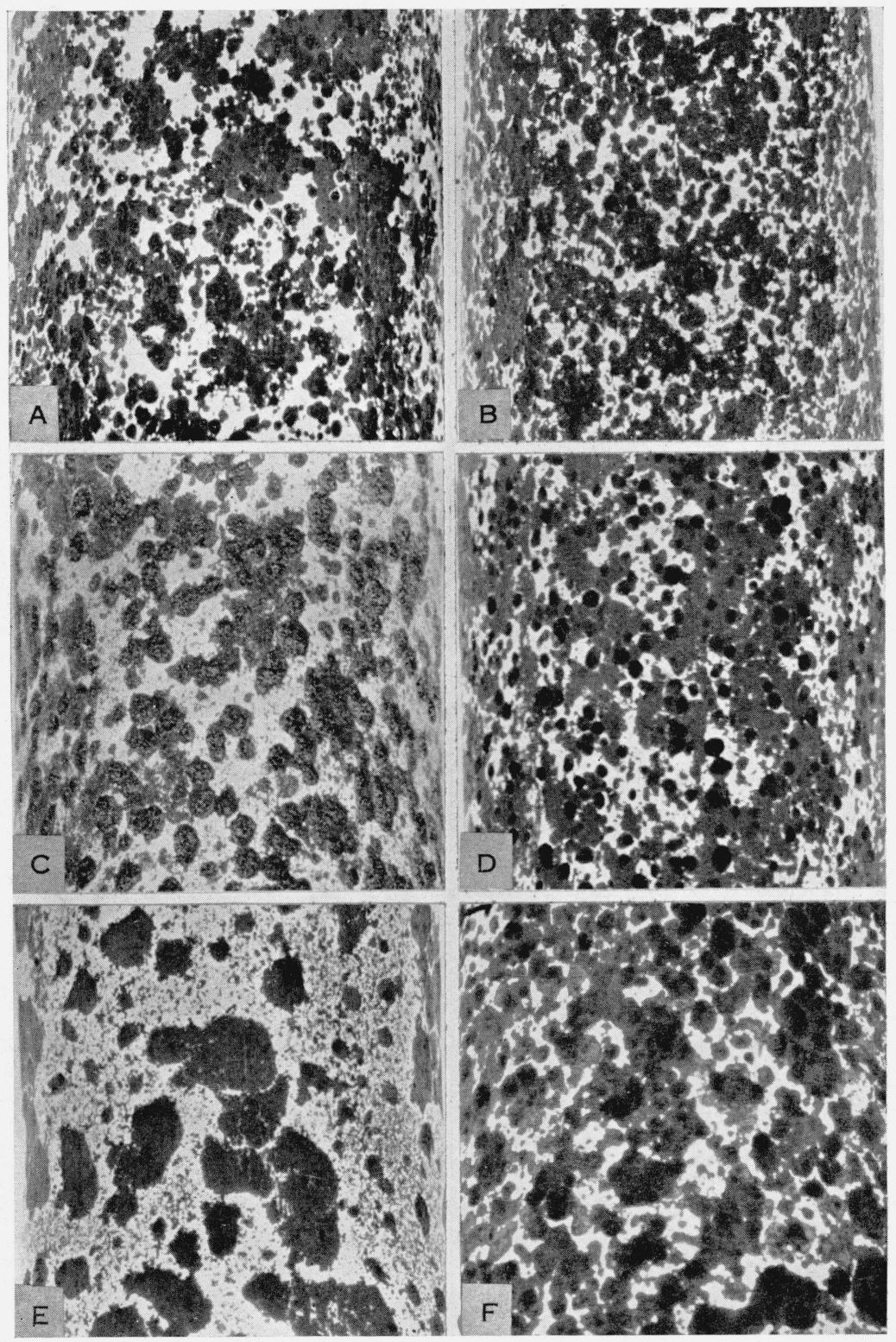

Figure 8,-Stressless corrosion; outer surfaces; $\times 4$.

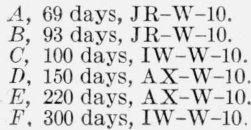



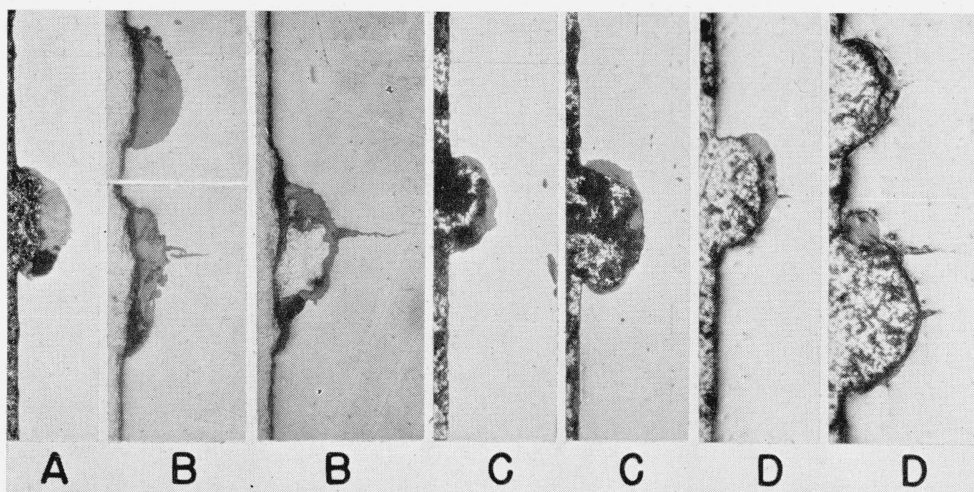

B

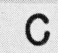

C
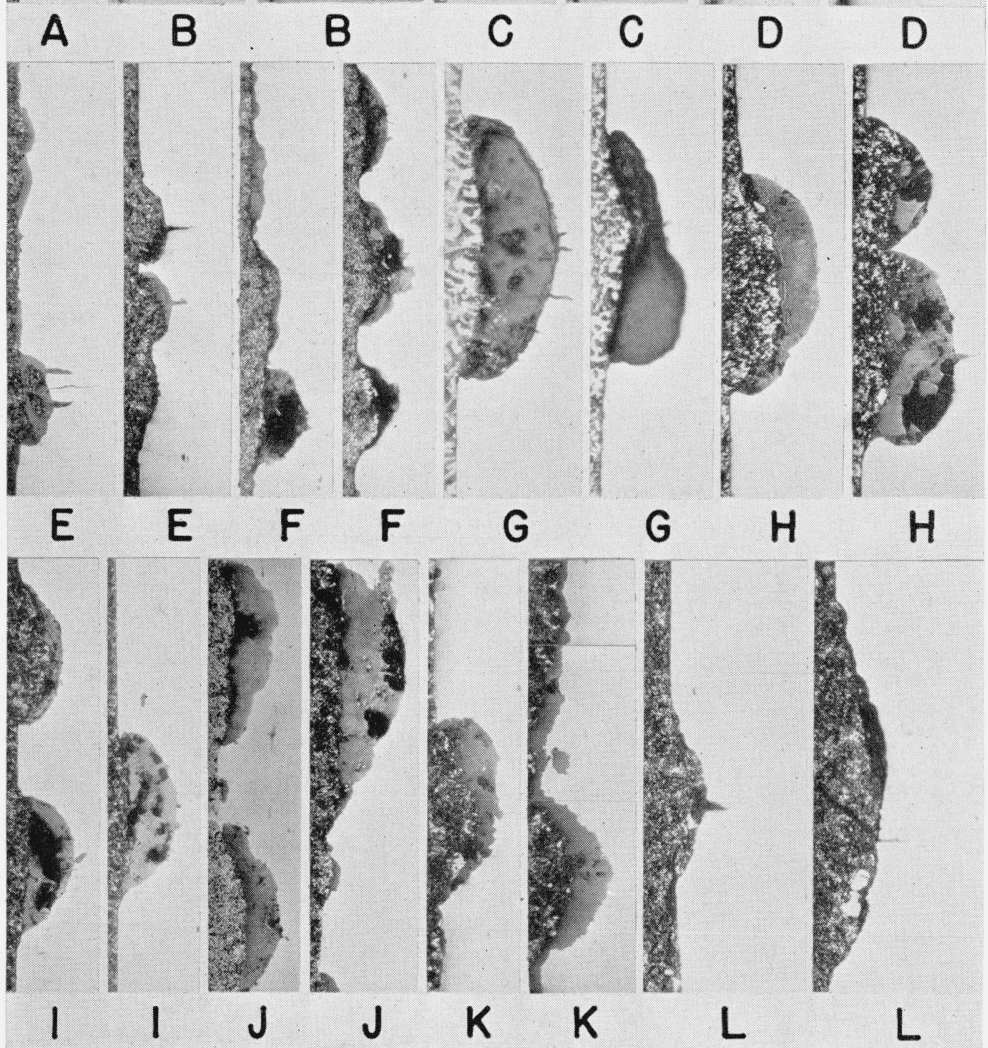

G
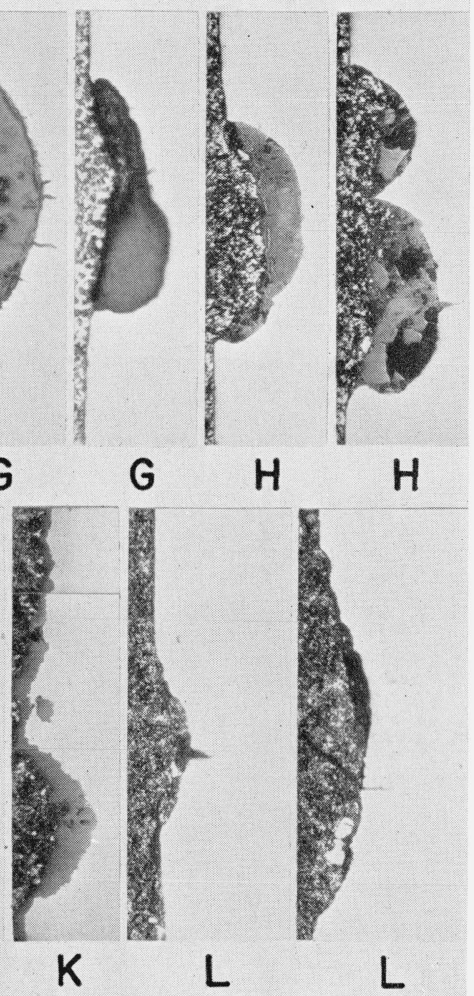

Figure $26 .-10 \mathrm{c} / \mathrm{min}$; longitudinal sections; $\times 50$.

$A, 45,000 \mathrm{lb} /$ in. $^{2}, 2.8$ days, $\mathrm{IW}-\mathrm{W}-10$.

$B, 40,000 \mathrm{lb} / \mathrm{in}^{2}, 6.5$ days, IW-W -10 .

$C, 35,000 \mathrm{lb} / \mathrm{in} .^{2}, 7$ days, $\mathrm{IW}-\mathrm{W}-10$

$D, 35,000 \mathrm{lb} / \mathrm{in}, 2,9$ days, $\mathrm{IW}-\mathrm{W}-10$

$F, 30,000 \mathrm{lb} / \mathrm{in}^{2}, 9$ days, IW-W-10.

$F, 25,000 \mathrm{lb} / \mathrm{in} .2,11$ days, IW-W-10.

G, 22,000 lb/in. ${ }^{2}, 15$ days, IW-W-10. $H, 18,000 \mathrm{lb} / \mathrm{in} .^{2}, 20$ days, $\mathrm{IW}-\mathrm{W}-10$.

I, $17,000 \mathrm{lb} / \mathrm{in} .^{2}, 25$ days, IW-W-10.

J $15,000 \mathrm{lb} /$ in $^{2}, 34$ days, IW-W-10

$K, 13,000 \mathrm{lb} / \mathrm{in}^{2}, 36$ days, IW-W-10

L, $12,000 \mathrm{lb} / \mathrm{in}^{2}, 20$ days, IW-W-10. 

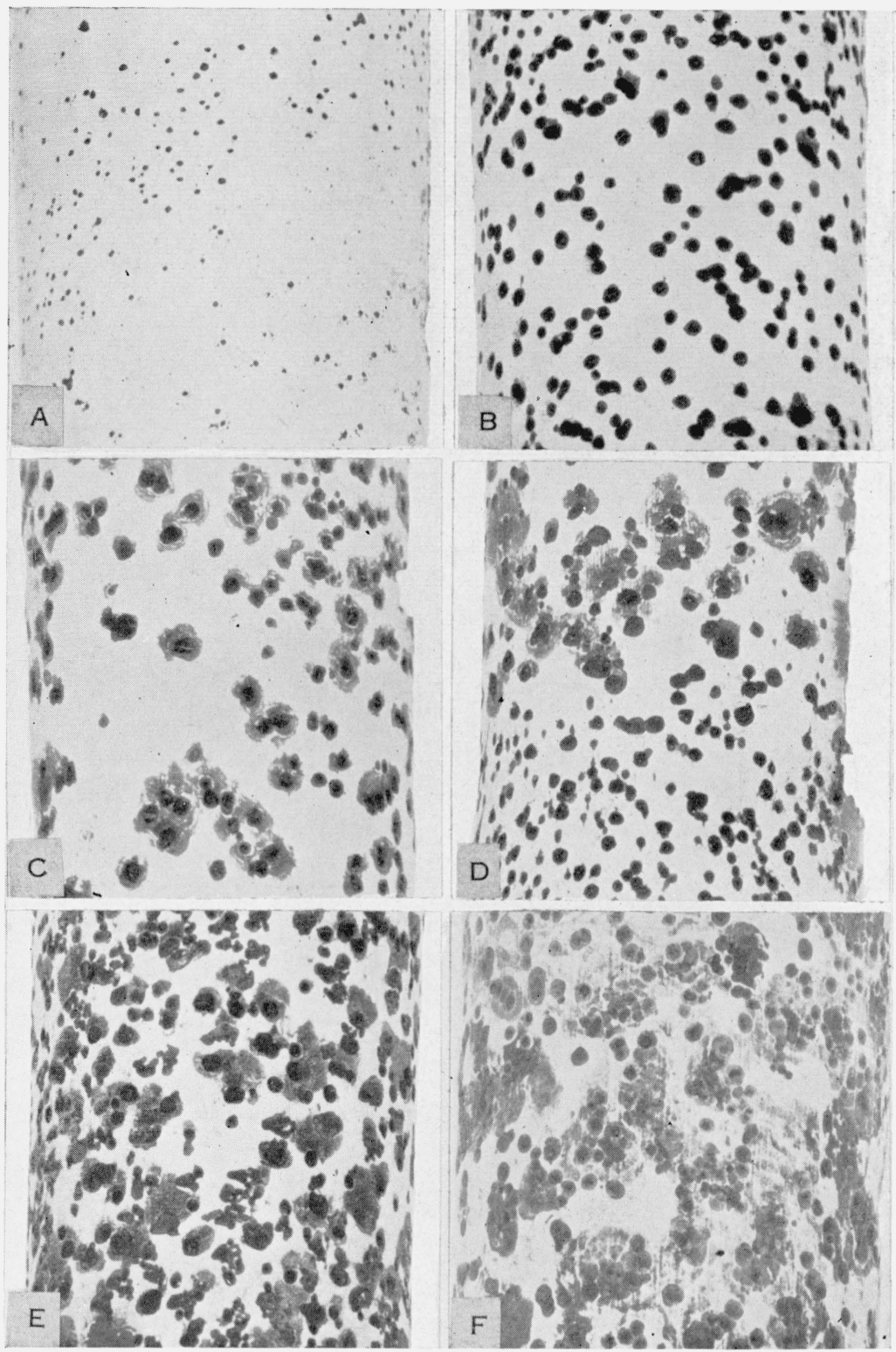

Figure 27.-1.5 c/min; outer surfaces; $\times 4$.

$A, 55,000 \mathrm{lb} / \mathrm{in}^{2}, 1.2$ days, $\mathrm{IW}-\mathrm{W}-10$. $B, 35,000 \mathrm{lb} / \mathrm{in}^{2}, 17$ days, $\mathrm{IW}-\mathrm{W}-10$. C, $35,000 \mathrm{lb} / \mathrm{in}^{2}, 20$ days, $\mathrm{IW}-\mathrm{W}-10$. $D, 30,000 \mathrm{lb} / \mathrm{in} .^{2}, 23$ days, IW-W-10. $E, 30,000 \mathrm{lb} / \mathrm{in}^{2}{ }^{2}, 26$ days, $\mathrm{IW}-\mathrm{W}-10$. $F, 20,000 \mathrm{lb} / \mathrm{in} .^{2}, 96$ days, IW-W-10. 


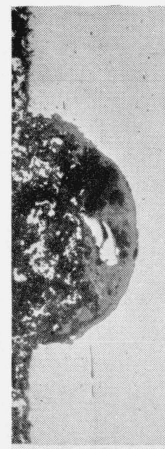

A

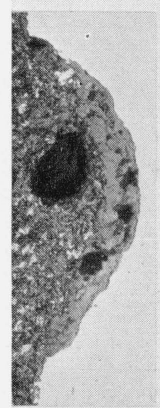

D
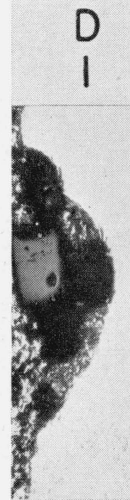

F

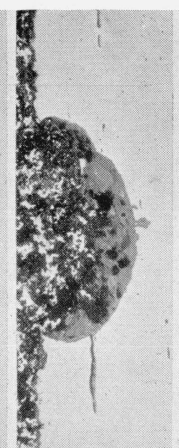

A

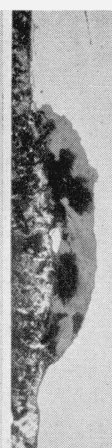

B

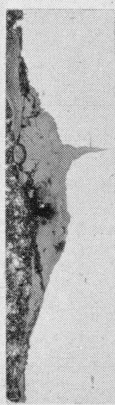

D

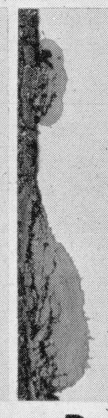

D
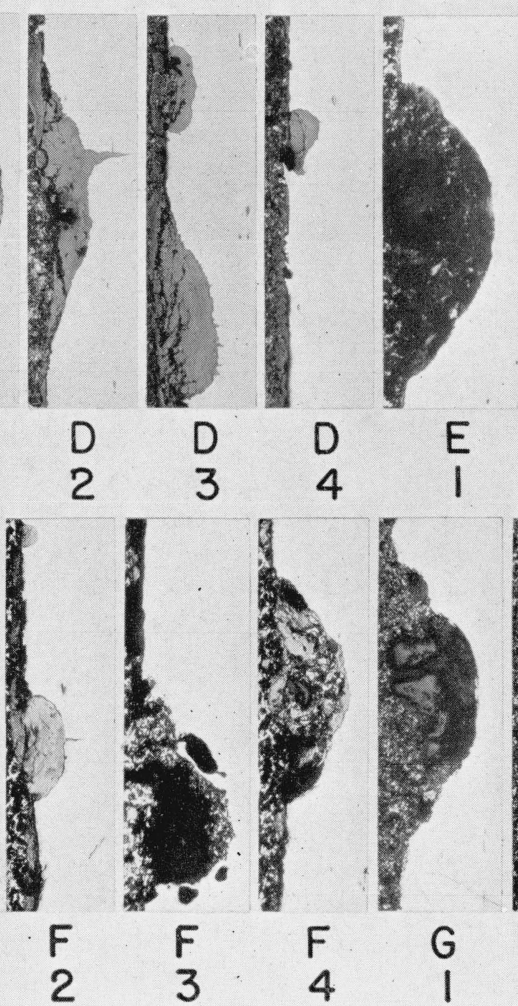

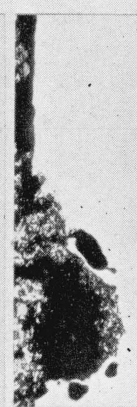

$\mathrm{F}$

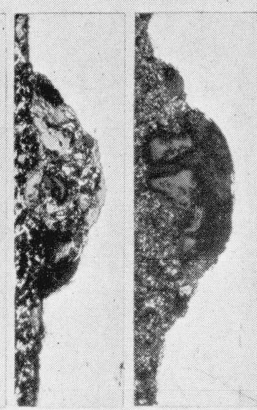

E

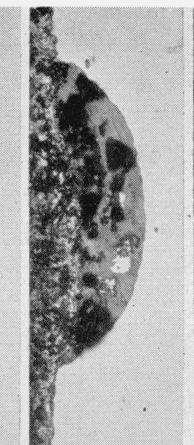

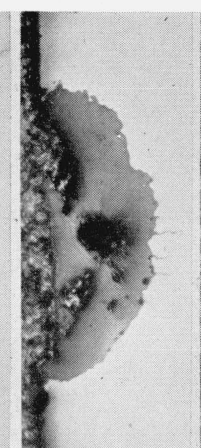

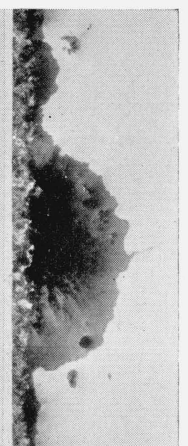

C
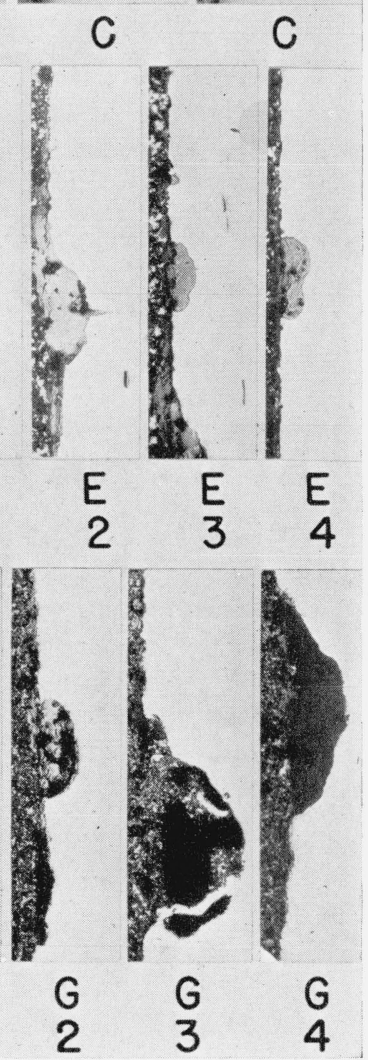

Figure 28, - $1.5 \mathrm{c} / \mathrm{min}$; longitudinal sections; $\times 50$.

$$
\begin{aligned}
& A, 35,000 \mathrm{lb} / \mathrm{in} .^{2}, 17 \text { days, IW-W-10. } \\
& B, 35,000 \mathrm{lb} / \mathrm{in} .^{2}, 20 \text { days, IW-W-10. } \\
& C, 30,000 \mathrm{lb} / \mathrm{in}^{2}, 23 \text { days, IW-W-10. } \\
& D, 25,000 \mathrm{lb} / \mathrm{in} .^{2}, 42 \text { days, IW-W-10. } \\
& E \text {, Same as } D \text {, with } 0.001 \mathrm{in} \text {. removed. } \\
& F \text {, Same as } D \text {, with } 0.002 \mathrm{in} \text {. removed. } \\
& G \text {, Same as } D \text {, with } 0.003 \text { in. removed. }
\end{aligned}
$$



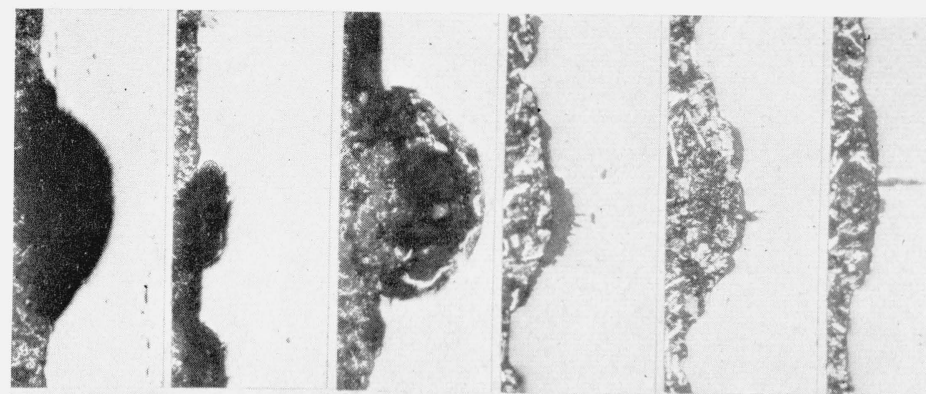

A

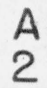

A
3
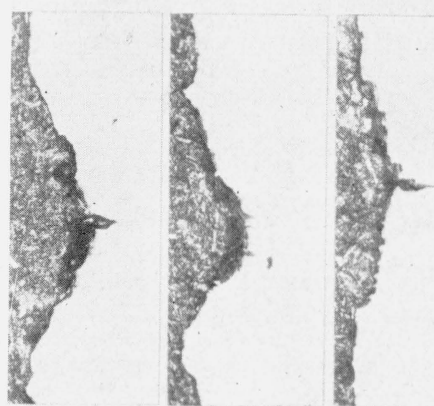

B

$B$
2

$B$
3

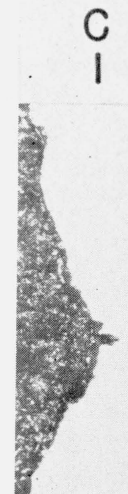

C
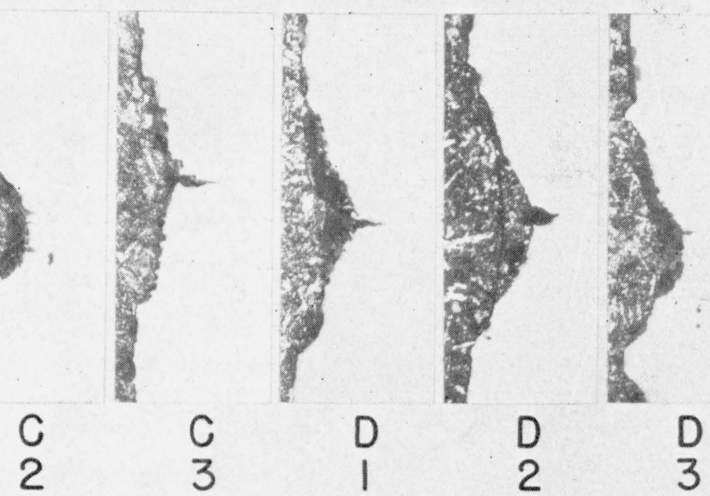

C
3

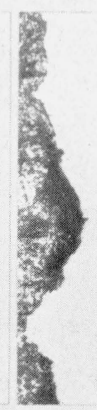

$\begin{array}{ll}E & E \\ I & 2\end{array}$

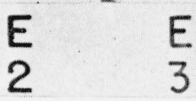

E

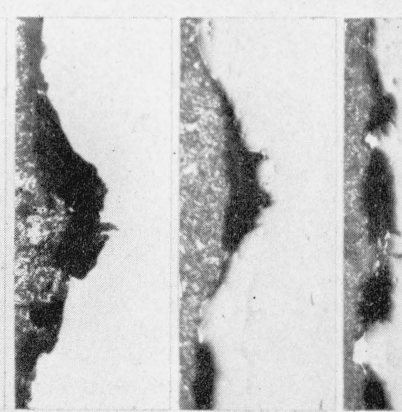

$D$
2
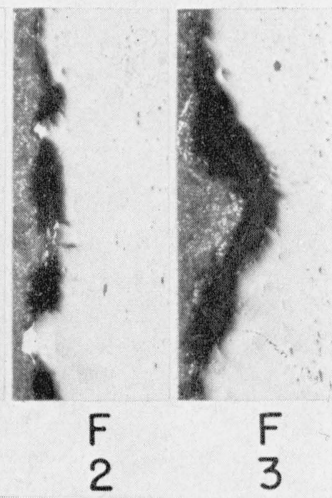

Figure 29.-1.5 c/min; longitudinal sections; $\times 50$.

$A$, Same as $D$ of figure 29 , with 0.004 inch removed.

$B, 20,000 \mathrm{lb} / \mathrm{in} .^{2}, 96$ days, IW-W-10.

$C$, Same as $B$, with 0.001 in. removed.

$D$, same as $B$, with 0.002 in removed.

$E$, Same as $B$, with 0.003 in. removed.

$F$, Same as $B$, with 0.004 in. removed. 

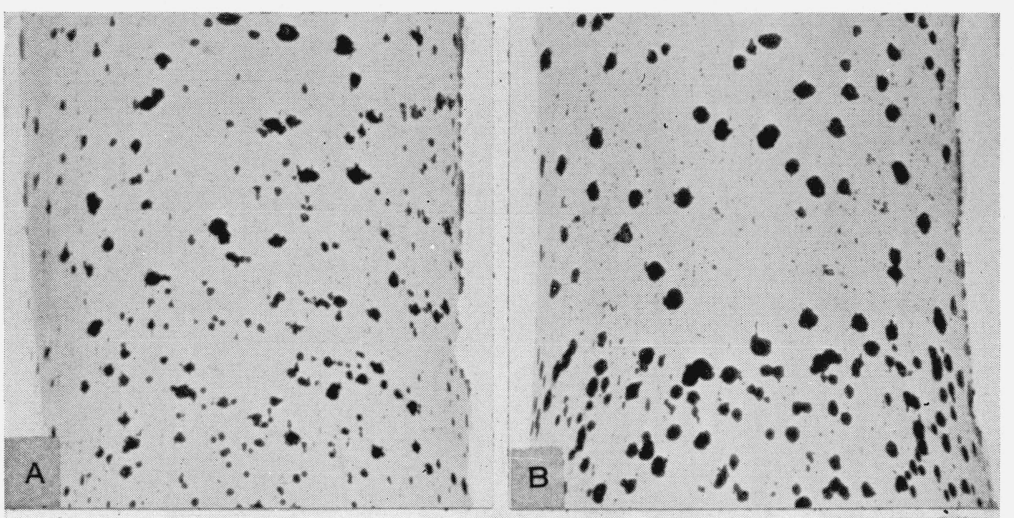

RP, 'y

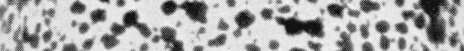

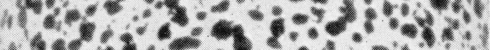

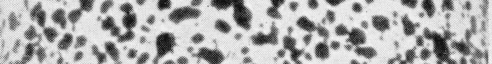

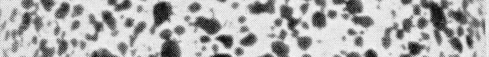

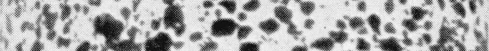

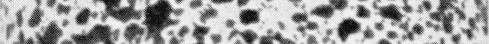

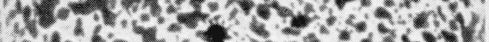

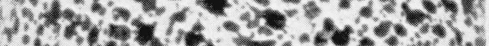
in 2 -

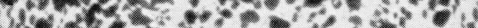

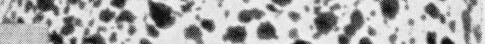

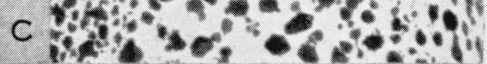
160.0 a 27 .

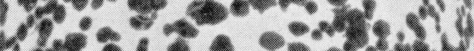

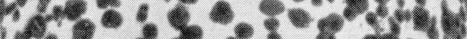

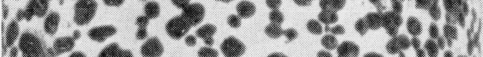
3. 1 s 60\% T\% $=-20$

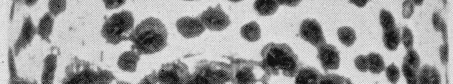

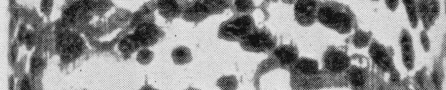
I.

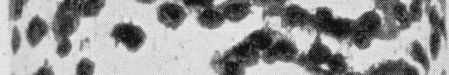

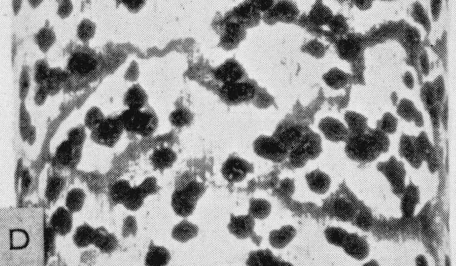

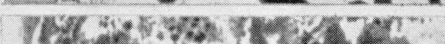
to -20 at is gु

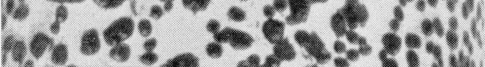

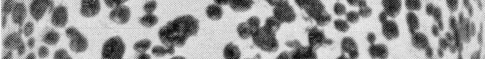

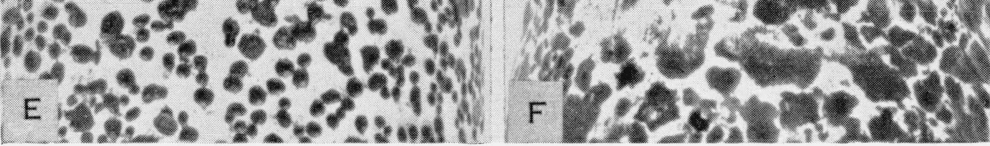

FiguRe 30. $-0.5 \mathrm{c} / \mathrm{min}$, and $5 \mathrm{c} / \mathrm{hr}$; outer surfaces; $\times 4$

$A, 45,000 \mathrm{lb} / \mathrm{in} .^{2}, 8.8$ days, $0.5 \mathrm{c} / \mathrm{min}$, IW-W-10.

$B, 40,000 \mathrm{lb} / \mathrm{in}^{2}, 16$ days, $0.5 \mathrm{c} / \mathrm{min}$, IW-W-10.

$C, 35,000 \mathrm{lb} / \mathrm{in} .^{2}, 19$ days, $0.5 \mathrm{c} / \mathrm{min}, \mathrm{JR}-\mathrm{W}-10$.

$D, 35,000 \mathrm{lb} / \mathrm{in}^{2}, 40$ days, $0.5 \mathrm{c} / \mathrm{min}, \mathrm{IW}-\mathrm{W}-10$.

$E, 30,000 \mathrm{lb} / \mathrm{in}^{2}, 38$ days, $0.5 \mathrm{c} / \mathrm{min}, \mathrm{JR}-\mathrm{W}-10$ 

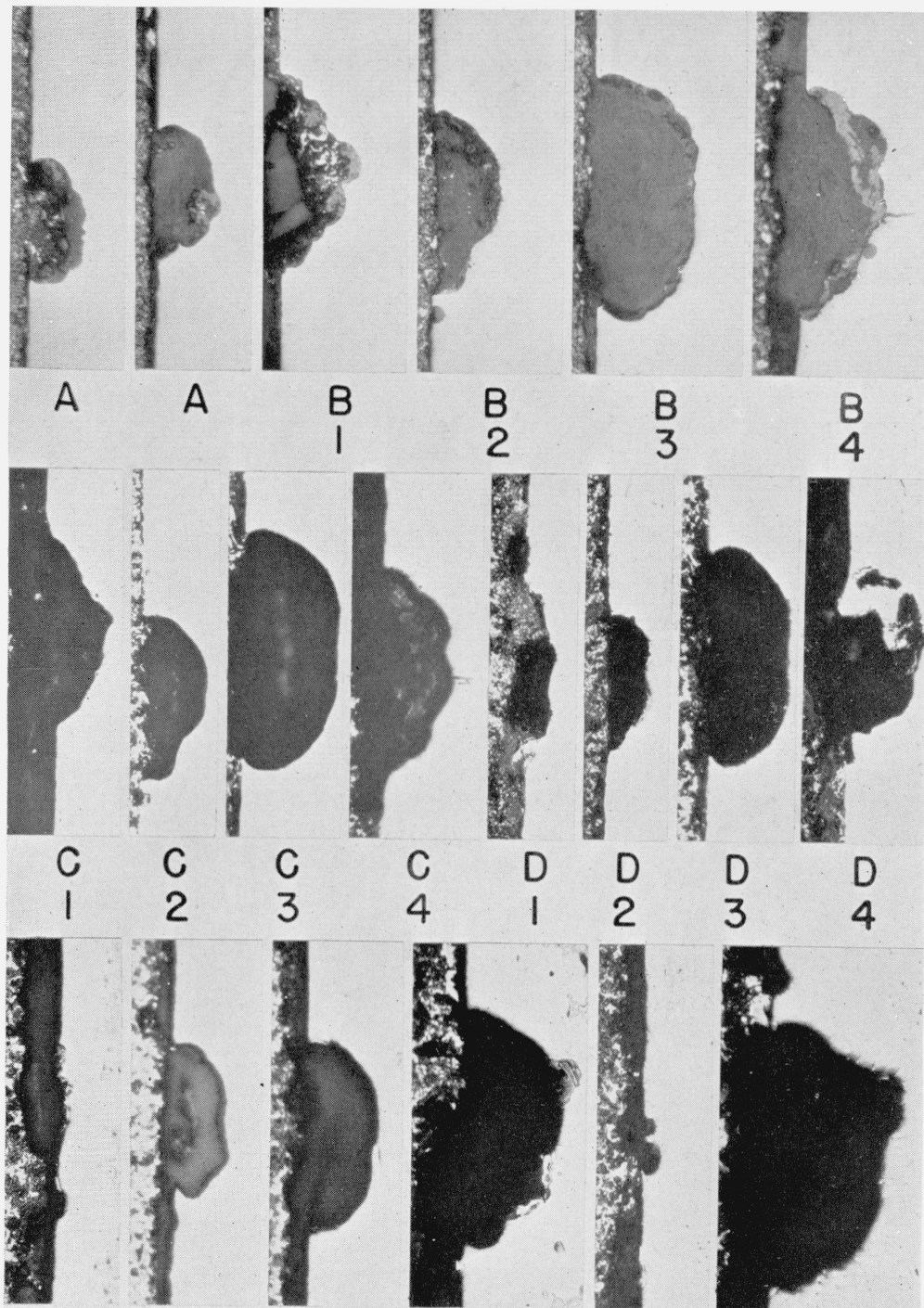

E

C

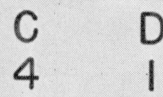

D
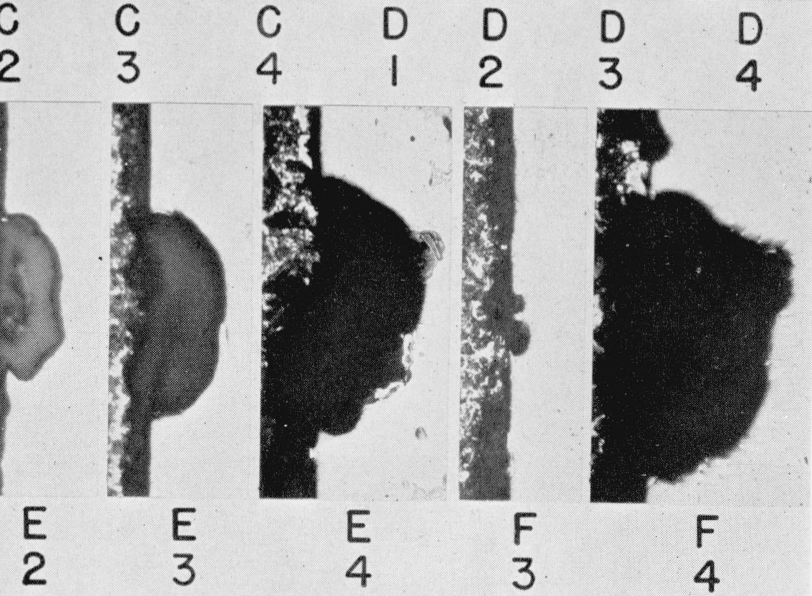

E

E

$\mathrm{F}$
3

$F$
4

FIGURE 31. $0.5 \mathrm{c} / \mathrm{min}$; longitudinal sections; $\times 50$.

$A, 45,000 \mathrm{lb} / \mathrm{in}^{2}, 8.8$ days, IW-W-10.

$B, 40,000 \mathrm{lb} / \mathrm{in} .^{2}, 16$ days, $\mathrm{IW}-\mathrm{W}-10$.

$C$, Same as $B$, with 0.001 in. removed.

$D$, Same as $B$, with 0.002 in. removed.

$E$, Same as $B$, with 0.003 in. removed.

$F$, same as $B$, with 0.004 in. removed. 

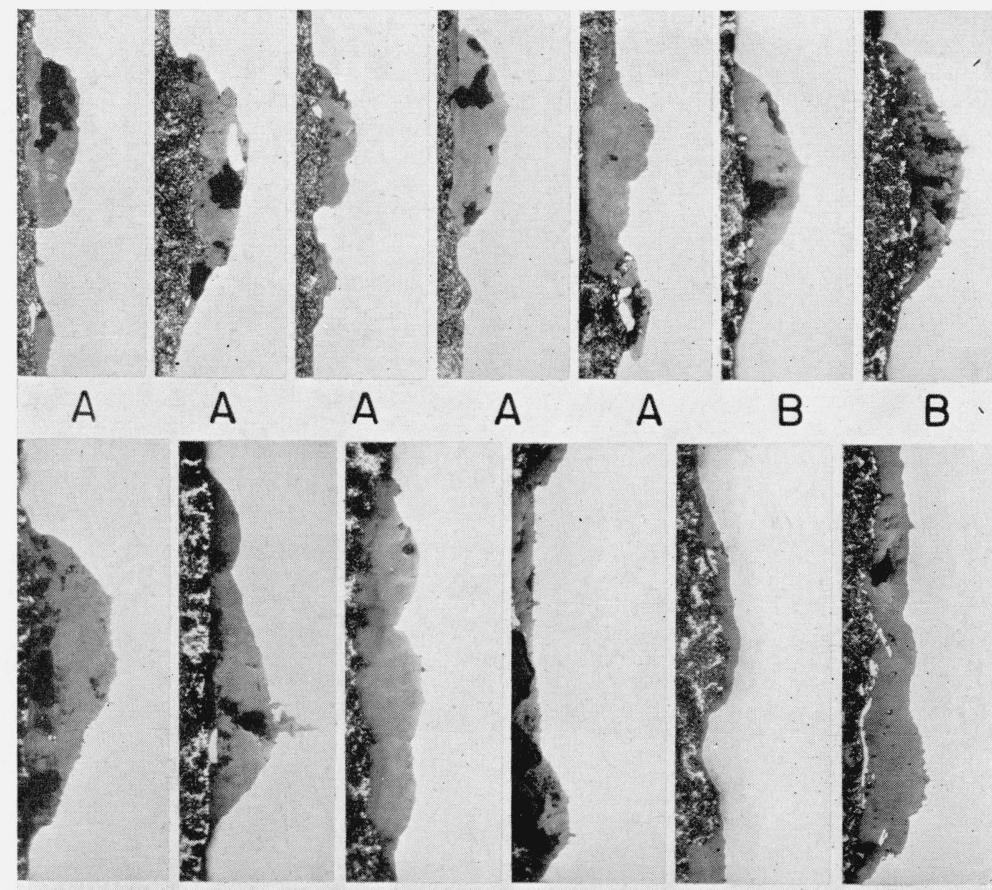

A

A
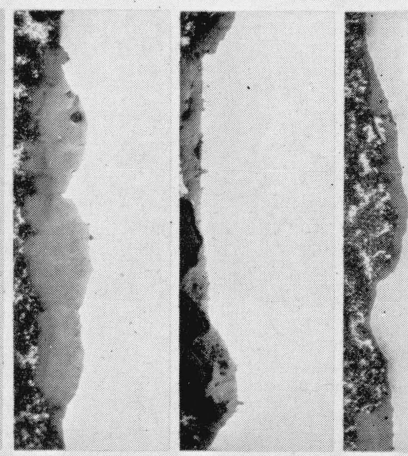

B
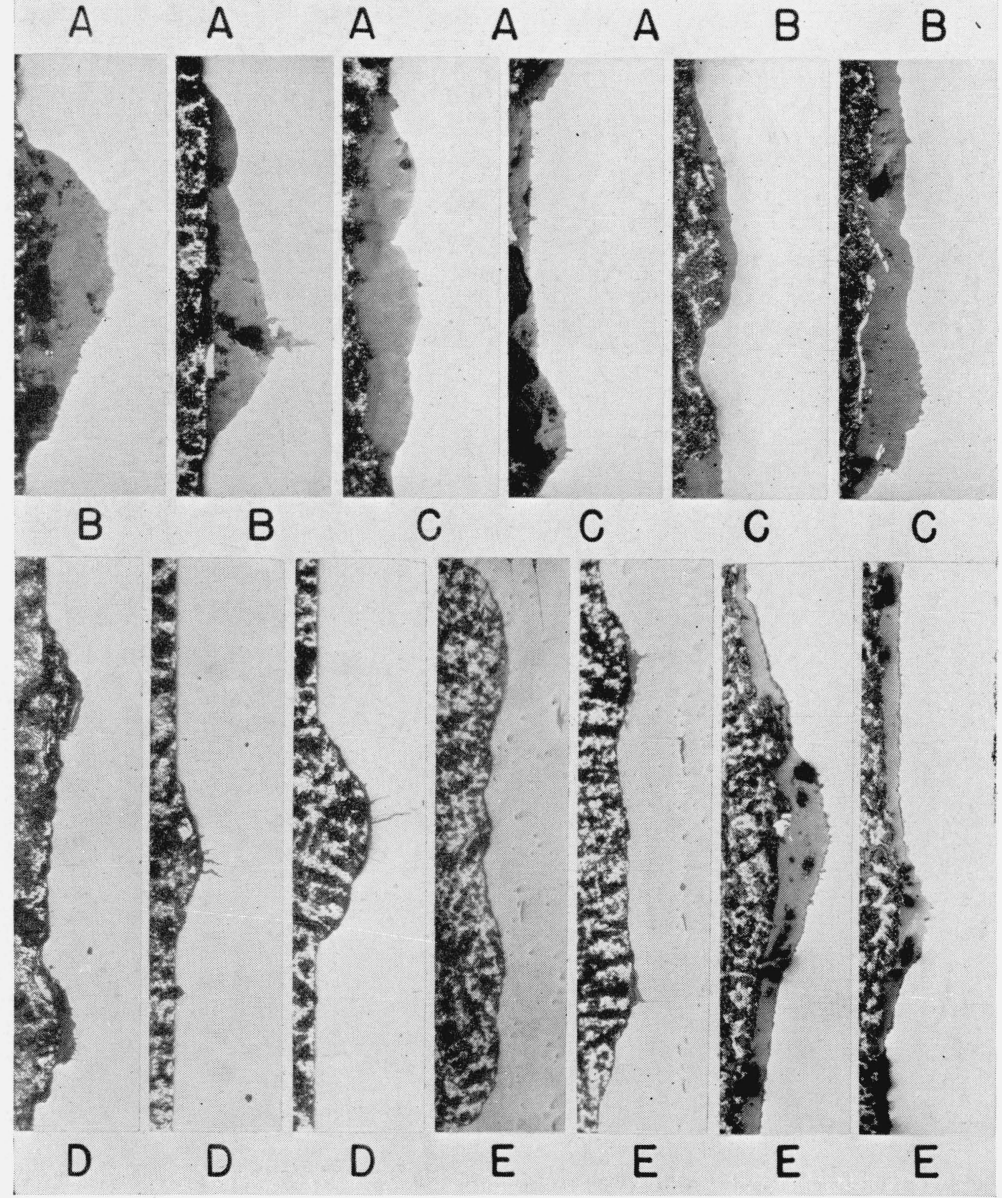

FigURE 32.-0.5 $\mathrm{c} / \mathrm{min}$ and $5 \mathrm{c} / \mathrm{hr}$; longitudinal sections; $\times 50$

$A, 35,000 \mathrm{lb} / \mathrm{in} .^{2}, 19$ days, JR-W-10, $0.5 \mathrm{c} / \mathrm{min}$.

$B, 35,000 \mathrm{lb} / \mathrm{in} .^{2}, 40$ days, $\mathrm{IW}-\mathrm{W}-10,0.5 \mathrm{c} / \mathrm{min}$

$C, 30,000 \mathrm{lb} / \mathrm{in} .{ }^{2}, 38$ days, JR-W-10, $0.5 \mathrm{c} / \mathrm{min}$.

$D, 25,000 \mathrm{lb} / \mathrm{in} .^{2}, 15$ days, $\mathrm{IW}-\mathrm{W}-10,0.5 \mathrm{c} / \mathrm{min}$

$E, 40,000 \mathrm{lb} / \mathrm{in}^{2}{ }^{2}, 146$ days, $\mathrm{LQ}-\mathrm{W}-10,5 \mathrm{c} / \mathrm{hr}$. 

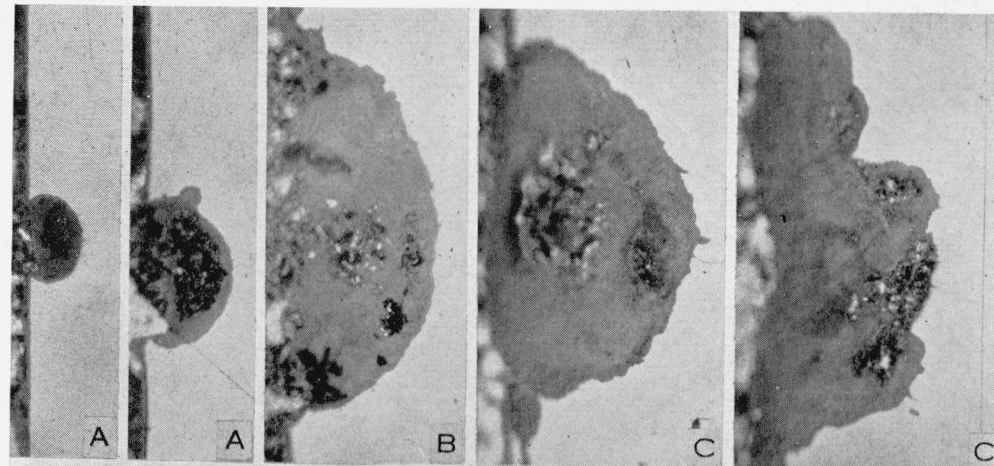

\section{STRESSLESS CORROSION}
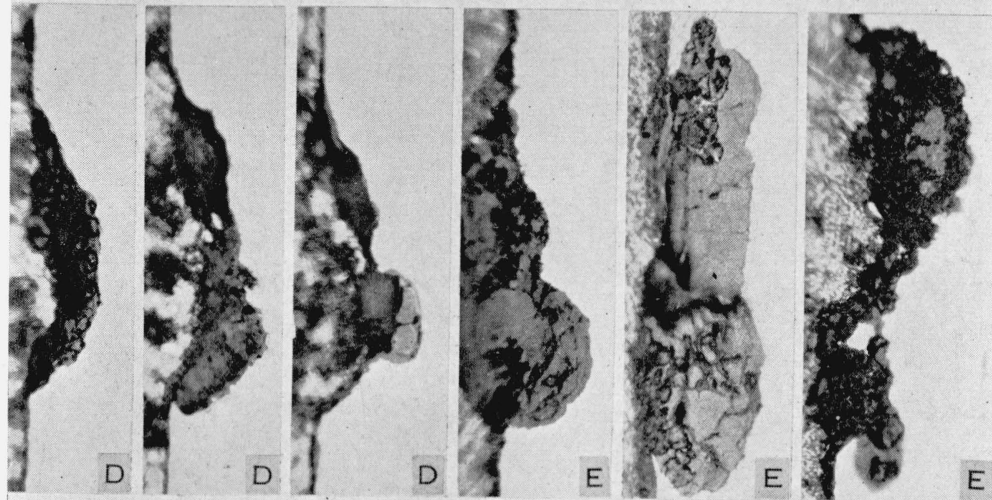

500 CYCLES PER MIN
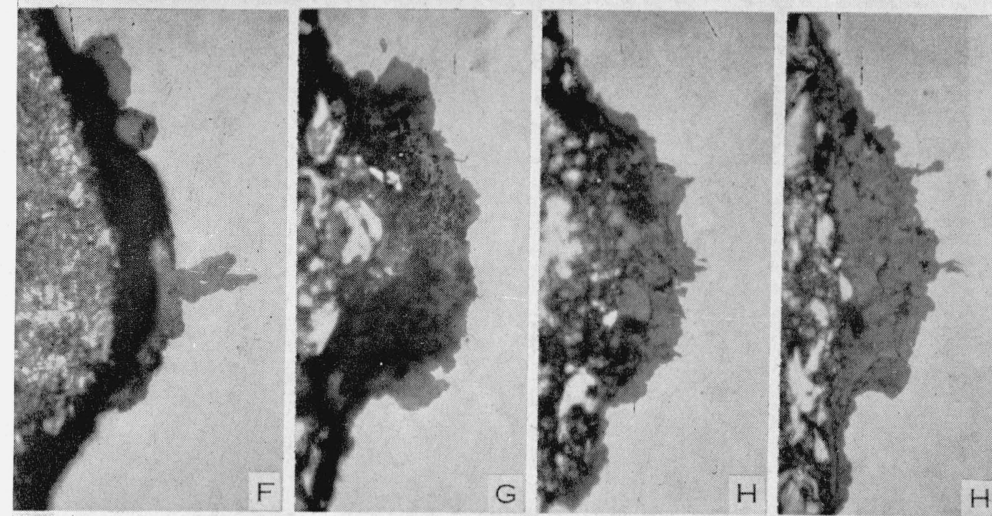

100 CYCLES PER MIN

Figure 33.-Stressless corrosion; stress corrosion at $500 \mathrm{c} / \mathrm{min}$ and $100 \mathrm{c} / \mathrm{min}$; longitudinal sections; $\times 250$.

Stressless corrosion

$A, 2$ days, $\mathrm{AX}-\mathrm{W}-10$.

$B, 4.7$ days, $\mathrm{IW}-\mathrm{W}-10$.

$C, 10$ days, $\mathrm{JR}-\mathrm{W}-10$.
Stress corrosion

$D, 10,000 \mathrm{lb} / \mathrm{in} .^{2}, 6$ days, $\mathrm{BC}-\mathrm{W}-10$ $E, 8,000 \mathrm{lb} /$ in. $^{2}, 32.5$ days, $\mathrm{BC}-\mathrm{W}-10$ $F, 20,000 \mathrm{lb} / \mathrm{in}^{2}, 4.5$ days, IW-W-10. $G, 12,000 \mathrm{lb} / \mathrm{in}^{2}{ }^{2}, 11$ days, IW-W-10. $H, 9,000 \mathrm{lb} / \mathrm{in}^{2}, 25$ days, IW-W-10. 

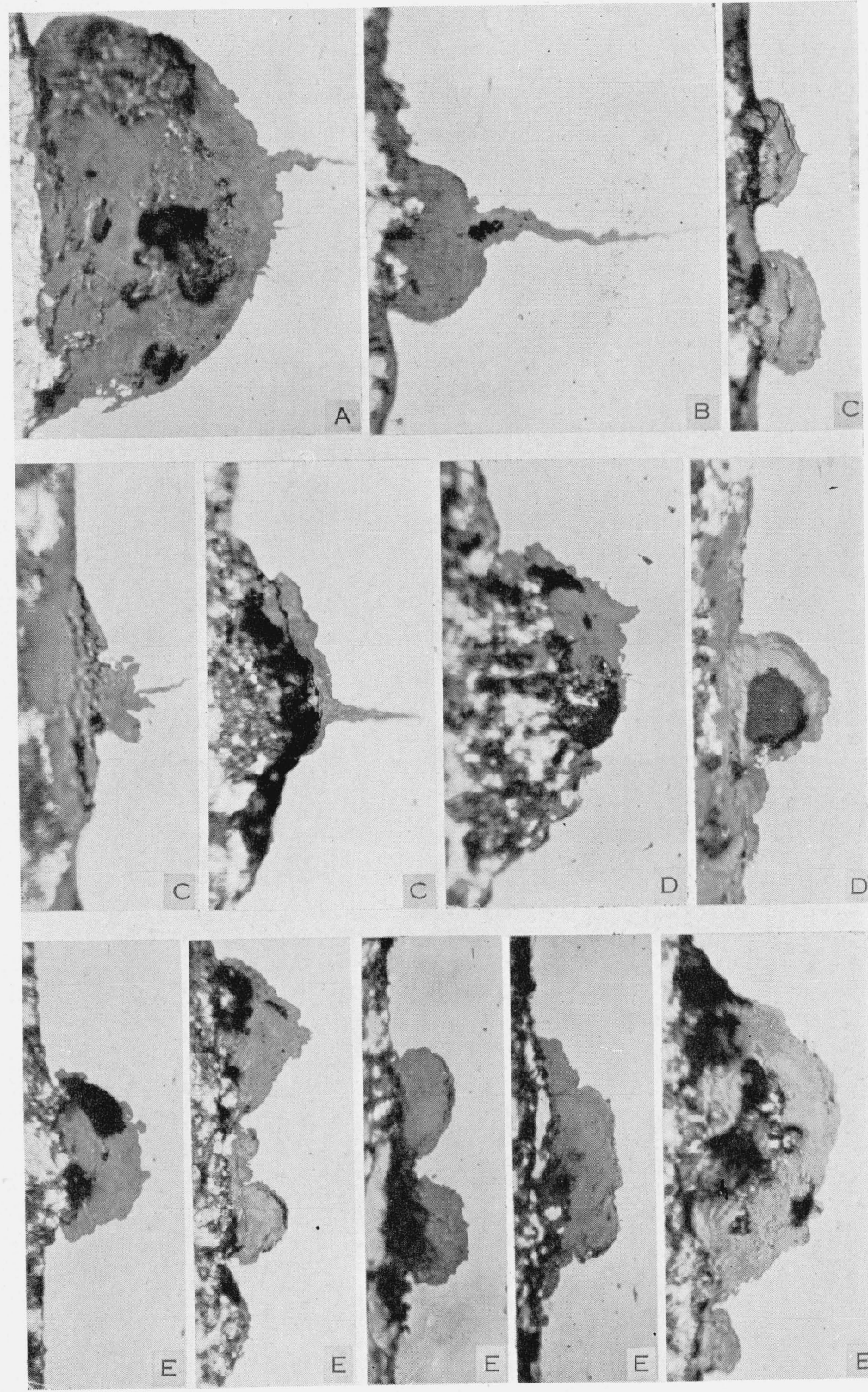

Figure 34.-50 c/min; longitudinal sections; $\times 250$.

$A, 35,000 \mathrm{lb} / \mathrm{in}^{2}, 2$ days, $\mathrm{IW}-\mathrm{W}-10$

$B, 30,000 \mathrm{lb} / \mathrm{in}^{2}, 8$ days, IW-W-10.

$C, 25,000 \mathrm{lb} / \mathrm{in}^{2}, 7$ days, $\mathrm{JR}-\mathrm{W}-10$.

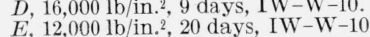




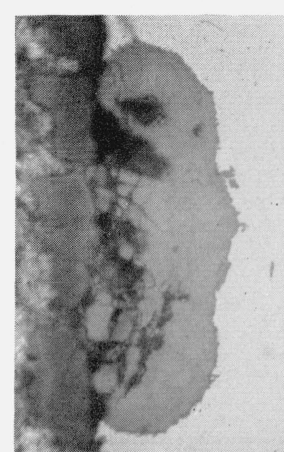

A

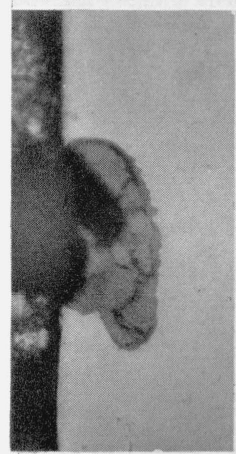

C

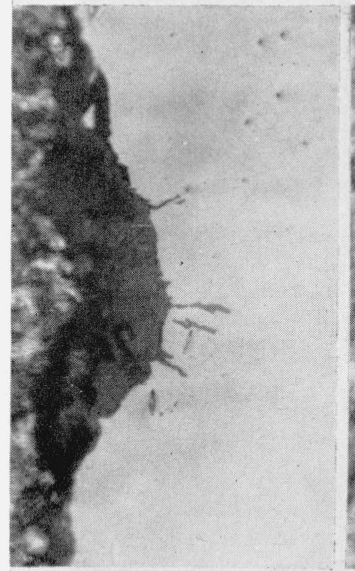

$E$

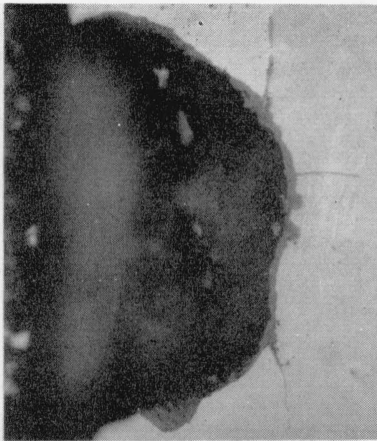

B

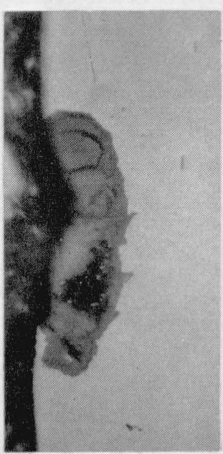

C

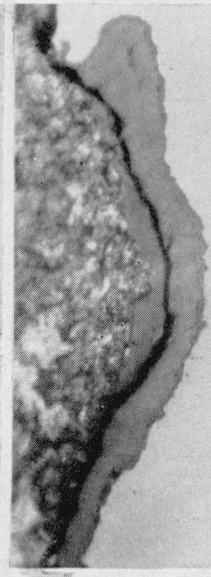

$\mathrm{F}$

D

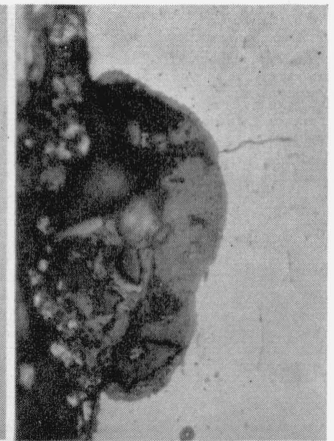

B

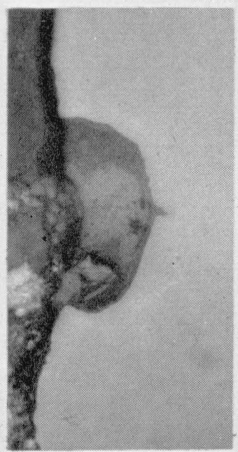

D
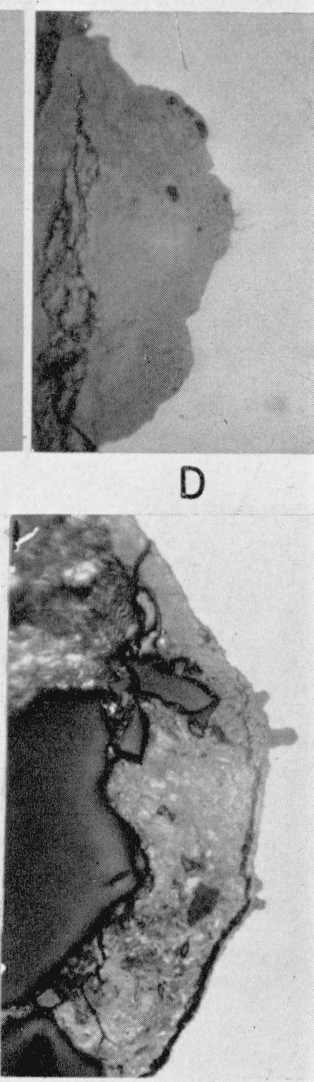

$\mathrm{F}$

FIgURE $35 .-1.5 \mathrm{c} / \mathrm{min}$ and $0.5 \mathrm{c} / \mathrm{min}$; longitudinal sections; $\times 250$.

A, 25,000 lb/in. ${ }^{2}, 42$ days, IW-W-10, $1.5 \mathrm{c} / \mathrm{min}$.

$B, 45,000 \mathrm{lb} /$ in $^{2}, 8.8$ days, $\mathrm{IW}-\mathrm{W}-10,0.5 \mathrm{c} / \mathrm{min}$.

$C, 40,000 \mathrm{lb} / \mathrm{in}^{2}, 16$ days, IW-W-10, $0.5 \mathrm{c} / \mathrm{min}$.

$D, 35,000 \mathrm{lb} / \mathrm{in}^{2}$, 19 days, J R-W-10, $0.5 \mathrm{c} / \mathrm{min}$.

$E, 35,000 \mathrm{lb} / \mathrm{in}^{2}, 40$ days, $\mathrm{IW}-\mathrm{W}-10,0.5 \mathrm{c} / \mathrm{min}$

$F, 30,000 \mathrm{lb} /$ in $^{2}$, 38 days, JR-W-10, $0.5 \mathrm{c} / \mathrm{min}$. 

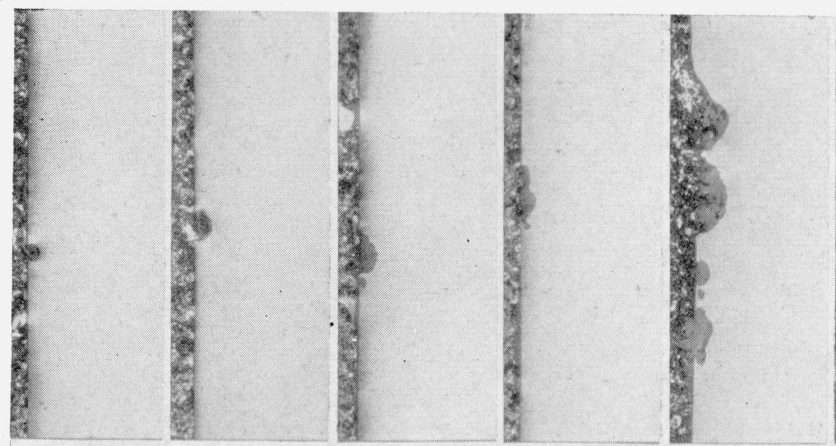

A $A$
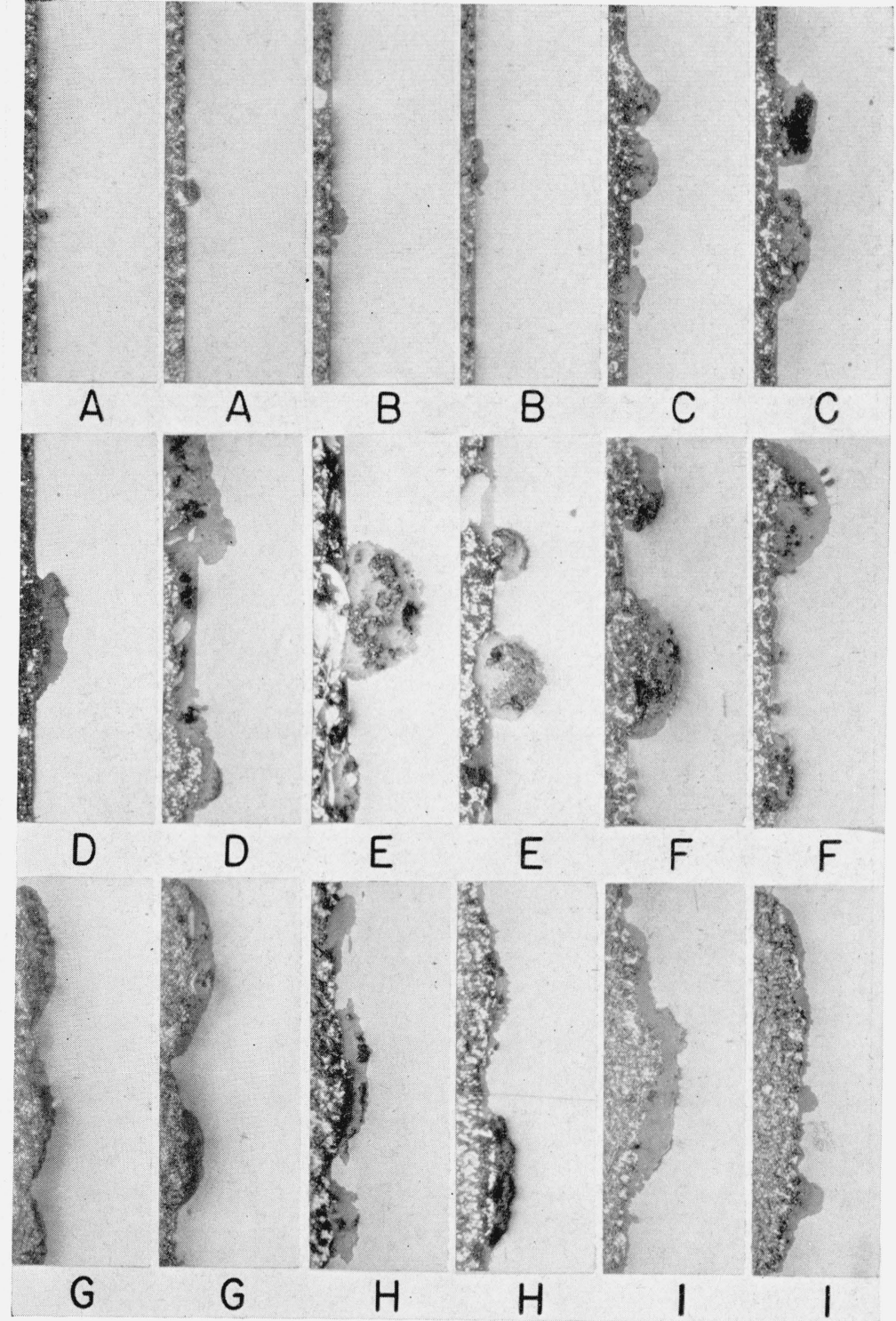

Figure 9.-Stressless corrosion; longitudinal sections; $\times 50$.

$$
\begin{aligned}
& A, 2 \text { days, } A X-W-10 . \\
& B, 4 \text { days, } A X-W-10 . \\
& C, 4.7 \text { days, } I W-W-10 . \\
& D, 10 \text { days, } I W-W-10 . \\
& E, 47 \text { days, } A X-W-10 .
\end{aligned}
$$

$F, 50$ days, $\mathrm{IW}-\mathrm{W}-10$.
$G, 59$ days, $\mathrm{JR}-\mathrm{W}-10$.

H, 69 days, $\mathrm{JR}-\mathrm{W}-10$.
$I, 84$ days, $\mathrm{AX}-\mathrm{W}-10$. 


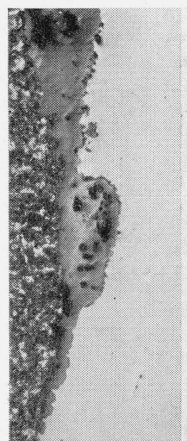

A

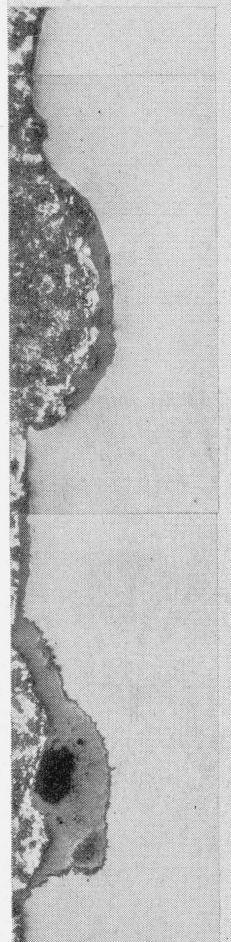

C

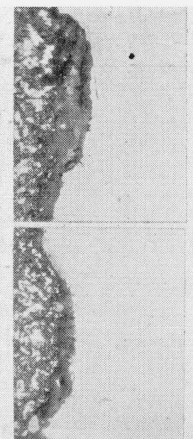

A
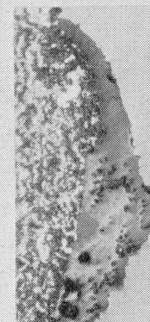

(68)

5.
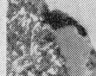

C. ${ }^{2}$
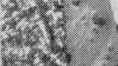

tox

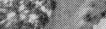

c.
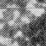

.
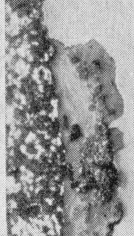

D

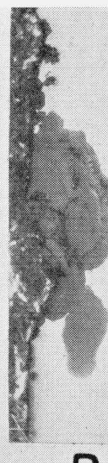

B
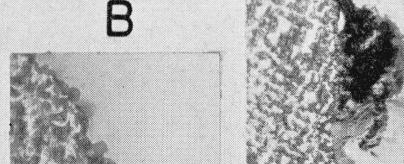

meth kat.

ain $x^{2}$

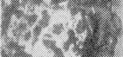

tras.

$x+2$

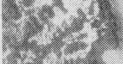

$2 x+3$

sity

19:

ity

2i.

y.

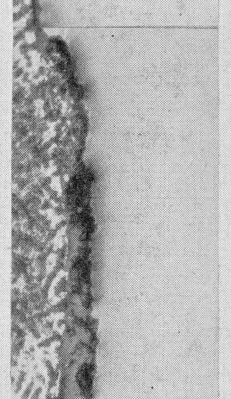

E

$4 x^{3}$
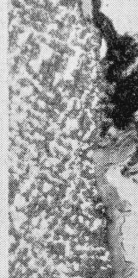

$37 \times 2 \times 2: 2$

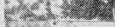

$3.6 x^{3}+38$

ziceit

xis mes
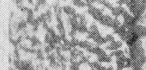

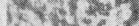
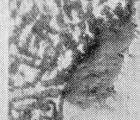

s.7

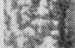

$+3$

83

- 63
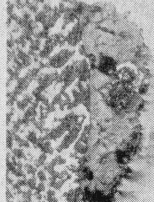

$\mathrm{F}$
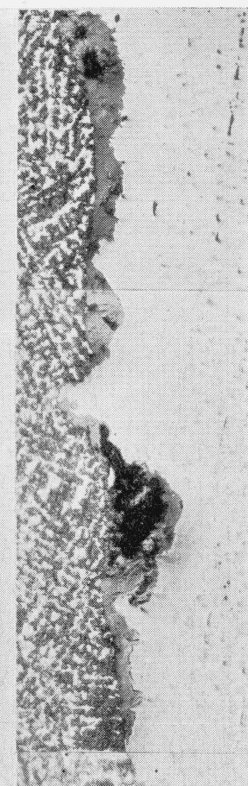

FiguRE 10.-Stressless corrosion; longitudinal sections; $\times 50$.

A, 93 days, JR-W-10.

$B, 100$ days, $\mathrm{IW}-\mathrm{W}-10$.

$C, 110$ days, IW-W-10.

D, 150 days, $\mathrm{AX}-\mathrm{W}-10$

$E, 220$ days, AX-W-10

$F, 300$ days, IW-W-10. 

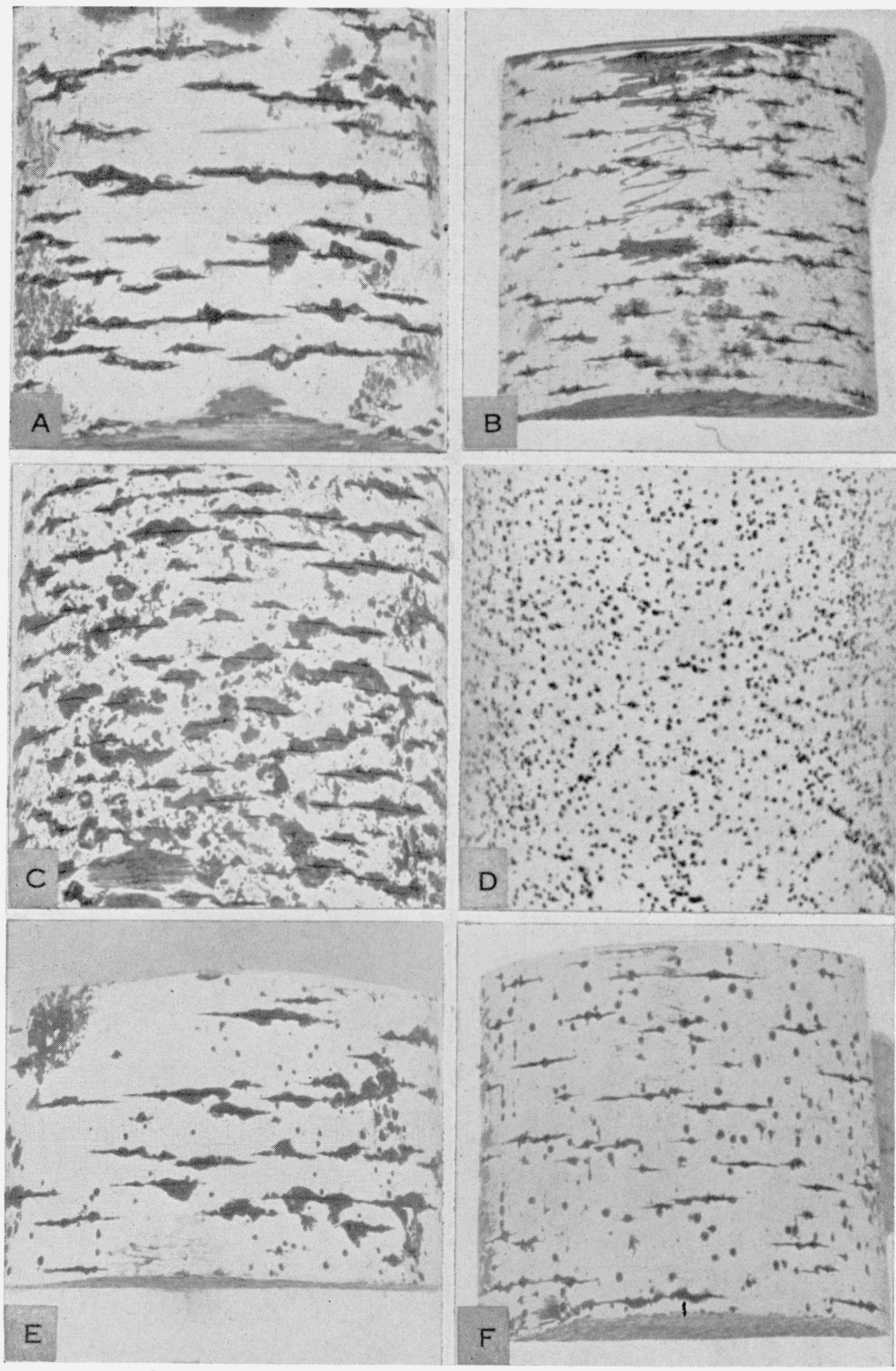

Figure 11. $-1,450 \mathrm{c} / \mathrm{min}$; outer surfaces; $\times 4$.

A, $15,000 \mathrm{lb} / \mathrm{in}^{2}, 10$ days, $\mathrm{IW}-\mathrm{W}-10$. $B, 13,000 \mathrm{lb} / \mathrm{in}^{2}{ }^{2}, 5$ days, IW-W-10. C, $13,000 \mathrm{bb} / \mathrm{in}^{2}, 10$ days, $\mathrm{IW}-\mathrm{W}-10$ D, $11,000 \mathrm{lb} / \mathrm{in}^{2}, 3$ days, $\mathrm{BC}-\mathrm{W}-10$. $E, 11,000 \mathrm{lb} / \mathrm{in}^{2}, 10$ days, $\mathrm{IW}-\mathrm{W}-10$ $F, 10,000 \mathrm{lb} / \mathrm{in},{ }^{2}, 10$ days, $\mathrm{IW}-\mathrm{W}-10$. 

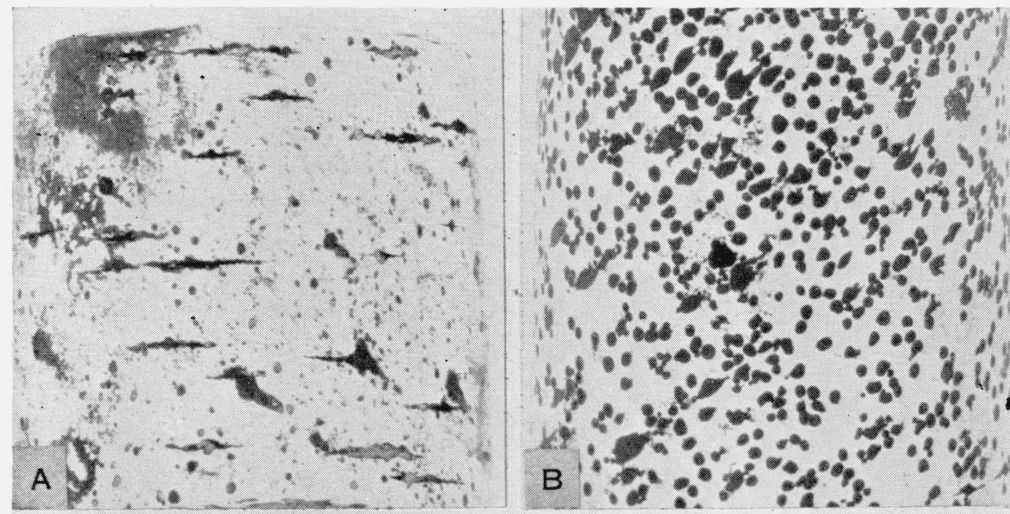
Ti:

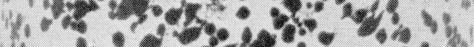

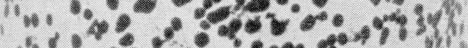

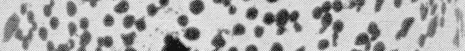

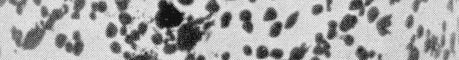

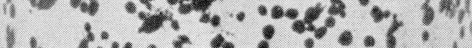

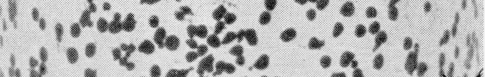

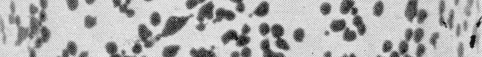

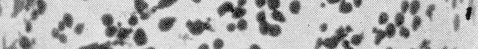
B :

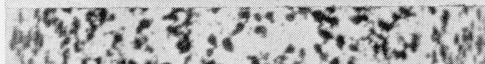

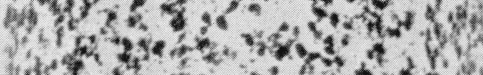

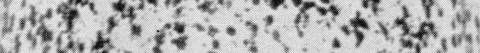

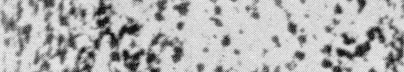

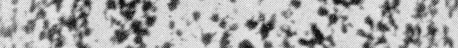

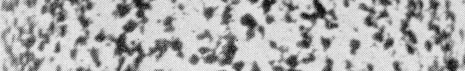
1. u.rif (4)

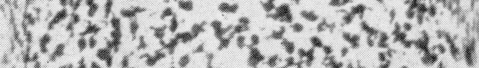

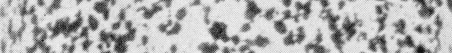

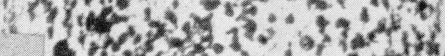

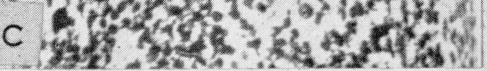

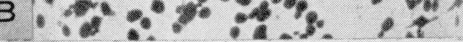

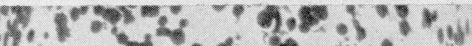

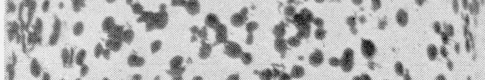

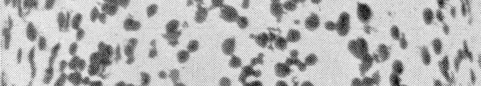

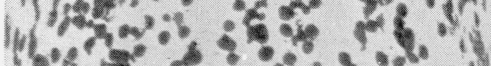
सP

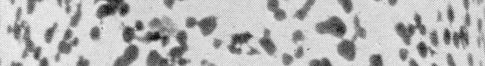

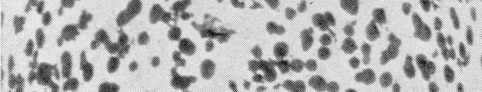
t.

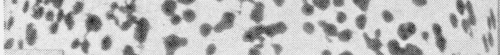

E
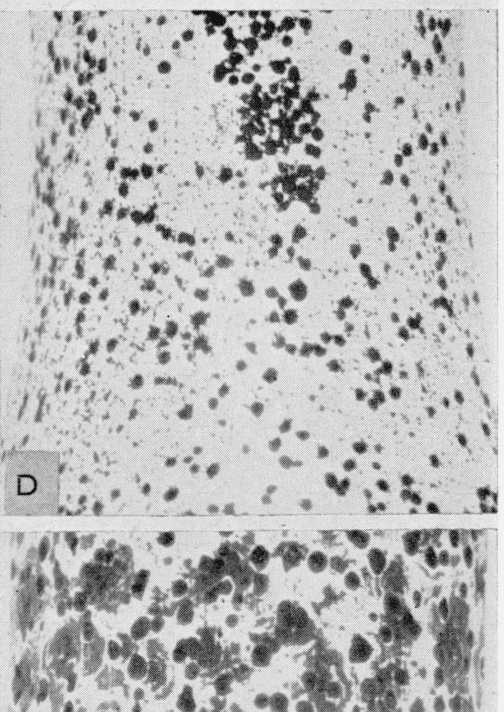

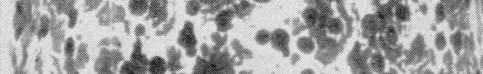

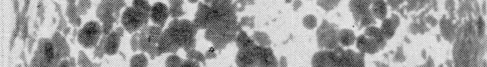

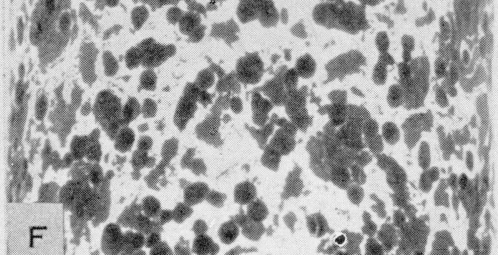

FiguRE 12.-1, $450 \mathrm{c} / \mathrm{min}$; outer surfaces; $\times 4$.

$A, 9,000 \mathrm{lb} / \mathrm{in}^{2}, 10$ days, IW-W-10.

$B, 8,000 \mathrm{lb} / \mathrm{in}^{2}, 10$ days, $\mathrm{IW}-\mathrm{W}-10$

$C, 7,000 \mathrm{lb} / \mathrm{in} .2,25$ days, $\mathrm{BC}-\mathrm{W}-10$.

,

$E, 4,000 \mathrm{lb} /$ in $^{2}, 31$ days, IW-W-10.

$F, 3,000 \mathrm{lb} / \mathrm{in} .^{2}, 97$ days, $\mathrm{IW}-\mathrm{W}-10$. 

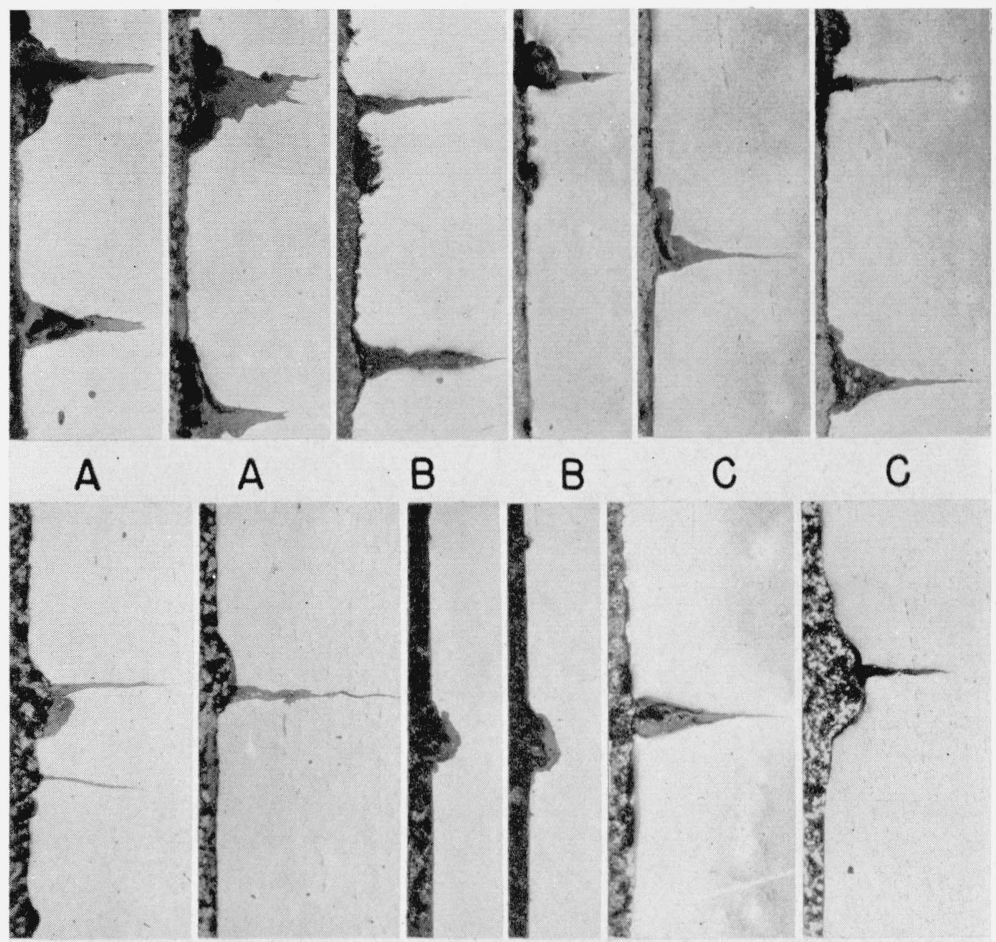

B

B

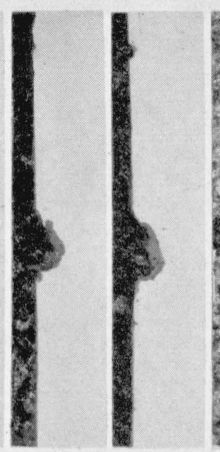

C

C

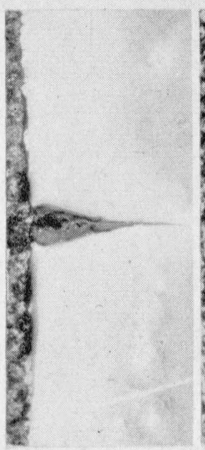

D

D

E

\begin{abstract}
E
\end{abstract}
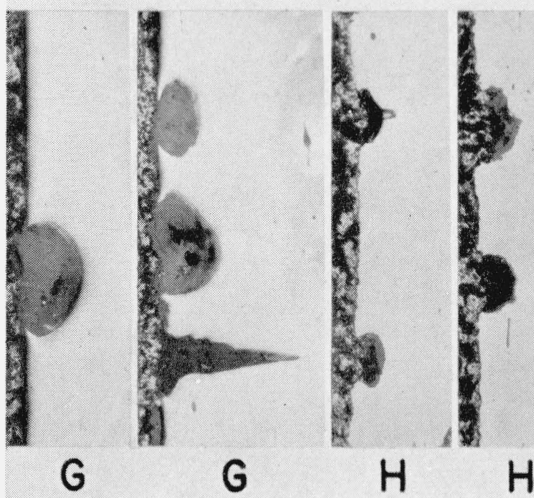

$F$

$\mathrm{F}$

FIGURE 13. - 1, $450 \mathrm{c} / \mathrm{min}$; longitudinal sections; $\times 50$.

$A, 15,000 \mathrm{lb} / \mathrm{in} .{ }^{2}, 10$ days, $\mathrm{IW}-\mathrm{W}-10$.

$B, 14,000 \mathrm{lb} /$ in ${ }^{2}, 3.2$ days, $\mathrm{IW}-\mathrm{W}-10$.

$C, 13,000 \mathrm{lb} / \mathrm{in}^{2}, 5$ days, IW-W-10.

D, $13,000 \mathrm{lb} /$ in. $^{2}, 10$ days. IW $-\mathrm{W}-10$.

$D, 13,000 \mathrm{lb} / \mathrm{in}^{2}, 10$ days, IW-W -10
$E, 11,000 \mathrm{lb} / \mathrm{in}^{2}, 3$ days, $\mathrm{BC}-\mathrm{W}-10$.

$F, 11,000 \mathrm{lb} /$ in $.^{2}, 10$ days, $\mathrm{IW}-\mathrm{W}-10$

$G, 10,000 \mathrm{lb} /$ in $^{2}, 10$ days, I W-W -10

$H, 9,000 \mathrm{lb} / \mathrm{in} .^{2}, 4$ days, $\mathrm{IW}-\mathrm{W}-10$

$I, 9,000 \mathrm{lb} / \mathrm{in} .^{2}, 10$ days, $\mathrm{IW}-\mathrm{W}-10$. 


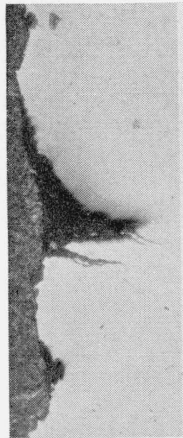

A

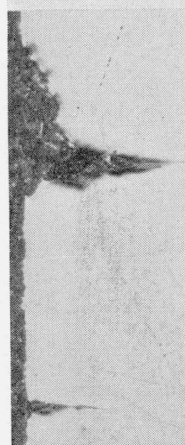

D

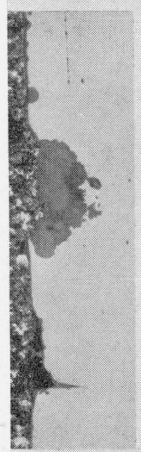

$\mathrm{H}$

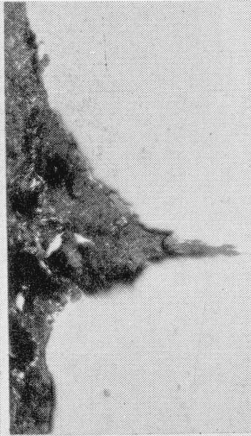

A

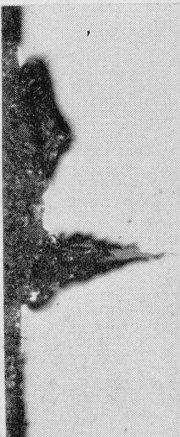

D

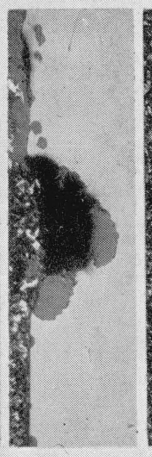

$\mathrm{H}$

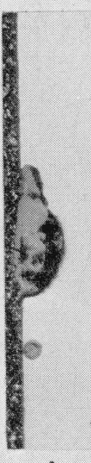

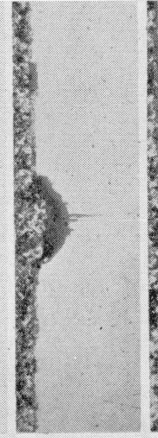

B

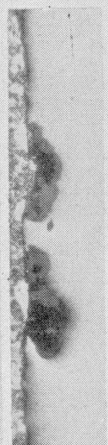

E

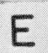

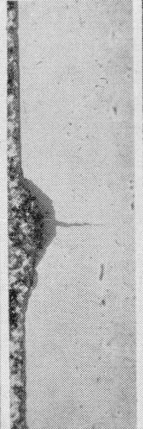
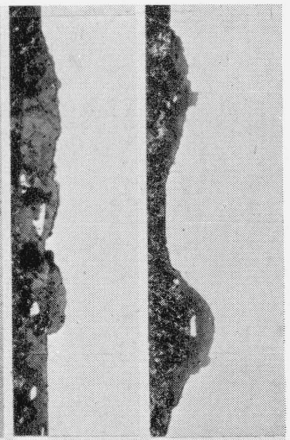

C
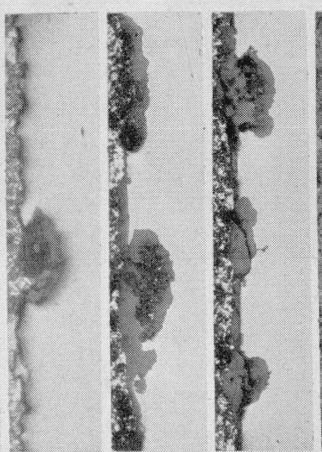

C

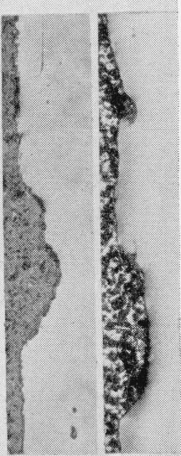

F

G G
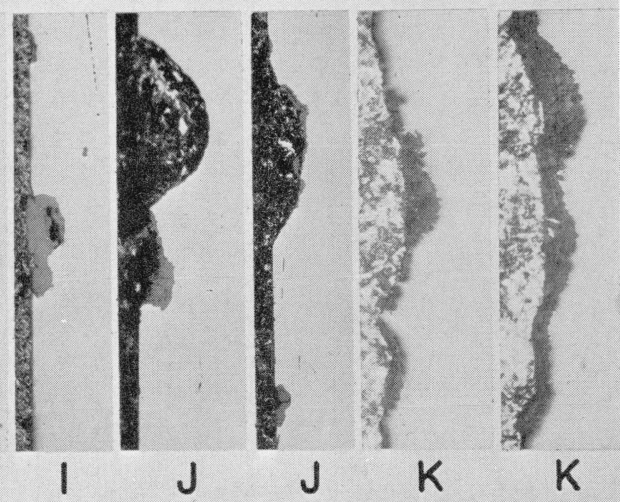

FIgURE 14.-1,450 c/min; longitudinal sections; $\times 50$.

$A, 9,000 \mathrm{lb} / \mathrm{in}^{2}, 50$ days, $\mathrm{BC}-\mathrm{W}-10$ $B, 8,000$ lb/in 2 , 4 days, IW-W-10. $C, 8,000 \mathrm{lb} / \mathrm{in}^{2}, 10$ days, $\mathrm{IW}-\mathrm{W}-10$. $D, 8,000 \mathrm{lb} / \mathrm{in} .^{2}, 24$ days, $\mathrm{BC}-\mathrm{W}-10$ $E, 7,000 \mathrm{lb} / \mathrm{in}^{2}, 10$ days, $\mathrm{IW}-\mathrm{W}-10$ $F, 7,000 \mathrm{lb} / \mathrm{in}^{2}, 25$ days, $\mathrm{BC}-\mathrm{W}-10$.
$G, 6,000 \mathrm{lb} / \mathrm{in}^{2}, 10$ days, $\mathrm{IW}-\mathrm{W}-10$. $H, 6,000 \mathrm{lb} /$ in $^{2}, 25$ days, $\mathrm{BC}-\mathrm{W}-10$. $5,000 \mathrm{lb} /$ in $^{2}, 10$ days, IW $-\mathrm{W}-10$ $J, 4,000 \mathrm{lb} / \mathrm{in}^{2}, 31$ days, IW-W-10 $K, 3,000 \mathrm{lb} / \mathrm{in}^{2}, 97$ days, IW-W-10 


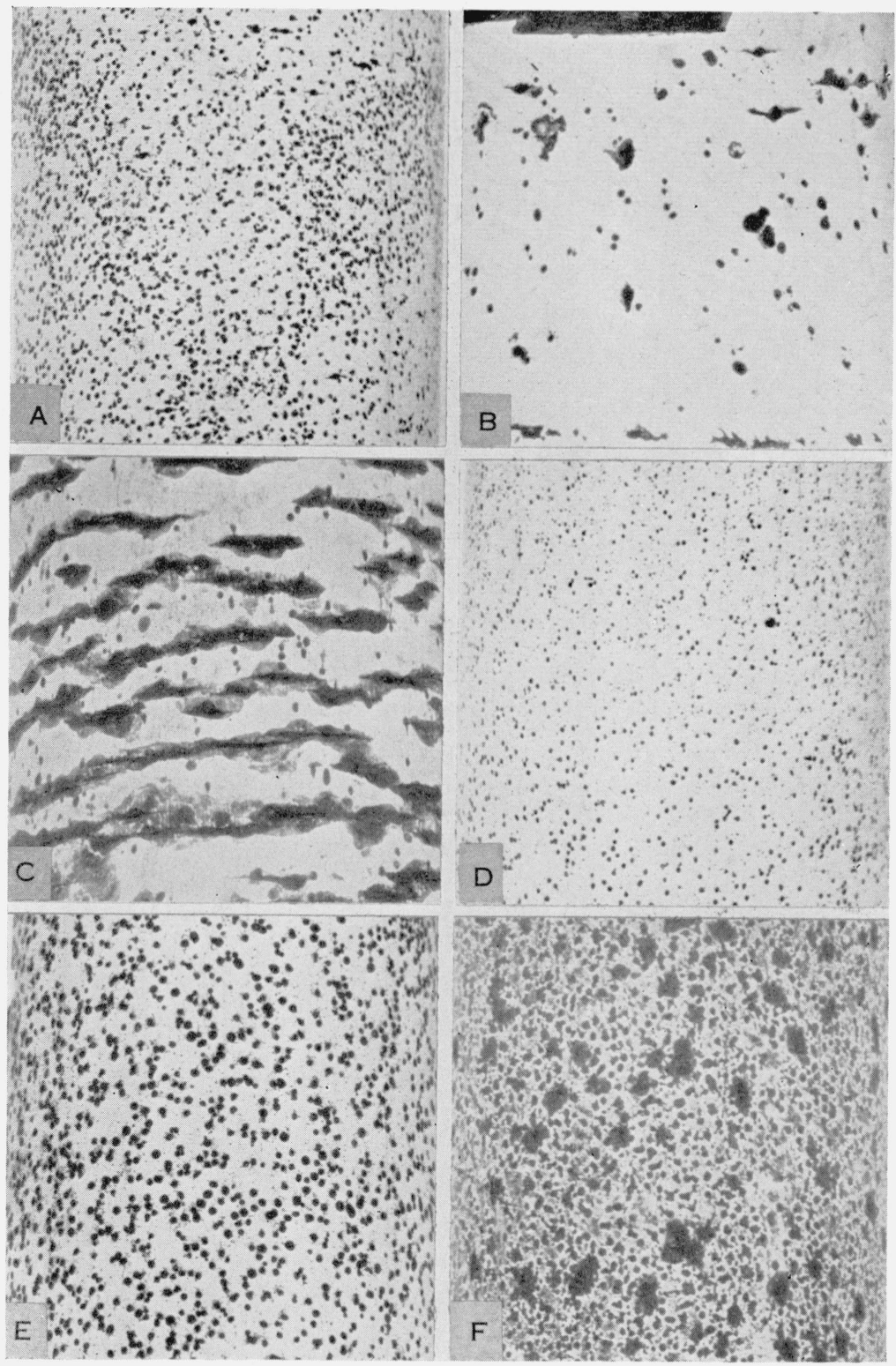

FIGURE 15.-500 c/min; outer surfaces; $\times 4$.
$4,14,000 \mathrm{lb} /$ in. $^{2}, 4$ days, $\mathrm{BC}-\mathrm{W}-10$. $B, 13,000 \mathrm{lb} / \mathrm{in}^{2}, 15$ days, $\mathrm{IW}-\mathrm{W}-10$ C, 13,000 lb/in. ${ }^{2}, 45$ days, IW-W-10. D, $12,000 \mathrm{lb} / \mathrm{in}^{2}, 4$ days, $\mathrm{BC}-\mathrm{W}-10$. $E, 9,000 \mathrm{lb} / \mathrm{in}^{2}, 9$ days, $\mathrm{BC}-\mathrm{W}-1 \mathrm{C}$. $F, 8,000 \mathrm{lb} /$ in $^{2}{ }^{2}, 33$ days, $\mathrm{BC}-\mathrm{W}-10$. 